\title{
THE NEW PHYSIOLOGY IN SURGICAL \\ AND GENERAL PRACTICE
}

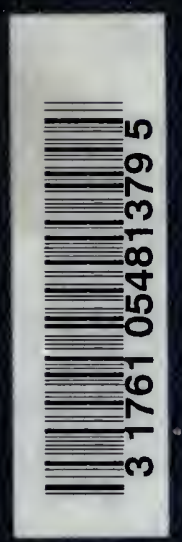




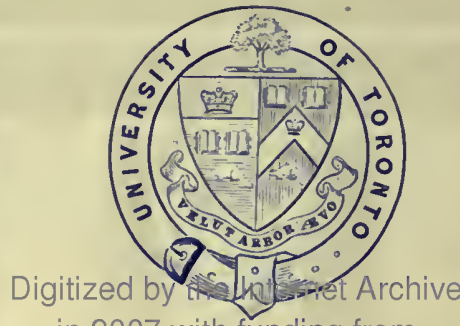

in 2007 with funding from

Microsoft Corporation

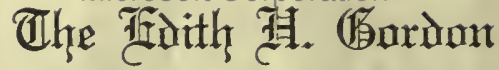
䟢equest - 1940 in mtemtariam

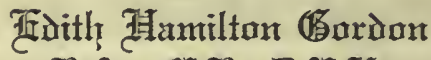

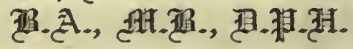

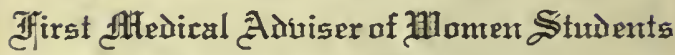

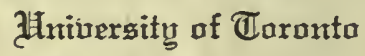
7from 1921 to 1939

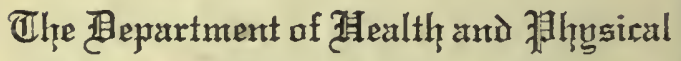
Tiducation for 睤anten Students 


\section{,}



MPhy

S

\section{THE NEW PHYSIOLOGY} IN SURGICAL.

\section{AND GENERAL PRACTICE}

BY A. RENDLE SHORT, M.D., B.S., B.Sc. (Lond.) F.R.C.S. (Eng.).

Hon. Surgical Registrar Bristol Royal Infirmary; Senior. Demonstrator of Physiology, University of Bristol.

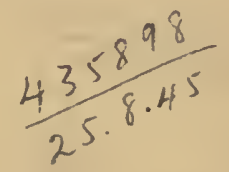

TORONTO :

THE MACMILLAN COMPANY OF CANADA, LTD. 1912 



\section{PREFACE}

THESE chapters are intended for the general practitioner, the consulting surgeon, and candidates for the higher examinations in physiology.

There was a time when one man could be physiologist and surgeon too, but the rapid march of progress in each field has left a great gap between the sciences which is continually widening. The triumphs of the surgeon are unknown to the physiologist, and the converse is equally true. Yet many of the discoveries of the past ten years which have so changed the face of physiology are fraught with vast possibilities for the clinician. This book is an at tempt to sift out from the New Physiology that which is likely to be of value in the actual diagnosis and treatment of patients.

It would be a small service to lay before the practical reader mere theories or guess-work. With but few exceptions, only the established and settled conclusions arrived at by many competent and independent workers have been introduced. Part of the chapter on cutaneous anæsthetics and a few other researches and passing suggestions for which the author is personally responsible, must stand in a different category. 
An effort has been made to explain matters so simply that they may be intelligible to those having the most elementary knowledge of physiology, and all technical terms have been avoided or defined.

There are excellent manuals now published treating of the application of physiology to diseases which principally concern the consulting physician. This little book limits itself to surgical problems, and to the common every-day aspects of disease that confront us all, physicians, surgeons, and general practitioners alike.

I owe a debt of thanks to my chief, Professor A. F. Stanley Kent, for some valuable suggestions and criticisms.
A. R. S.

BRISTOL,

September, I9Ir. 


\section{CONTENTS}

CHAPTER

PACE

I.-The Thyroid and Parathyroid Glands -

History.-Removal of the thyroid and parathyroids.-Removal of the parathyroids alone. -Removal of the thyroid alone.-Thyroid feeding.-Chemistry of thyroid colloid.Parenchymatous goitre.-Iodoform and thyroidism.-Action of iodides on gummata and atheroma.-Exophthalmic goitre.-Practical deductions.

\section{II.-The Pituitary Gland}

The effects of removal in animals.-Injection of extracts; pituitary feeding.-Acromegaly and gigantism.-Fröhlich's type.-Functions of the pituitary gland.-Therapeutic value of pituitary extract.

III.-Studies in Digestion AND ABsorption -

The process of secretion of saliva.-The process of secretion of gastric juice.-The influence of appetite.-The influence of bitters and alcohol.-Movements of the stomach.Sensation in the stomach.-Causes of variation in the hydrochloric acid of gastric juice.-The physiological effects of gastro-jejunostomy. -Feeding after gastrostomy.-The process of secretion of pancreatic juice.-The bile.The absorption of peptonized foods.-The functions of the large intestine.-The value of nutrient enemata.

IV.-The Applied Physiology of Blood-Pressure

Apparatus for measuring arterial, venous, and capillary pressure in man.-Factors controlling the blood-pressure.-The influence of gravity. -The influence of the internal secretion of the suprarenal glands.-Surgical shock; its nature, prevention, and treatment.-The intracranial circulation.-Blood-pressure after head injuries.-The pulmonary circulation.-The internal administration of hæmostatics. 
The physiology of the coagulation of the blood.-Hæmophilia.-Pathology of hæmophilia.-Treatment of hæmophilia.-The therapeutics of calcium salts.

VI.-The Physiology of URIC ACid and other URINARY DEPOSITS

Uric acid.-Derivation from food-stuffs.Derivation from the tissues.-The purin bodies. -Gout.-Calcium oxalate.-Cystin.-General laws of calculus formation.

VII.-Acidosis, ACETon

Conditions of occurrence of acetone, diacetic acid, and $\beta$-oxybutyric acid.-Origin from fats. - Sugar starvation the cause of acidosis.-Acid poisoning.-The diagnosis of starvation.-The essential nature of diabetes.-The treatment of non-diabetic acidosis.-The prevention of postoperative coma in diabetics.

VIII.-Immediate AND Remote Poisoning By CHLOROFORM -. -

The mode of action of the organic hypnotics. - The immediate dangers of chloroform narcosis.-Vagus inhibition.-Lowering of the blood.pressure.-Delayed chloroform poisoning.

IX.-NERVE INJURIES

The effects of nerve section.-Epicritic, protopathic, and deep sensibility.-Causation of trophic lesions.-Diagnosis of partial nerve section.-How degenerated nerve is regenerated. -The results of primary and secondary nervesuture.-Methods of dealing with wide gaps.

$\mathrm{X}$.-The Surgical Physiology of the Spinal CORD

The effects of division of the posterior nerve. roots.-The diagnosis and localization of tumours of the spinal cord.-The exact dia. gnosis of injuries of the spinal cord. 


\section{CONTENTS}

The causation and significance of optic neuritis.-Localization in the cerebellum.Tumours in the cerebello-pontine angle.Localization of sensation in the cerebral cortex. -Functions of the frontal cortex; spasticity. - Apraxia. - Aphasia.-Misleading localizing signs of cerebral tumour.-The cerebrospinal fluid.

XiI.-The Action of Cutaneous Anesthetics

Local anæsthetics given hypodermically: cocaine, novocain, eucain, stovain.-Drugs applied to the unbroken skin; opium, belladonna.-Counter-irritants; the theory of their action.

APPENDIX.-URine ANalysis in Cases Fed By 


$$
<
$$




\section{The New Physiology}

$I N$

\section{Surgical and General Practice}

\section{CHAPTER I.}

\section{THE THYROID AND PARATHYROID GLANDS.}

History-Removal of the thyroid and parathyroids-Removal of parathyroids alone-Removal of thyroid alone-Thyroid feeding-Chemistry of thyroid colloid-Parenchymatous goitre -Iodoform and thyroidism-Action of iodides on gummata and atheroma-Exophthalmic goitre-Practical deductions.

UCH of the clinical and experimental work 11 which has been done in connection with these glands can no longer be described as new, but it will be helpful to mention in passing some of the well-known results obtained by the first observers.

\section{HISTORY.}

As long ago as 1859 , Schiff described the fatal result which inevitably supervenes after removal of the thyroid gland in dogs, but it was not until " cachexia strumipriva," or operative myxodema, was found to follow so many of Kocher's early operations for goitre on patients coming from the goitrous Swiss valleys, that this fact attracted much attention. The 
relation of the thyroid to myxœedema was then established by Gull and Ord. The highly successful treatment of myxœdema and cretinism by thyroid feeding was introduced by Murray, following on the observation by Schiff and subsequent workers that transplantation of the gland beneath the skin of the thyroidectomized animal relieved the symptoms.

\section{REMOVAL OF THYROID AND PARATHYROIDS.}

We will consider first the consequences of removal of the thyroid gland in animals. The effect of total removal varies greatly with the species. Thus rodents are little if at all affected, sheep and cattle more so; in man and monkeys the symptoms are marked, and in carnivores, especially foxes, a rapidly fatal result ensues. To some extent this striking diversity depends, as we shall see, on the liability to simultaneous removal of the parathyroids; for a long time this was not recognized. Males are more severely affected than females, and castration is said to modify the symptoms. Thyroidectomized animals are very susceptible to cold, and keeping cats warm may save their lives; of course thyroid medication must be undertaken at the same time. It is well known that human patients with myxœdema feel the cold very much. The symptoms in dogs and monkeys are vomiting, muscular prostration, emaciation, and often death. Of great importance is the frequent occurrence of tetany. The spasms are at first slight, affecting the jaw muscles, then they spread over the whole body and may be fatal. 
This condition has several times followed a too extensive removal of the thyroid in man, and may also occur in myxœdema. Another symptom present frequently in monkeys is narrowing of the palpebral fissure, so-called enophthalmos; we shall see that administration of thyroid extract may cause exophthalmos. True myxœdema is not often seen in the experimental animals. It has been induced in mild degree in monkeys by Horsley, Edmunds, and others, but not with any constancy, and in other animals it is not seen at all.

It is not usually possible to save the lives of dogs or monkeys, whose thyroids have been removed, by feeding on sheep's thyroid, although a good deal of relief may be obtained for the symptoms in this way. Grafting a piece of the gland under the skin is successful for a while, but eventually it is absorbed.

The effects of removal of, or insufficient secretion by, the thyroid gland in man are myxcedema, and occasionally tetany.

In 408 cases in Kocher's clinic at Berne complete extirpation of the thyroid was followed by myxœedema in 69 cases, and a similar operation in 78 cases in Billroth's clinic was followed by tetany in $\mathrm{I}_{3}$ cases, of which 6 proved fatal. Feeding with sheep's thyroid is wonderfully successful in myxœdema, but is not usually effectual in tetany.

Partial removals of the thyroid in dogs produce symptoms of correspondingly lessened severity Halstead found that in one case one-eighteenth of the gland sufficed to ward off symptoms of athyroidism, but the amount which could safely be 
left varied in different animals. One bitch which had lost two-thirds of her total thyroid became pregnant by a healthy male, and all her whelps had enormous goitres, a fact which has also been observed by Edmunds.

Histological examination of the portion remaining shows a sequence of changes remarkably like those occurring in exophthalmic goitre, namely, distension and irregular shape of the vesicles, with watery fluid instead of colloid, and columnar epithelium instead of cubical.

\section{REMOVAL OF PARATHYROIDS.}

The variation in the symptom-complex following on thyroidectomy, and the variability of response to thyroid feeding, both depend on any coincident injury to the parathyroid glands. For many years these glands passed unrecognized, and most of the effects attributed above to removal of the thyroid are as a matter of fact due to loss of the parathyroids. These are two pairs of small glands lying behind the lateral lobes of the thyroid close to the trachea, not easily distinguishable from the thyroid except by the microscope, when they are seen to consist of columns of polygonal cells with no regular arrangement into acini, and secreting no colloid. One pair was discovered by Sandstrom in I880, and the functions were investigated by Gley in 1892 ; but the second pair was not recognized till Kohn's monograph appeared in I895. A number of physiologists have since described the effects of removal (Vassali and Generali, Edmunds, Moussu). 
If all four parathyroids are taken away, the animal succumbs rapidly, with symptoms just such as have been described under the heading of thyroidectomy, tetany being a marked feature. The signs are the same whether the thyroid gland is removed or left. Leaving one parathyroid is usually sufficient to prevent death, but tetany may still ensue.

It would seem that in man, myxœdema is due to loss of the internal secretion of the thyroid itself, but that tetany and fatal symptoms in both man and animals are due to loss of the parathyroids. The convulsions of tetany in dogs may be arrested by feeding on a watery extract of twelve to twenty horses' parathyroids (Moussu).

\section{REMOVAL OF THYROID ALONE.}

Removal of the thyroid gland without the parathyroids is usually not fatal; myxœema results in man; occasionally, perhaps, in animals also, but more commonly only cachexia. In young animals, however, the results are much more distinct, and Eiselsberg and others have induced very convincing cretinism, with a remarkable stunting of growth, in lambs, goats, rabbits, and asses. It is interesting and important to notice that the animals so treated developed exceedingly marked atheroma of the aorta, of which Eiselsberg gives good figures.

THYROID FEEDING.

We now turn to the effects of thyroid feeding in the normal man and animal. These are perfectly 
characteristic if large doses are given. The bloodpressure falls, the pulse becomes rapid (I20-I4O or more), there may be fever, headache is usual, and there is great mental depression or excitement in many cases. Exophthalmos has been recorded several times after an overdose in man (Béclere, Notthaft), and monkeys (Edmunds). The metabolic exchanges of the body are increased, consequently there is loss of weight and an increased output of urea, chlorides, and phosphates, and the gaseous exchanges in the lungs are above normal (Roos, Magnus Levy). It will be noticed that the parallelism with Graves' disease is very striking.

\section{CHEMISTRY OF THYROID COLLOID.}

Chemical investigation of the colloid has yielded some important results. The active principle, iodothyrin, has the characters of a globulin (Oswald) which contains a variable proportion of iodine. This element is usually abundant in the thyroid, but almost absent in the other tissues of the body. Its presence was first proved by Baumann of Freiburg, in 1896 , and has been abundantly confirmed since. The amount present varies with the species and also with the individual; in some cases it falls below the limits of chemical recognition. Herbivores possess it in abundance, most vegetables containing iodine. In carnivores it is very scanty. In man it is nearly always present in recognizable quantities, except in young children. Wells finds that the amount varies with the locality, and in general is inversely in proportion to the local prevalence of 
goitre. In parenchymatous goitre the iodine content is too low; in exophthalmic goitre it is too high.

\section{PARENCHYMATOUS GOITRE.}

Directing our attention now to enlargements of the thyroid gland, we rule out those that are merely due to tumour formation, such as adenoma or cystic disease, and confine ourselves to the parenchymatous goitres. It has long been known that there is some connection between drinking waters and the incidence of goitre. The disease is extraordinarily prevalent in certain districts, and especially where the water-supply is derived from particular geological formations, such as the molasse in Switzerland and the carboniferous limestone in Derbyshire. In Khokand, Turkestan, a very large proportion of the whole population suffers, and Russian soldiers stationed there rapidly acquire the disease. The introduction of a new water-supply has several times induced an epidemic of goitre in a town, or, on the other hand, reduced the number of cases in an endemic area. Thus at Rupperswyl, near Aarau, an endemic area in which 59 per cent of the children were goitrous, in 1884 the water-supply was changed for one from a non-goitrous district, and in ten years the percentage had fallen to eleven. There are on the Continent certain goitre wells called Kropfbrunnen, at which young men anxious to escape conscription drink. They have been known for centuries, and the water will induce goitre in horses and dogs, as well as in man. Boiling the water destroys its remarkable effect on the thyroid 
gland. This has been taken to prove that some living organism is the effective cause, but another theory is more probable, as we shall see later.

In the earlier stages, parenchymatous goitre can usually be cured, either by feeding on thyroid extract or by means of potassium iodide. Marine* has pointed out that in America there was formerly a serious commercial loss in some districts from cretin lambs, and that sheep and dogs with goitre were numerous; the substitution of an iodiferous salt for pure rock-salt has been completely successful in preventing all these manifestations.

Chalmers Watson, and more recently Edmunds, have obtained goitre in fowls by a meat diet. The low iodine-content of the meat makes it necessary for the thyroid to enlarge, so as to take the greatest advantage of what iodine it can get.

There is abundant evidence that iodides, and especially organic combinations of iodine such as iodoform, have great power in enhancing the activity of the thyroid gland. We have already seen that the gland normally secretes iodine in the blood-stream, combined with a globulin. Roos, and more recently Hunt and Seidel, have shown that the activity of the colloid varies directly with the amount of iodine contained in it. When iodides or iodoform are given by mouth, they are taken up by the thyroid and secreted in the blood-stream in the form of iodothyrin, the normal active principle of the gland. The amount of iodine in the gland

*Johns Hopkins Hosp. Bull., I907, xviii. p. 359. 
in these circumstances rises considerably, as has been proved by Oswald in man, and by Hunt and Seidel in dogs.

What, then, is the relation between iodine metabolism and goitre?

In the first place, we may conclude that the thyroid enlarges in goitre because it is necessary for it to do increased work. A certain quantity of iodothyrin is needful for the general well-being of the individual; if the gland is scantily supplied with iodine, it must enlarge in order to take the fullest possible advantage of all that may be brought to it by the blood-stream. In the same way a kidney hypertrophies when its fellow is degenerated, in order to obtain more urea for excretion, and the red bloodcorpuscles double in number when a man takes up his abode in the rarefied atmosphere of great altitudes, to make the best use of the diminished supply of oxygen. It has been shown by Oswald in a number of observations that in goitre the thyroid colloid is exceedingly deficient in iodine, both in calves and man. Thus we get a clue to the successful treatment of the affection either by iodiferous compounds or by thyroid extract. It is well known that either of these remedies will cure early cases of goitre, before the enlargement becomes chronic. The success of the iodiferous rock-salt on the American farms may be accounted for in the same way. An explanation is also offered of the fact, noticed previously, that the whelps of bitches from whom a good part of the thyroid has been removed are all goitrous, the plasma supplied to the fœtal glands 
evidently containing a deficiency of iodine derived from the maternal thyroid. Of 2,333 cases of congenital goitre collected by Fabre and Thevenot,* the mother was almost invariably goitrous. The fotal thyroid enlarges in order to obtain as much iodine as it can.

It was natural to suggest that the waters of the Kropfbrunnen were deficient in iodine, but this theory would overlook the fact that the bulk of our iodine is derived from vegetables, not from drinkingwater, and as a matter of fact these wells show no constant deficiency or excess of iodine. It is more probable that they contain minute traces of some metal having a great affinity for iodine, and forming with it an insoluble compound. It is quite conceivable that boiling the water might precipitate such a metal. There are probably many metals, known and unknown, that would fulfil the conditions; it wiil suffice to mention silver as an illustration. This, if taken into the body, would withdraw so much of the available iodine as inert silver iodide, that the thyroid must enlarge to obtain the indispensable minimum.

The theory has been advanced that the Kropfbrunnen contain some organism capable of causing a goitre. To accept this, however, is to overlook the weight of evidence bearing on iodine metabolism in relation to the thyroid. Again, it is quite in accordance with the common laws of Nature to find a metal or mineral specially limited to particular geological formations in widely separated areas; but there is no evidence that bacteria are dependent

* Revue de Chirurgie, June Io, Igo8. 
on geology. And thirdly, it has recently been shown by Wilms that the waters of a goitre well retain their power to cause goitre in rats after filtering out all bacteria by a Berkefeldt filter, but not after heating to $80^{\circ}$. The heating probably precipitates the metal as an insoluble carbonate, by driving off carbon dioxide which holds it in solution.

There are goitre wells in England. One is known to the writer near Berkeley, in Gloucestershire. Its water is used by only one or two families, but four cases of goitre have resulted. It is usually the growing children who suffer.

\section{IODOFORM AND THYROIDISM.}

The conclusions which modern physiology has reached with regard to the relation between iodine compounds and the thyroid gland lead us to some further important explanations of obscure problems. We are now able to understand the toxic effects of iodoform, and the beneficial action of iodides on arteriosclerosis, aneurysm, and gummata.

Iodoform poisoning has become a well-recognized condition, and every textbook on pharmacology or toxicology gives a clear description of the clinical picture, which the writer has verified by consulting the reports on some roo cases scattered through the literature, not including the very numerous records of dermatitis or erythema following its local use. A long list of well-described cases (not always very convincing) is given by Cutler.*

*Boston Med. Soc. Journal, 1886, ii. pp. 73, I01, I 10. 
1 There are four main varieties of iodoform poisoning :-

I. Skin eruptions, such as dermatitis, erythema, and swelling.

2. Persistent subjective taste and smell of the drug long after its application has been discontinued.

3. Toxic amblyopia (5 cases), and optic atrophy (I case).

4. Acute thyroid symptoms, comprising rapid pulse, delirium, headache, vomiting, and a variable amount of fever. The most characteristic sequence is when the pulse is very rapid but the temperature normal.

Of the above groups we are now concerned only with the last.

It will be noticed that the clinical picture corresponds exactly with that seen after the administration of excessive doses of thyroid extract. Iodoform causes its toxic effects by stimulating the internal secretion of the thyroid gland, with the production of acute thyroid intoxication.

I have described a case in which chronic thyroid intoxication, that is to say Graves' disease, clearly followed the application of iodoform to an absorbing surface. There was certain proof that too much iodoform was absorbed, because for weeks after the drug had been withdrawn the patient was haunted by its smell and taste. The tachycardia and wasting were first noticed a week or two after this symptom developed. The Graves' disease was still present in a mild form one year later, but eventually disappeared. Hunt and Seidel have shown that after dosing 
a dog with iodoform, the iodine content and the activity of the thyroid colloid are both increased greatly. The thyroid secretes into the blood, as iodothyrin, the iodine derived from the iodoform. When strychnine is excreted by the kidneys the excretion is merely discharged from the body, and therefore the drug can do no more harm. But the increased secretion of the thyroid is discharged not externally but into the blood, and may poison the patient.

\section{ACTION OF IODIDES ON GUMMATA AND ATHEROMA.}

A similar increase in the thyroid secretion may be obtained by giving iodides, but apparently the gland is not able to utilize these as readily as it does iodoform, for large doses do not so easily cause acute thyroid intoxication. Here we find the explanation, so long sought in vain, of the effect of iodides on gummata, arteriosclerosis, and aneurysm. The beneficial agent is really the increased internal secretion of the thyroid gland.

Two important results of observation and experiment confirm this theory.

In the first place, in cases of myxœdema, arteriosclerosis is early and intense. The same is true in animals after removal of the thyroid. Eiselsberg gives a number of very convincing photographs of intense atheroma of the aorta in his cretin lambs in which the thyroid had been removed in early life. In the second place, thyroid extract has a wonderful power over young connective tissue, as is seen by the 
way in which it absorbs the subcutaneous thickening of myxœdema and cretinism. It is not surprising, therefore, that it should be able to deal also with gummata and atheroma. By its absorptive effect on the atheroma, it may work some improvement in aneurysm.

\section{EXOPHTHALMIC GOITRE.}

The arguments in favour of the hypersecretion theory of this disease appear to almost all observers to be of overwhelming strength. The thyroid gland is enlarged, vascular, and soft in most cases ; occasionally it is normal in size. Microscopically, the acini are dilated and irregular, and the contents too watery. These are just the changes seen in the actively secreting fragment left after a sub-total thyroidectomy. The colloid contains too much iodothyrin as compared with the normal gland. The wasting, restlessness, and quick pulse may all be reproduced with constancy in man or animals by thyroid feeding, and exophthalmos has also been obtained occasionally in both man and the monkey. The bearing of these conclusions on treatment will now be considered.

\section{PRACTICAL DEDUCTIONS.}

We may seek here to summarize the conclusions, in so far as they are of importance to the clinician, that the New Physiology has reached. We learn that parenchymatous goitre is a hypertrophy of the thyroid gland, designed to enable it to obtain sufficient iodine from the blood, this element being an essential constituent of its internal secretion. The deficiency in iodine is in some complicated way 
connected with the drinking-water. In the early stages, iodides, thyroid feeding, or probably iodoform will work improvement, and the water should be boiled, or the supply changed. Should operative measures be adopted, we learn that the whole gland must not be removed, or myxœdema may result, and that the four small parathyroids lying behind it must also be respected, or the patient may develop tetany. In some cases the loss of the parathyroids on one side only has caused this unpleasant sequel. An attempt should therefore be made, in removing one lobe of the thyroid for goitre or adenomata, to leave these little glands intact and in situ, and to preserve their blood-supply. They will not be injured if the posterior part of the capsule of the thyroid is left.

If myxœedema or tetany do follow the operation, they may be remedied by thyroid and parathyroid feeding respectively. There is some evidence that even the medical varieties of tetany are due to loss of the internal secretion of the parathyroids; according to Kocher, this has been proved in the case of the tetany of pregnancy, and other observations have since been made in which the parathyroids were diseased when tetany was present. Parathyroid feeding should therefore be worth a trial in such cases also. Macallum* recommends the administration of calcium salts, or milk, which is rich in calcium salts. He has shown experimentally, and Edmunds $\uparrow$ has confirmed the statement, that these salts will cure tetany. Thyroid and parathyroid

* Journal of Experimental Med., New York, I909, vol. xi. p. I I8.

$\dagger$ Journal of Path. and Bact., I9ro, p. 288. 
grafting have both been undertaken in man for cretinism and tetany respectively, with the idea of relieving the patient from the necessity of taking drugs all his days. In a few cases success has resulted, but unfortunately the graft becomes absorbed as a general rule, and soon ceases to function. In a case recently described by Brown, of Melbourne, parathyroid feeding and calcium salts both failed to relieve tetany in a patient who had been treated by a too-extensive thyroidectomy for Graves' disease. The in-grafting of parathyroid tissue from dogs and monkeys gave pronounced relief for about $\mathrm{x} 2$ days, but she relapsed after each operation. Human parathyroid was then grafted, and the cure seemed to be permanent. I have seen a case apparently cured by the grafting of human parathyroid.

We see also that exophthalmic goitre is due to hypersecretion of the iodothyrin, as is proved by the artificial imitation of the disease by excessive thyroid feeding, by the excess of iodine present in the colloid in Graves' disease, and by the character of the histological changes. Thus we have reason to expect good from partial removal, which has been very successful in the hands of Kocher, the Mayos, and others. It would be reasonable also to try the effect of iodine starvation, by eliminating vegetables and ordinary tap-water from the dietary, and substituting for the latter the water of a goitre well.

Further, we are helped to understand and to recognize cases of iodoform poisoning, and to learn caution in the use of this drug on absorbing surfaces. It is safer in children than in adults, 
possibly because the thyroid in children contains less iodine. It ought not to be used in patients who have ever shown a tendency to thyroidism, lest acute poisoning or an attack of Graves' disease be precipitated.

Finally, we obtain a clue at last to the remarkable action of iodides in arteriosclerosis and gummata, and it is reasonable to hope that organic compounds of iodine, which cause acute thyroidism more readily than the alkaline salts, may be yet more effectual in stimulating the activity of the thyroid gland. In fact, thyroid extract itself may prove to be the best remedy of all.

Seeing that the activity of thyroid extracts depends only on the iodothyrin, these should be standardized chemically if they are to be given as drugs. Leading chemists now issue an extract which contains not less than 0.2 per cent organic iodine.

\section{REFERENCES.*}

Richardson. - " The Thyroid and Parathyroid Glands," Philadelphia, I905.

Allbutt's System of Medicine, vol. iv. part. i., p. 333 , 1907 Edition (a full bibliography).

Hunt AND SeIDel.- "Studies on Thyroid," Hygienic Labor. atory Bulletin of Public Health, Washington, 1909.

A. RENDLE SHORT.-Bristol Medico-Chirurgical Journal, I9IO, P. 122 .

Kocher, Hector MackenziE.-Discussion on Exophthalmic Goitre, Brit. Med. Journal, 1910, vol. ii. pp. 931, 935.

* Here, as in the other chapters, references are given only to a few accessible authorities, in which a fuller bibliography will be found. 
CHAPTER II.

\section{THE PITUITARY GLAND.}

The effects of removal in animals-Injection of extractsPituitary feeding-Acromegaly and gigantism-Fröhlich's type -Functions of the pituitary gland-Therapeutic value of pituitary extract.

T $\mathrm{T}$ will be remembered that this gland is lodged 1 in the sella turcica of the cranium, in an exceedingly secluded position in the body, and it is only recently that its functions have been recognized. It may be that the interesting researches of Schäfer, Paulesco, Cushing, and others, will prove to have opened up a very important and useful chapter in medicine as well as in physiology.

The gland consists of two distinct portions, anterior and posterior, closely fused in man, but with a wellmarked line of junction in the dog. The anterior part is glandular in structure, consisting of columns of epithelial cells which generally contain colloid. In young animals these cells line tubules; later, the central lumen disappears. Large blood sinuses are present. The posterior lobe consists of vascular neuroglia. Between it and the anterior lobe is a cleft containing glairy fluid. The anterior portion is derived from a pit in the dorsal wall of the pharynx of the embryo; the posterior is budded out from the brain. We are thus prepared to expect a difference in function. 
All the ductless glands are studied by four methods. We have to find the effects, firstly, of removal in animals; and secondly, of the injection or ingestion of extracts. We have, thirdly, to make chemical analyses of the extracts, to isolate any active principle. Finally, a clinical study of symptoms in man associated with any abnormalities of the gland may be expected to throw a light on the problem, and the effect of treating these conditions will also need to be known.

These are here set forth in the rational, not in the historical order. It may be said at once that the active principle or principles have not yet been isolated.

THE EFFECTS OF REMOVAL OF THE PITUITARY GLAND IN ANIMALS.

It is so difficult to remove the organ from its wellconcealed nest that the earlier published results inspired no confidence. It was said that the animals died, but the injury to vital structures was necessarily great, and it has been remarked that the result would probably have been equally fatal if the operator had removed the dorsum sellæ instead of the gland! But the careful and repeated observations of Paulesco on twenty-two animals, and of Cushing on about Ioo puppies, have completely established confidence in the statements now before us.

It is proved that removal of the anterior lobe alone, in dogs, produces just as much effect as removal of the whole gland, but that a removal limited to the posterior lobe causes no symptoms at all. 
The animal, after a total removal, shows no deviation from the normal for a period varying from thirtysix hours to two weeks after the operation. Then it becomes unsteady, there is arching of the back, low temperature, shivering, and death in unconsciousness.

Cushing has found it possible to effect partial removals of the anterior lobe. In young animals, the result is that an "infantile" type is maintained, and the secondary sexual characters do not develop. In older animals, the genitals atrophy, and they get very fat. He gives very convincing photographs showing that these changes are quite marked.

INJECTION OF EXTRACTS OF PITUITARY GLAND. PITUITARY FEEDING.

Injection of extracts of the anterior lobe causes no evident results. Injection of extracts of the posterior or nervous lobe causes quite constantly a prolonged rise of blood-pressure. Not only the blood vessels, but all varieties of unstriped muscle, are stimulated to contract. Peristaltic movements are set up in the bowel, and the bladder and uterus, whether pregnant or not, also contract.

Pituitary feeding in man causes diuresis. Indeed, it is said to be our best available diuretic, and is now on the market for that purpose. Its effect is better seen when the urinary flow is diminished than when it is normal.

Pituitary feeding in young rats causes an exaggeration of their growth. In this case it is not the 
posterior but the anterior or glandular lobe that is concerned (Schäfer).

\section{CLINICAL RESULTS OF LESIONS OF THE PITUITARY GLAND.}

It is well known that the somewhat rare diseases acromegaly and gigantism, are generally but not quite invariably associated with enlargement of the pituitary gland, which has usually been a simple overgrowth, although later adenoma or fibrosis may have developed. Whether acromegaly or gigantism will result appears to be principally a question of the age at which symptoms commence. If they have their onset before growth ceases, gigantism will result. The skulls of most of the classical cases of gigantism, including Patrick O'Byrne, Hunter's famous giant, and Patrick Cotter, the Bristol giant, have enormous sellæ turcicæ to accommodate the enlarged pituitary gland. It is probable that giants usually suffer from acromegaly as well. There are two authentic casts preserved in Bristol of Patrick Cotter's hand, one of which is much larger than the other, indeed it is colossal, measuring 12 inches from wrist to fingertips, whereas the earlier cast measures only II inches. His shoes, which are also preserved, are I5 inches long. It is therefore clear that although he was $7 \mathrm{ft}$. Io in. high, his hands and feet were large out of all proportion, and that the hand rapidly increased in size between the taking of the first and second casts. The lower jaw was enormous, and out of all relation to the rest of the skull.*

* E. Fawcett, Jour. Royal Anthropological Institute, 1909, vol. xxxix. p. 196 . 
Associated with the enlarged bones of the face, hands, and feet seen in acromegaly, there are in some cases other features; these are glycosuria, amenorrhœa, impotence, and, in the young, failure of the secondary sexual characters. The temperature is subnormal. This train of symptoms will recall the effects of total or partial removal of the anterior lobe of the gland in animals.

Fröhlich and others have shown that there is another group of cases, totally distinct from acromegaly, but again associated with tumours of the pituitary gland. These are characterized by excessive fatness, by infantile stature and development, by a childish type of the genital organs, and by absence of the secondary sexual characters. It may be that we shall yet find abnormalities of the pituitary gland in other varieties of infantilism or of adiposity.

Most cases of pituitary tumour which have been diagnosed during life have given additional evidence of their presence by involving the optic chiasma and causing blindness of the nasal half of each retina.

There are already many successful cases on record of removal of a tumour of the pituitary gland in cases of acromegaly. Most recovered from the severe operation, and there was usually a definite shrinking of the enlarged bones. There are also cases in which tumours or cysts of the pituitary have been removed successfully for Fröhlich's type of infantilism and adiposity with bi-temporal hemianopsia.*

* A list of about fifty operations for tumours of the pituitary is given by Bode (Deutsche Zeitschr. f. Chirurg. I9I I, p. 480. 
In two cases of acromegaly there was evidence that the anterior lobe was specially affected; in the one it alone was enlarged, the posterior being normal; in the other it was unusually full of secretion granules.

\section{FUNCTIONS OF THE PITUITARY GLAND.}

Probably it is still too soon to endeavour to piece together these highly interesting observations. It is agreed that we must dissever in toto the functions of the anterior lobe from those of the posterior. All we know about the latter is that it contains a principle which will act as a diuretic and raise blood-pressure.

It is further concluded that the anterior lobe is a vital organ, one of whose functions is to preside over the growth of the body. When it performs these functions to excess, we get overgrowth, as in acromegaly and gigantism. The enlargement of the gland in these cases is analogous to that seen in exophthalmic goitre. In confirmation of this view we have the following facts: in acromegaly there is overgrowth of the anterior portions in most of the cases, and excess of secreting cells in others; young rats fed on the gland become gigantic; puppies which have suffered partial removals fail to grow; removal of a pituitary tumour in man causes shrinking of the enlarged bones. We also find here an explanation for the few cases of acromegaly on record without a large pituitary, just as there are cases of Graves' disease without an enlarged thyroid. In both the function is excessive, although there is no manifest swelling of the gland. 
On the other hand, Cushing holds that the cases of infantilism and adiposity associated with nondevelopment of the sexual apparatus, are due to deficient or absent secretion from the gland, usually in consequence of tumour formation.

$\mathrm{He}$ would further explain the appearance of impotence, amenorrhœa, and subnormal temperature in acromegaly by failure of the secretion after a period of excess. Similarly, Graves' disease may pass into myxœdema, hyperthyroidism ending in hypothyroidism. If this were so, however, one would expect to find that when the sexual organs began to fail the bones would get smaller, or at least not continue to enlarge. The truth of this, however, is very doubtful; indeed the contrary is probably the case.

THERAPEUTIC VALUE OF PITUITARY EXTRACT.

As practical men, what do we gain by the researches described?

We are the richer by a new and powerful diuretic, which may prove itself as superior to caffeine and digitalis as, in another direction, adrenalin is superior to ergot and the styptics.

Another field of usefulness may be found for pituitary extract by giving it hypodermically or intravenously to raise the blood-pressure in surgical shock; but it remains to be seen whether it will prove to be more useful than saline injections containing adrenalin or ergot. The vasoconstrictor action is much more prolonged than that produced by adrenalin, and some good clinical reports of its value have been published. It is no use to repeat the dose 
within an hour or two, because the second injection produces no rise, but even a fall of blood-pressure.

It will be gathered that pituitary extract should not be given for acromegaly or gigantism, just as thyroid extract must not be given for Graves' disease, or it may make matters worse, and cases are on record in which this has actually happened; on the other hand, there is no convincing clinical evidence that pituitary extract will cure acromegaly.

There is, however, a prospect of relief for sufferers from acromegaly and gigantism by operative interference. And finally, we have the hope set before us that pituitary extract may be the specific for infantilism and adiposity, and even add inches to the stature of our diminutive youths and maidens. If so, Mr. H. G. Wells' "Food of the Gods" is already on the market! For this purpose the anterior part of the gland will need to be used, whereas for the diuretic and vasoconstrictor effects the posterior lobe is required.

Extract of the posterior lobe is being tried in obstetrics and gynæcology as a substitute for ergot, its action on the musculature and blood-vessels of the uterus being very similar.

\section{REFERENCES.}

Oliver AND SchäFER.-Journal of Physiology, r895, vol. xviii., p. 277.

Paulesco. - "L'hypophyse du cerveau," Vigot Frères, Paris, r908.

Sch Ä FER.- " The Functions of the Pituitary Body," Croonian Lecture, Proc. Royal Soc., I909, lxxxi. p. 442 (with bibliography).

Cushing.-Amer. Jour. Med. Sci., rgro, vol. cxxxix. p. 473. EISELSBERG. - Annals of Surgery, July, rgro, p. r. 


\section{CHAPTER III. \\ STUDIES IN DIGESTION AND ABSORPTION.}

The process of secretion of saliva-The process of secretion of gastric juice-The influence of appetite-The influence of bitters and alcohol-Movements of the stomach-Sensation in the stomach-Causes of variations in the hydrochloric acid of gastric juice-The physiological effects of gastro-jejunostomy-Feeding after gastrostomy-The process of secretion of pancreatic juice - The bile-The absorption of peptonized foods-The functions of the large intestine-The value of nutrient enemata.

TO more remarkable discoveries have been made 1 by the modern school of physiologists than those to be related in this chapter. They are of revolutionary importance in physiology, and will in time bear practical fruit in their application to clinical diagnosis and treatment. Probably we do not yet see the true value of our heritage in this department.

The first question which has now received an answer is this-Why do the flow of the salivary, the gastric, and the pancreatic juices bear so definite a relationship to the taking of food? We know that the mere thought, sight, smell, or taste of some foods calls forth a secretion of saliva. The mischievous errand boy acts on that physiological principle when he shows a lemon to a German band. In the same way, a flow of the other digestive fluids is provoked by taking certain foods. Pawlow has demonstrated in the dog 
a very remarkable illustration of adaptation of the saliva to the food supplied. Meat calls forth a viscid mucous saliva, to assist in swallowing. Biscuit excites a watery flow containing more ptyalin. Sand, which will be spat out, evokes a copious watery secretion.

We have known for half a century that the secretion of saliva is a nervous reflex. The up path may be the nerves of smell, of sight, or of taste; the down paths are the chordæ tympani, lesser superficial petrosals, and the sympathetic nerves. It has only lately been shown that the secretion of gastric juice is, at first, a nervous reflex of which the vagus is the down path, but that as the stimulus of appetite wears off, this mechanism is replaced by a chemical excitation of the glands. The secretion of the pancreatic juice is controlled from the first by a chemical messenger.

\section{THE SECRETION OF GASTRIC JUICE.}

The secretion of gastric juice was investigated by Pawlow and the St. Petersburg school in a fascinating research on dogs. A sort of gastrostomy was performed in such a manner that an isolated portion of stomach was brought into communication with the surface, and shut off to some extent from the rest of the cavity of the viscus, yet without sacrificing its vascular or nervous supply. Then, to avoid admixture of gastric juice with the food, the œsophagus was divided and brought out in the neck, so that food taken by mouth merely fell out again in the neck. Genuine feeding had to be carried out through 
the gastric fistula, as in a case of gastrostomy for cancer of the œsophagus.

It was found that dogs would survive this procedure for months without suffering. The effects of feeding on the flow of gastric juice could easily be determined. When the animal was shown a savoury meal, not only did his eyes sparkle and mouth water, but the stomach "watered" also. An even greater effect was produced by allowing him to swallow it, though of course it never reached the stomach. If, however, he learned by disappointing experience that he would not be allowed to partake of the meal so temptingly displayed, he ceased to show signs of appetite, and there was no flow of gastric juice.

Section of both vagi had the remarkable effect of preventing the flow of this "appetite juice," by blocking the down path of the reflex. On the other hand, stimulation of the vagi (with certain precautions) induced constantly a flow of gastric juice after an interval of several minutes.

We have considered so far the nervous regulation of the flow of gastric juice, and now turn to the second or chemical regulation.

If water was introduced directly into the stomach, a slight flow of gastric juice was excited. Alcohol had no more effect than water. Mechanical irritation by solid bodies produced no flow. Food substances dissolved in water, such as proteins, starch, salts, and drugs, had no more effect than the water itself. To this rule there were a few significant exceptions. Extractives (that is, the soluble substances in meat, contained in broths, meat extracts, etc.) excited a 
copious flow. Dextrin and commercial peptone caused a smaller flow. It has since been shown by Edkins that these bodies, by their contact with the mucous membrane of the pyloric end of the stomach, induce the formation of a chemical messenger, soluble in the plasma of the blood or lymph, which has the property of exciting the activity of the secretory glands of the cardiac end. To this substance the name of "gastrin," or "gastric secretion," has been given.

In considering the interpretation of these researches we find that, as usual, the scientist has but furnished a belated explanation of the empirical experience of the ages. If food is served in an uninviting manner or for any other reason is eaten without appetite, the proper reflex to excite the secretion of gastric juice will be lacking, and dyspepsia may follow. Yet the stimulus of appetite is not the only means of exciting a flow. The man who rises from a generous dinner has no appetite left, but gastric juice will be needed in his stomach for two or three hours to come, in order to deal with the food present. Nature has adopted the beautiful device that when the first gush of juice produced by the relish with which the food was taken has ceased to flow, the soluble extractives which always accompany a flesh diet shall be used to call forth a further supply. As long as any of these bodies are to be found in the stomach, so long will sufficient gastric juice be forthcoming. When the stomach is empty, the flow ceases. We see here the rational explanation of the ordering of the courses of a dinner. First comes the soup, rich 
in extractives, to excite a secretion by chemical means even when the appetite is deficient. Next are put on the table the lighter and more digestible fish and poultry. Then comes the roast or boiled beef, the item which will tax most the power of the gastric juice to deal with it. The courses which follow do not depend so much on gastric as on pancreatic digestion.

Pawlow and his fellow-workers have shown further that the quantity of gastric juice and, especially, the amount of pepsin that it contains bear a remarkable relationship to the nature of the diet. A meat diet calls forth the most powerful secretion, and a milk diet the weakest.

When we remember that ferments such as pepsin are highly complex and, so to speak, very expensive bodies, it becomes clear why weakly people, convalescents, fever patients, and dyspeptics may do very much better on a milk diet, which makes small demands on the pepsin, and why they find meat unappetizing and indigestible, seeing that they cannot afford to provide for its efficient disintegration.

Let us now look at the effects of those few simple remedies, the bitters, alkalies, acids, and alcoholic preparations which every practitioner must occasionally prescribe. Not one of these substances, when introduced by Pawlow's fistula directly into the stomach, excites any greater flow of gastric juice than does plain cold water. Some of them are actually harmful in the stomach. Alcohol and bitters, if present in any quantity, diminish the activity of the gastric ferments; alkalies, if enough is given to neutralize 
the hydrochloric acid of the gastric juice, bring digestion to a standstill. Yet an alkaline gentian or other bitter mixture has been the comfort of the dyspeptic for centuries.

The explanation lies here. The alcohol or bitter produces its beneficial effects in the mouth, by exciting appetite juice reflexly. When it has been swallowed, it does more harm than good. The expedient at once suggests itself that it would be better therefore to use these time-honoured remedies as a mouth-wash, without swallowing them. But probably few physicians would venture to prescribe for the squire that he should take his bitter beer in that manner! And indeed there is reason to believe that the treatment would fail. Even Pawlow's dogs no longer troubled to produce any appetite juice when they learned that they would not be allowed to enjoy the coveted dainties. It is a much sounder conclusion, that it is futile to give bitters in pill form, yet this mistake is commonly made.

With reference to the relative value of acids and alkalies, probably we have been in error in the past in giving either as a routine to the exclusion of the other. Hydrochloric acid is indicated when the gastric juice is deficient therein, as in cases of atonic dyspepsia or carcinoma of the stomach; in cases of gastric ulcer, or in young people with excessive acidity of the gastric juice, alkalies will be more useful, especially if combined with some insoluble oxide, such as magnesia, to prolong the effect.

It has been thought that any virtue of alcohol in the treatment of dyspepsia lay in its power to promote 
the absorption of peptones. Not only is this untrue, but as we shall see, peptones are not absorbed at all in the stomach, nor indeed anywhere else.

It is not always safe to argue from dogs to man, and Bickel declares that alcohol has some power to produce a flow of gastric juice when placed into the stomach through a gastrostomy wound in the human subject. The experiment, however, is beset with fallacies, and it is not clear that he was successful in eliminating them all ; for instance, the substance must be introduced without the knowledge of the patient; he must not smell or see it; and it must be proved that the flow is greater than that set up by water. $\mathrm{He}$ also states that condiments such as mustard and pepper increase the flow of gastric juice by direct action. But none of these bodies have anything like the proved efficacy and power of meat extracts.

Fats and oils exert a powerful inhibitory effect on gastric secretion (Pawlow). Strong irritants, such as absolute alcohol, cause a very profuse protective outpouring of mucus.

\section{MOVEMENTS OF THE STOMACH.}

It is possible to study the shapes assumed by the stomach after a meal, and its peristaltic movements, by watching or photographing with the $x$-rays animals or men fed with milk or mashed potato containing bismuth salts. For this purpose the subnitrate should be avoided, as large doses have caused nitrite poisoning. It has been shown by Cannon and by Gray that the pyloric portion is frequently shut off 


\section{AND ABSORPTION}

by a strong contraction ring from the fundus; the latter being distended and globular whilst the pyloric antrum is tubular. Formalin-hardened bodies often show a similar disposition, but, as Hertz has proved, this separation into two portions does not always take place. The cardiac end acts as a reservoir, while the muscle of the pyloric end is principally concerned with driving the food through the pylorus.

The general trend of gastric movements is as follows. Soon after food is taken, the muscular wall of the stomach is thrown into contractions, starting from the cardiac end, and the contents are hurled repeatedly from left to right against the tight-closed pylorus. At length, when the fluid mass impinging on it is thoroughly impregnated with acid, the sphincter yields momentarily, and allows a little to pass through. This process continues until the stomach is empty. Solid pellets, such as bismuth pills, are not readily allowed to escape, and a bread mixture, which normally began to pass into the duodenum fifteen minutes after eating, was delayed for over forty minutes when the pills were given with it.

When the stomach is empty the pylorus is relaxed, but quite energetic gastric peristalsis continues to take place. It is probable that these movements give rise to the gastric sensation which we call hunger (Hertz). Bile and duodenal contents readily pass in and out again without exciting any discomfort.

It is interesting to note that Cannon and Murphy have found, if the jejunum is cut across near the upper end and then sutured, that the pylorus remains 
tightly closed for about six hours, until such time as firm cementing of the wound has taken place. Even if food was given, the same effect was seen.

Skiagraphy of the stomach after a bismuth meal has now attained a high pitch of perfection, and furnishes us with our most reliable means of diagnosing hour-glass contraction or simple dilatation. Photographs should be taken just after swallowing, and again after several hours have elapsed.

\section{SENSATION IN THE STOMACH.}

In his recent Goulstonian lecture, Hertz shows that the sensory functions of the viscera are much more limited than those of the skin. The stomach does not possess any temperature sense or any tactile sense, nor is cutting painful. The feeling of heat or cold after swallowing liquids is appreciated by the lower end of the œsophagus. Temperature and tactile sense are quite well developed in the œsophagus, and localization is very accurate-seldom more than an inch out.

Hydrochloric acid may be poured into the stomach, either through a stomach-tube or gastrostomy wound, without producing any sensation at all, even if the percentage rises to $0^{\circ} 5$ or even 2 , and this is true also in cases of gastric ulcer. Alcohol does excite a burning feeling. Distention of the stomach causes a sensation of fullness; the amount of distention necessary depends on the tonicity of the gastric muscles. Gastralgia, whatever its cause, is due to colicky, irregular contractions of the muscle, the pylorus remaining closed. There is often a referred 


\section{AND ABSORPTION}

pain or tenderness in the cutaneous area also. The pain of peritonitis is probably quite a different thing. Sensation in the intestine corresponds closely in its physiology with sensation in the stomach. The anal canal, however, can detect thermal and tactile stimuli.

\section{VARIATIONS IN THE HYDROCHLORIC ACID OF THE STOMACH.}

Thus far we have concerned ourselves particularly with the production of pepsin in the gastric juice, and its physiological variations in quantity. It will repay study to inquire also into the behaviour of the hydrochloric acid. The amount normally present as free $\mathrm{HCl}$ is given differently by different physiologists, some following Töpfer and relying on amidoazo-benzol as the indicator, others using the more accurate but somewhat tedious method of Willcox.*

The contradictory results obtained by various workers are worthy of explanation. The significant figure, the 0.2 per cent of $\mathrm{HCl}$, means (a) $\mathrm{HCl}$ which has already got to work on and combined with protein in the food, together with $(b)$ any free $\mathrm{HCl}$ still unattached. Obviously, a larger or more albuminous test-meal would reduce the free $\mathrm{HCl}$ still further in any stomach, however normal the acidity. In spite of this, some still prefer to estimate the free $\mathrm{HCl}$ and to regard it as the significant figure; they take the normal to be 0.02 per cent after a test-meal, the remaining 0.18 having combined with the food.

The total acidity of course includes lactic acid and

* Lancet, I905, (i), P. 1566. 
any other fermentation acids, also acid phosphates, and is of no great importance.

The most reliable test for the presence of $\mathrm{HCl}$ is Gunsberg's (phloroglucin and vanillin); this is too well known to need description. It is merely a qualitative test.

By whichever method the estimation is made, it would appear that diet exercises little or no effect on the percentage of active hydrochloric acid, although it so markedly affects the pepsin, as we have seen. Nevertheless, the percentage of acid is liable to change, and the changes are of great value for both diagnosis and treatment.

Increased relative amount of $\mathrm{HCl}$ is particularly common in gastric ulcer, so much so that an analysis of a test-meal is of diagnostic importance. It is also seen in duodenal ulcer, and, as has recently been pointed out, in many other affections of the alimentary canal, such as appendicitis. It is probable that the cases which have been diagnosed as simple hyperchlorhydria have usually some latent disease, if not in the stomach or duodenum, then in the gall-bladder or appendix, and removal of the offending organ will cure the hyperchlorhydria. The characteristic symptom of this condition is "hunger-pain," that is, a feeling of gnawing of the stomach, which may be only a discomfort or may amount to positive pain; it occurs two or three hours after a meal, and is relieved by food or alkalies. It is probably due to the spasmodic contraction of the pylorus set up by the acidity. Another view is that it is caused by incipient self-digestion of the stomach. This is 
normally guarded against by an anti-pepsin in the mucous membrane reversing the activity of the gastric juice, but the continual presence of an abnormally powerful combination of acid and pepsin breaks down the resistance, just as is seen in an exaggerated degree when a healthy man dies suddenly during the process of digestion ; the supply of antipepsin fails with the circulation, and a big hole is dissolved through the stomach wall post-mortem. It is highly probable that hyperchlorhydria is a cause as well as a consequence of gastric ulcer; certainly it determines the peculiar-punched-out character which the typical round ulcer assumes. It is significant that more than one such lesion is frequently present, as though the excessively acid juice resulting from the irritation of some initial abrasion had not only deepened that lesion into an ulcer but had determined the formation of others also. It is again significant that the typical punchedout ulcer occurs just where the acid has access, and nowhere else-at the lower orifice of the œsophagus, in the stomach, and in the first two inches of the duodenum, while in the jejunum it is unknown except at the site of a previous gastrojejunostomy. opening, and not even then unless this operation has failed to cure the hyperchlorhydria, which usually means that the orifice was too small or badly placed. Another evil consequence of excessive $\mathrm{HCl}$ is spasm of the pylorus, which may lead to dilatation of the stomach. A curious and suggestive symptom is pyrosis, a periodical copious secretion of saliva probably designed to neutralize the acidity when swallowed. 
In infants, Willcox and R. Miller have stated that there are two types of dyspepsia causing pain, wasting, vomiting, and constipation. One is congenital stenosis of the pylorus, in which the $\mathrm{HCl}$ is subnormal but the pepsin (which may be conveniently tested by the curdling effect on milk) is excessive ; and mucin is also in excess. The other is "acid dyspepsia," in which the $\mathrm{HCl}$ is excessive and the ferments are subnormal. In this case peristaltic waves may be seen, but the pyloric tumour is not felt. The prognosis is very much better than in congenital stenosis, and operation is not needed as it so often is in the more serious condition.

Enough has been said to show that hyperchlorhydria and its advertisement, "hunger-pain," are more than an inconvenience to the patient; they are in many cases the consequence and in other cases the precursor of serious organic mischief which may lead to dilated stomach, to chronic gastric ulcerwhich in its turn is very apt to become malignantor to an abdominal catastrophe from perforation of the stomach or duodenum.

Medical means will often give a large measure of relief. Taking food, and especially a hard-boiled egg, when the pain comes on will generally abate the symptoms. Alkalies are indicated, especially magnesia, which has two advantages: it does not dissolve and exert all its effect in a few minutes, and it does not give off carbon dioxide as the carbonates do. The bismuth lozenges of the B.P. are convenient to carry and very successful in stopping the discomfort. We will barely mention such useful 
measures as rest in bed, milk diet, and lavage. Pawlow on theoretical grounds recommends fats and oils to check the flow of the gastric juice.

If these means are not successful, it is very desirable to perform laparotomy and to explore the stomach, duodenum, appendix, and gall-bladder. If gastric or duodenal ulcer is present, gastrojejunostomy is of course indicated. If no abnormality can be discovered in either stomach or duodenum without opening into them (which is seldom if ever called for), it may be that some adhesions or kinking of the appendix may be found, and removal of the organ will effect a cure in many of the cases, but not all. Paterson cured $\mathrm{I}_{7}$ out of 24 cases of epigastric pain in which the stomach and duodenum were normal but the appendix was diseased ; the Mayos in similar cases cured 84 , and greatly improved 7 , out of II5. It might be well to do a gastrojejunostomy at the same time; one of Paterson's failures was subsequently relieved by this means. This operation will often lead to a permanent cure of pain, vomiting, or hæmatemesis, even when no abnormality can be found. The important point is that it is not right to do the short-circuiting operation on a normal stomach without also exploring the appendix and gall-bladder. Soltau Fenwick states that of Ir2 cases of hyperchlorhydria, in 34 the stomach and duodenum were normal ; in 22 of these the appendix was at fault, and in 12 gall-stones were present. In 9 cases appendix trouble complicated gastric or duo. denal ulcer. In 66 patients an ulcer was present in the stomach or duodenum; 4 of these were malignant. 
Hydrochloric Acid Deficient.-It is well known that the $\mathrm{HCl}$ in the gastric juice is deficient or absent in cases of cancer of the stomach, but the practical value of this is lessened by the fact that old-standing gastritis, or cancer of other organs than the stomach, may abolish the $\mathrm{HCl}$. On the other hand, cancer more often than not is preceded by ulcer, and there will be a stage in which the hyperchlorhydria has not yet passed off although cancer is already present. Nevertheless, we cannot afford to neglect the chemical test in the diagnosis of cancer of the stomach, as the other early signs are often equally dubious.

\section{THE PHYSIOLOGY OF GASTROJEJUNOSTOMY.}

What effect is produced upon the functions of the alimentary canal by the operation of gastrojejunostomy? We have to ask: (I) Does the food pass through the new opening or by the pylorus? What is the effect upon the gastric juice? and, (3), What is the effect upon the absorption of proteins, fats, and carbohydrates?

Some light has been thrown upon the first of these questions by watching with the $x$-rays the course taken by a meal containing bismuth oxide, and it would appear, as might have been expected, that both routes are followed, unless either the pylorus or the artificial opening is or becomes greatly narrowed. On this subject the writings of Cannon and Gray may be consulted.

The effect upon the gastric juice is nil if it has previously been normal; if hyperchlorhydria was present, an efficient gastrojejunostomy appears 


\section{AND ABSORPTION}

invariably to restore the amount of acid to normal. Stenosis of the opening may be followed by a return to the greater acidity. If the $\mathrm{HCl}$ is absent, however, the operation will seldom if ever cause it to appear.

That there cannot be any serious loss of power to digest and absorb food-stuffs is shown by the remarkable way in which the great majority of cases operated on become fat and flourishing after gastrojejunostomy for non-malignant affections, the improved condition being maintained for many years. There is at least one patient who at the age of seven was described by his father as strong and healthy, with good appetite and exceedingly good digestion, after a gastrojejunostomy at the age of eight weeks for pyloric stenosis. Paterson has proved that the amount of fat and protein passed in the fæces without assimilation is very little greater than in the normal individual. In four cases it was only about 2 per cent above normal; that is, the fres contained about 9 to 9.5 per cent of protein nitrogen taken as food instead of the normal $7 \cdot 7$ per cent. Much less favourable results previously published by Jöslin were due to the fact that he used cancerous cases on which to experiment. Paterson's results are confirmed by Cameron, * who finds that the only ill-effect is some slight diminution in the power of absorbing fat.

Feeding after Gastrostomy.-Pawlow's experiments, above referred to, give a valuable hint as to the feeding of patients who are unable to swallow and have suffered a gastrostomy. It is well known

* Brit. Med. Jour., I908, (i), p. I40. 
that they may fail to make progress even when the operation has apparently not been postponed too long. Sometimes they will request that they should still be allowed to take food into the mouth "just to taste it." Evidently they lack the first secretion of gastric juice due to the relish with which the food is tasted and swallowed, and digestion may in consequence be very imperfect. This may be overcome by the simple device of adding some form of extractives to the feed, such as beef-tea, gravy, soup, or a meat essence. Thus the chemical mechanism is brought into play though the nervous reflex fails. Excellent practical results have been obtained by this expedient.

\section{THE SECRETION OF PANCREATIC JUICE.}

This was first thought by Pawlow to be due to a reflex through the vagus, but it has been shown by Bayliss and Starling that the stimulus is in reality chemical. When the hydrochloric acid of the gastric juice touches the mucous membrane of the duodenum, a soluble chemical substance is formed called "secretin," which passes into the rootlets of the portal vein, is carried to the liver and heart, and thence all over the body. Some of it in due course reaches the pancreas, and a flow of pancreatic juice is at once instituted and continues as long as the acid contents of the stomach continue to enter the duodenum. The secretion acts chemically on the pancreatic cells, liberating steapsin from pro-steapsin, amylopsin from pro-amylopsin, and trypsinogen from pro-trypsinogen. There is some evidence that secretin 


\section{AND ABSORPTION}

stimulates also the activity of the liver cells, thus pouring into the bowel not only pancreatic juice but also bile.*

We find in this mechanism a clear indication for the administration of hydrochloric acid in cases where that of the gastric juice is deficient. At least we may be able to preserve for the patient the activity of his pancreatic juice, which is likely to be suppressed when the usual stimulus is lacking. The exhibition of secretin itself has so far been a failure ; it is not absorbed from the bowel, and giving it subcutaneously produces dangerous depression, due apparently to other substances, which we do not know how to separate, extracted along with it from the duodenal mucous membrane.

Pawlow and his followers have described a marvellous adaptation of the various pancreatic ferments to the work in hand; thus, they thought that a meat diet called forth much trypsin, and a starchy diet much amylopsin. These statements were made before we knew that the flow of pancreatic juice was started by secretin, which in its turn depends

* This is only one of several recently discovered chemical messengers, travelling from one part to another in the blood. stream (so-called " horrnones,"-Starling). We have often wondered why the uterus enlarges in extra-uterine gestation; it is because the internal secretion of the corpus luteum, left by the scar in the ovary of the ruptured Graafian follicles, is the normal stimulus causing the great development of the uterus which takes place during pregnancy. Injection of extract of corpus luteum into a virgin animal of the same species causes such enlargement of the uterus and adnexa. In the same way the mammary glands are stimulated to secrete milk, by an internal secretion derived from the fœtus, and lactation may be obtained by injecting an extract into the virgin animal. One of the individuals of a "Siamese twins" was recently delivered of a child, and both started lactating. 
on the amount of $\mathrm{HCl}$ coming through from the stomach. A still more disturbing factor is the action of the ferment in the intestinal juice called enterokinase, without which trypsin is inert, being secreted in an inactive form called trypsinogen and only activated by the enterokinase. More recent work, taking these new facts into account, shows that the composition of the pancreatic juice does not vary. It is probable, however, that other substances besides hydrochloric acid have the power of calling forth pancreatic juice, and, indeed, if it were not so patients with cancer of the stomach would usually starve. Workers in Pawlow's laboratory have demonstrated that the most important of these are fat and soaps, and the action is similar to that of the gastric juice, namely, by exciting the formation of a secretin. It is very probable, also, that the sight and smell of food set up a flow of pancreatic juice, but it is difficult to be sure of this.

Pawlow's operative experience in making pancreatic fistulæ in dogs and in the after-treatment may suggest devices for surgical practice. To obtain a permanent fistula it was necessary to bring the duct out on the abdominal wall, and still to preserve its natural orifice, otherwise it closed rapidly. Therefore a small square of duodenum containing the opening of the duct was transplanted to the skin. With careful nursing and treatment, such dogs would live for months or years.

There were two principal points in the after-treatment. At first there was great difficulty on account of tryptic digestion of the skin around the wound, 


\section{AND ABSORPTION}

such as is so trying for surgeon and patient in some cases after operation for acute pancreatitis, pancreatic cyst, rupture of the pancreas, or artificial anus in the small intestine. One of Pawlow's dogs, suffering in this way, kept on tearing down mortar from the wall to lie upon, and by so doing greatly improved the condition. The hint was acted upon, and afterwards a bed of sand or mortar was always provided, and the excoriation avoided.

About a month after the operation, most of the animals became very weak and refused food, and several died. Yet there had been no loss of weight, there was no peritonitis, and merely ligating the pancreatic duct produced no such symptoms, indeed, no special harm resulted. Pawlow concluded that the loss of juice must be the cause of the trouble, so a diet of milk and bread, which excite the smallest flow of secretion, was substituted for meat, which excites the greatest flow, and alkalies were given regularly by mouth. By these means the dangerous symptoms were entirely averted.

Both the above experiences may help us in dealing with some special difficulties in surgical cases after operations on the pancreas. For the sand or mortar, bags containing some drying powder would probably be substituted.

\section{THE BILE.}

We may dismiss the recent researches on the bile in a very few words, as their clinical bearing is not yet apparent.

The secretion of bile by the liver cells is excited by 
secretin, just as is the pancreatic secretion. No bile, however, enters the duodenum except when food is there, two hours after a meal. The quantities of bile and pancreatic juice poured into the intestine rise and fall exactly together. The reflex contractions of the gall-bladder which determine this flow of bile are brought about by the presence of fat or of extractives in the duodenum. Here probably we find the explanation of any virtue which olive oil may have in getting rid of gall-stones, because it is highly questionable whether any of the oil is actually excreted by the bile, or in any other way brought into contact with the concretions so as to dissolve them.

Of the many functions which have been charged upon the bile, the most important is that of an intensifier of the action of the pancreatic juice. The pancreatic ferments have their activity enhanced threefold in the presence of the sodium taurocholate and glycocholate of the bile. Moreover, these salts dissolve fatty acids, and so help in the absorption of fats.

\section{ABSORPTION OF PROTEINS.}

There remains to be described a fundamental change in our views of the digestion and absorption of proteins. It was formerly taught that the gastric and pancreatic ferments converted the albumin of the food into soluble, diffusible bodies called peptones ; that these passed through the intestinal wall into the blood-stream, and in so doing were by some means built up again into the proteins of the blood. Some readers may recollect a Cleavage Theory, suggesting 
that half of these peptones were further acted on by the trypsin of the pancreatic juice and broken down into two aminoacids called leucin and tyrosin, whose fate was in doubt. The modern view is very different. The researches of Fischer, Kossel, and others have thrown a flood of light on the composition of the protein molecules. We now know that protein consists of a complicated chain of the bodies called aminoacids (that is, organic acids of which a hydrogen has been replaced by the $\mathrm{NH}_{2}$ group). These may be classified as monoamines (as leucin, glycin), diamines (as arginin, lysin), and aromatic amines (as tyrosin, tryptophan). By the trypsin of the pancreatic juice proteins are resolved into their various components, and consequently a mixture, in differing proportions, of these aminoacids is found in the intestine. Peptone is only a stage on the way to this final dissolution, and is not absorbed at all. It would appear, however, that some of it is never broken down to aminoacids.

The ferment which brings about the full dissolution is the trypsin of the pancreatic juice, which converts albumin into aminoacids. Pepsin can carry the action only as far as peptones, unless its action is unnaturally prolonged, and consequently there is no absorption of protein material in the stomach. There is a ferment in both the pancreatic and intestinal juices called erepsin, which completes the action of the gastric juice by converting peptones into aminoacids.

Neither albumin nor peptone can be absorbed by the intestine. They must first be converted into 
aminoacids. These are the actual substances which traverse the intestinal wall and enter the bloodstream. They do not circulate as serum albumin, but as aminoacids, and are taken up by the tissue proteins according to their needs. Should these require more of the aromatic amines, they will abstract tyrosin or tryptophan from the blood, and so on. Any aminoacids that are in excess of the requirements of the body are broken down by the liver to urea, and excreted by the kidney. This constitutes the so-called exogenous origin of urea.

The evidence for these fundamental changes in our view of the absorption of proteins may be summarized briefly as follows:-We now know that

(a). Aminoacids are abundantly formed in the intestine.

(b). Feeding on aminoacids will sustain life. Gelatin will not sustain life, because it lacks the aromatic amines, but if it is given with tyrosin and tryptophan, the animal lives.

(c).. During protein absorption, it is not the proteins (serum albumin and globulin) which increase in the blood, but the nitrogenous constituents of the plasma which are not coagulated by heat.

Carlyle said that an error is never proved to be an error until it is shown how the error arose, and this is possible in regard to the older theory, that peptones were converted by the intestinal epithelium into albumin. The disappearance of the peptone in contact with the intestinal wall was taken to indicate a conversion into albumin, because the nature and function of the ferment erepsin were not then known. 


\section{AND ABSORPTION}

The erepsin had converted the peptone into aminoacids.

We must not hope, therefore, when we feed a patient on peptonized foods, that we have completely saved him the necessity of digesting them. We have carried the process only part of the way. It is not feasible, perhaps, to feed him on aminoacids, because the prolonged pancreatic digestion makes the food unpleasantly bitter and might cause diarrhœa ; aminoacids are not normal occupants of the stomach. But there may be a future for rectal feeding with the products of a pancreatic digest extending over two days. In giving nutrient enemata of peptonized milk we take the presence of erepsin in the mucous membrane of that particular patient's rectum on trust. Sometimes the patient seems to starve although having nutrients. If we gave him aminoacids instead of peptones, we might remove at least one difficulty in the way of nourishing him.

\section{FUNCTIONS OF THE COLON.}

Motor Functions.-We have always known that the small intestine is continually in movement, the main character of the movement being an onward sweeping wave called peristalsis, carrying the bowel contents from the stomach to the colon. Peristalsis consists of a wave of relaxation pursued by a wave of constriction. It is controlled by a purely local mechanism, and will go on after all nerves have been severed, or even after cutting the intestines right out of the body. After cutting the bowel across the wave is stopped at the point of division. Fortunately 
for the practice of end-to-end anastomosis of the intestines, any bowel contents which may be pushed through the junction will start a fresh wave of peristalsis on the distal side of the union. Though the movements are not dependent on nerves, they can be controlled by the central nervous system, as every one knows who has suffered from an attack of "exam-funk diarrhœa." The vagus stimulates peristaltic movements; the splanchnic nerves inhibit them. In the small intestine peristalsis is normally only from stomach to colon, and a bismuth meal makes the journey in about four hours. There is a sort of pendulum swing-swang of whole loops of bowel going on at the same time. In the large intestine the conditions are very different, and have an important bearing on certain operative procedures. The movements in man may be studied by skiagraphy after bismuth meals or bismuth enemata, and by observations on patients who have suffered various forms of colostomy, ileosigmoidostomy, and exclusion operations.

The rectum is of course under direct control of the centre near the tip of the spinal cord, the motor path being the pelvic visceral nerves from the second to the fifth sacral roots; the sympathetic system also supplies the rectum. The physiology of defecation is well known, and need not detain us.

In the cæcum and the ascending, transverse, descending, and pelvic portions of the colon, however, the motor functions are involuntary, as in the small intestine, but with a striking difference. In the small intestine antiperistalsis, that is, peristalsis in 


\section{AND ABSORPTION}

a reverse direction, is pathological, occurring in intestinal obstruction and rare hysterical conditions. In the colon antiperistalsis is the rule. The contents of the cæcum and the ascending colon are continually seething up and down. The descending colon is normally empty. The pelvic colon is a store for fæces. Once or twice daily the contents of the ascending and transverse colons are suddenly carried over into the pelvic colon and rectum.

The existence of these currents of antiperistalsis is very important surgically. Many patients on whom ileosigmoidostomy (turning the ileum into the pelvic colon or sigmoid) has been performed for growth of the ascending colon have suffered great subsequent discomfort from the passage of gas and fæces into the blind loop of colon, from the opening into the sigmoid up into the descending colon, and so round towards the cæcum. In some cases a second operation has been necessary. In all anastomoses and excisions of the large intestine this physiological factor must be calculated upon and provided for. In some cases an appendicostomy has been performed to allow flatus to escape and to make lavage possible.

Before turning from the motor functions of the intestines, another experimental observation merits attention. Pawlow found that strong stimulation of any sensory nerves might cause, in dogs, prolonged reflex arrest of peristalsis. Injury of abdominal viscera was particularly likely to do so. Cannon and Murphy have shown that even gentle manipulation of the bowel causes cessation of all intestinal 
movements for three hours or more. The condition might be described as "intestinal shock." It is of great surgical importance. Arrest of peristalsis, quite apart from peritonitis, occasionally follows strangulated hernia, even after successful operation; it may accompany gall-stone colic, and it may even occur as a neurosis or in association with organic nervous disease. Some interesting cases are reported by Walton in a discussion of the subject. Fortunately, he is able to direct us to promising lines of treatment. The milder degrees of the condition will yield to turpentine enemata and to saline purges, but there are instances in which all drugs are vomited and the block seems to be too high for enemata to act. Here we may try the effect of physostigmine (eserine) salicylate, in $\frac{1}{100}-\mathrm{gr}$. doses, given hypodermically every four hours for six doses. Walton shows by a chart that the evacuations when this drug is given after abdominal operations are much more frequent than without it. It is scarcely at all aperient in health, working best when the local nerve ganglia in the intestine are thrown out of action. It is of course an old and well-known remedy, acting like pilocarpine by stimulating the nerve endings in unstriped muscle.

Absorption in the Large Intestine.-We may sum up the ordinary functions of the various parts of the bowel with regard to absorption thus:-

Drugs, salts, and sugars are absorbed in the stomach.

Proteins (as aminoacids), carbohydrates (as sugar), and fats (as soap and glycerin) are absorbed in the small intestine. 
Water is absorbed in the large intestine.

The practical physician or surgeon is concerned with the physiologist's answer to two questions. First, Is the colon a necessary organ, or may it be eliminated with safety? Second, Can the large intestine absorb useful food-stuffs in case of need ?

With regard to the first point, we are at once confronted with the fact that in some bats the colon is exceedingly short. Again, it is well known that patients with an artificial anus in the cæcum are able to keep up their nutrition. The same is true after the ileum has been cut across and turned into the sigmoid. Careful analyses made by Groves and Walker Hall under these conditions show that the normal amount of water can still be absorbed by the short piece of rectum and sigmoid traversed by the food; the fæces are not too fluid. By comparing the amount of water in the intestinal contents at the ileo-cæcal valve and as passed naturally in man, they conclude that the colon absorbs about to to 20 per cent of water from the fæces. Bacteria make up nearly half the weight of the fæces as passed normally. Treves, Lane, and others have excised almost the whole colon without the patient's nutrition suffering.

We conclude then that the colon is not a necessary organ. If, however, a permanent artificial anus is made in the ileum more than 12 to 18 inches away from the ileo-cæcal valve, absorption is inadequate and the patient dies of starvation.

Turning to the second question, it is scarcely necessary to call attention to its very great importance. If the colon cannot absorb a reasonable 
quantity of food-stuffs, the whole theory of feeding by nutrient enemata would collapse.

In the experiments described above, Groves and Walker Hall found that the absorption of nitrogen and fat by the colon was so small as to be negligible. Laidlaw and Ryffel, analysing the urine during rectal feeding, found that the nitrogen output corresponded pretty closely to the published figures for professional fasting men at the same date of starvation ; the enemata used were, however, not particularly suitable, consisting of the whites of nine eggs, six ounces of raw starch, and twenty-four ounces of peptonized milk. The albumin and starch were probably not touched. Langdon Brown found no difference in the urea of the urine whether the patients were given peptonized milk or normal saline. Further observations on these lines, using dextrose and adequate quantities of milk, either peptonized or even converted into aminoacids by prolonged digestion, are greatly needed.

Sharkey and others claim that a good deal of nitrogen can be absorbed by the rectum, basing their findings on the analysis of rectal washings; but this method is open to criticism, as sometimes, in spite of washing out, the patient may pass an enormous putrid evacuation, showing that the lavage was not effectual.

I am kindly permitted to quote some unpublished analyses, which will be found in the Appendix, made by Dr. R. E. Thomas on patients of Dr. Nixon's, in the Bristol Royal Infirmary. A daily estimation of the output of urea and ammonia nitrogen, and also 
of the excretion of acetone and diacetic acid, was made on patients being "fed" by nutrient enemata for hæmatemesis. It will be seen that the figures are so little different from those obtained when no food at all is given, that we are compelled to believe that little if any protein or carbohydrate was absorbed. The carbohydrate was given in the form of lactose.

It is quite certain that dextrose can be absorbed from the rectum, because it will cure acidosis when given in this way, and also it will raise the respiratory quotient by increasing the amount of $\mathrm{CO}_{2}$ expired.

It is very difficult to obtain evidence as to whether fats are absorbed. In a patient who had a fistula of the thoracic duct only from 3.7 to 5.5 per cent of the fat given per rectum was recovered from the fistula.

In another patient, the thoracic duct was blocked and a lymphatic vessel had ruptured into the urinary passages, so that most of the fat absorbed by the lacteals escaped into the urine, which became milky after a fatty meal (chyluria). There was no chyluria when all fats were stopped by mouth, and nutrient enemata containing milk administered.

It must not be supposed that rectal feeding supplies absolute rest to the stomach. It may be observed in patients with a gastrostomy wound that each nutrient enema excites a reflex flow of gastric juice.

There is thus grave doubt as to whether nutrients really do much good. It has been claimed that a dog has been fed for many months on nutrients only, but even if this be true it does not necessarily prove that it would be possible in man. Patients have 
been kept alive on nutrients for several weeks, but it is well known that there are sometimes sudden and unaccountable deaths. It must not be forgotten that if water is supplied life will usually be prolonged for a month with no food at all, and in one instance a man was alive after sixty-four days of complete starvation. If water also is withheld, death takes place in about a week ; but a girl buried in an Italian earthquake lived eleven days without either food or drink.

Public opinion in England may not yet be ripe enough to allow us to practise sheer starvation for gastric ulcer, but if we cannot feed a patient, at least we can disturb his peace as little as possible by nearly useless enemata.

\section{REFERENCES.}

PAwlow.- "The Work of the Digestive Glands." Translated by W. H. Thompson. 2nd Edition. Griffin \& Co., Igro.

StaRLING.-." Recent Advances in the Physiology of Diges. tion." London, Ig06. (Gives an excellent list of authorities.)

Edkins.-Journ. of Physiol., vol. xxxiv., 1906, p. I33; xxxviii., 1908, p. 263.

LANGDON BRown.- " Physiological Principles in Treatment." 2nd Edition. London, I9I0.

Soltau Fenwick,-Proc. Royal Soc. Med.; Surgical Section : I9I0, p. I77.

Paterson.-Ibid., p. 187.

CanNon.-Amer. Jour. of Physiology, 1902, vi., p. 253.

GRAY.Lancet, I908, (i), p. 549 ; (ii), p. 224.

WILlcoX.-Lancet, I905, (i), P. I566; 1908, (ii), p. 220.

WALTON.-Ibid., I908, (ii), pp. I7, 85.

GRoves.- "Transac. Royal Soc. Medicine," vol. ii., 1909, part iii., Surgical Section, p. I2I. 


\section{CHAPTER IV. \\ THE APPLIED PHYSIOLOGY OF BLOOD-PRESSURE.}

Apparatus for measuring arterial, venous, and capillary pressure in man-Factors controlling the blood-pressure-The influence of gravity-The influence of the internal secretion of the supra. renal glands-Surgical shock: its nature, prevention, and treat. ment-The intracranial circulation-Blood-pressure after head injuries-The pulmonary circulation-The internal administration of hæmostatics.

$\mathrm{T}^{\mathrm{T}}$ has become a truism that when feeling the 1 pulse it is of more importance to observe the "tension," or blood-pressure, than to count the rate. But only within the last few years has it been recognized how inadequately even the skilled finger can judge of the blood-pressure, because of the complicating factor of the variable rigidity of the arterial wall. In an arteriosclerotic vessel the tension will be over-estimated.

Two well-known apparatus have therefore been introduced to clinical service. The first to be widely used in England was Hill and Barnard's sphygmometer, and later came some form of the Riva-Rocci instrument. Both may be used to measure either the systolic or the diastolic pressure. They have in common a hollow rubber armlet capable of inflation with air, and covered by a leather or leaden shield to be strapped round the arm; each is to be inflated by an air-pump with a leaking valve, so that the 
pressure induced gradually falls. The Riva-Rocci sphygmometer is to be read, by the level of a column of mercury, at the point where the pulse, at first obliterated by the pressure, becomes just perceptible to the finger or the ear. This gives the systolic pressure. The diastolic is read by noting the point of maximum oscillation of the column of mercury. The apparatus of Hill and Barnard is to be read on a pressure gauge when the recording needle shows the greatest oscillation; this gives the diastolic pressure. An average reading for the maximum or systolic pressure is IIo to I20 millimetres of mercury ; for the diastolic pressure a little less. The figure is seldom continuously below roo (except in Addison's disease), but it may be higher than 200 in arteriosclerosis.

For the study of cases of raised or lowered blood-pressure these instruments are essential, and are very widely used to-day. We shall, however, consider them rather in their surgical application.

Methods for the measurement of venous and capillary pressure have been introduced more recently, and are of less clinical value so far. Venous pressure may be determined by stroking a vein until it becomes empty up to a valve, then applying the Riva-Rocci sphygmometer, and noting the pressure at which the vein fills. Capillary pressure may be obtained by determining to what height above the arm normal saline in a funnel must be raised before it will begin to flow through a hypodermic needle into the subcutaneous tissues (Leonard 
Hill). The normal capillary pressure varies with the locality, being ro to 20 millimetres of water in the arm, and 90 millimetres in the leg.

\section{THE FACTORS}

CONTROLLING THE BLOOD-PRESSURE.

The factors normally at work in maintaining the blood-pressure are more complicated than was at one time apparent. Of course it varies with the activity of the heart. It is further controlled by the calibre of the smaller arteries, which in their turn are regulated by the vasomotor centre in the medulla of the brain. Vasoconstriction naturally raises the blood-pressure, and vice versa. Then, again, the respiratory movements have an influence. In experimenting with animals under an anæsthetic this influence is marked and constant; the bloodpressure rises with each inspiration, and falls with each expiration. In the normal human subject this does not obtain with the same constancy. Lewis has demonstrated that it is true when the respiration is abdominal in type, but that in the costal type of breathing the blood-pressure falls with inspiration, and rises with expiration.

Gravity also affects the blood-pressure. It is well known that many people faint on rising too suddenly from a hot bath, because the vasomotor control is not sufficiently powerful to constrict all the vessels in an instant, so as to keep enough blood circulating through the brain. Leonard Hill's well-known experiment on the hutch rabbit and the wild rabbit illustrates the same condition. The hutch rabbit 
held up by the ears will die; the wild rabbit survives. In the tame animal, all the blood tends to collect in the pendulous belly, and the feeble vasomotor control is unable to constrict the vessels and to drive it up to the brain. This picture is very similar to that of surgical shock in man.

There is yet another governing factor, and, we must believe, an essential one. The suprarenal glands are constantly pouring into the blood their internal secretion, which we know as adrenalin. The medulla of the suprarenal glands is developed from the sympathetic nervous system, and adrenalin is essential for the proper action of all the motor nerve endings of that system. Injection of adrenalin produces all the effects on involuntary muscle that are characteristic of stimulating the sympathetic, and some of the effects on glandular secretion. Yet it does not act by stimulating these nerve endings themselves, because it continues to produce its action after section and degeneration of sympathetic nerves. The most prominent of its effects is a powerful but transient vasoconstriction.

That adrenalin is being poured out continually to maintain the activity of the vasoconstrictors we know by research along two distinct lines of access. If the suprarenal veins are clamped for a few hours, the blood-pressure falls. On their release the accumulated adrenalin passes into the circulation, and the blood-pressure rises rapidly above normal.

Further light is shed upon the matter by a study of the phenomena of Addison's disease, in which the 
adrenalin has been proved to be absent.* The blood-pressure is extraordinarily low, and the various functions of the sympathetic are more or less paralysed. The vasomotor control is very deficient. Adrenalin is so extensively used as a hæmostatic, and as an injection for various purposes, that it is important to realize its dangers and danger signs. It is not at all improbable that some so-called deaths from anæsthesia, especially in operations on the nose, have been due to the injection of too much of this potent drug. The symptoms of an overdose are not at all unlike those of chloroform poisoningpallor, salivation, dilated pupil, and small pulse; but the pulse rate may be slow. In animals its prolonged use may cause glycosuria of pancreatic type.

\section{SURGICAL SHOCK.}

We shall next set forth the important researches of Crile and Mummery on surgical shock, and the means of combating it. It has been well said that the surgeon has triumphed over pain by means of anæsthetics, and over sepsis by means of sterilization, but that shock remains as the great barrier to perfect success.

The clinical measure of surgical shock is the bloodpressure, as recorded by some form of sphygmometer. For this purpose, as for most, the RivaRocci instrument is preferable. As shock deepens, the blood-pressure falls; as it passes off, the

* A. Rendle Short, "Blood-Pressure and Pigmentation in Addison's Disease, Lancet, 1906, (ii.), p. 285. 


\section{THE APPLIED PHYSIOLOGY}

blood-pressure regains its normal standard. During an operation such as a high amputation it will be found that the fall of blood-pressure is induced principally by the division of the great nerves; in abdominal operations, by evisceration or by dragging on the organs.

According to Crile and Mummery, surgical shock is due to exhaustion of the vasomotor centre in the medulla of the brain. In consequence, the small arteries are allowed to dilate, blood collects and stagnates in them, especially in the capacious vessels of the abdomen, and there is not enough circulating blood to maintain the proper supply to the brain and other important structures. Sherrington has shown that there is in practice another factor, namely, a concentration of the blood, owing to loss of water, from the vessels to the tissues.

It is possible only to summarize briefly the practical deductions as to our best means of combating surgical shock: the fascinating original papers should be consulted by any who have not read them. It is clear, in the first place, that when dealing with a patient with a crushed limb, it is futile to "wait for the shock to pass." It is the crushed nerves which are maintaining the shock. Injection of nerve trunks with cocaine or novocain five minutes before dividing them prevents completely any fall of blood-pressure or other evidence of shock during amputations. The writer has successfully employed injections of 5 minims each of 2 per cent novocain into the anterior crural and great sciatic nerves, in amputating through the 
thigh. Crile envelops the patient in a pneumatic suit under pressure, so as to prevent relaxation of the vessels. Bandaging the limbs is a less efficient but more serviceable means of obtaining the same result. Intravenous transfusion with normal saline is not as efficacious in the treatment of shock as of collapse from hæmorrhage or cholera, but it is nevertheless a valuable proceeding. The addition of adrenalin up to $I$ in 50,000 (even I in 20,000 may be used) will restore the calibre of the vessels even when the vasomotor centre is powerless. Crile and Mummery speak disparagingly of the use of stimulants; alcohol does nothing but harm, and strychnine, though it may perhaps raise the bloodpressure for a while, soon allows it to fall even lower than it was before. Indeed, Crile declares that large doses of strychnine exhaust the vasomotor centre, and induce shock apart from any injury. Pituitary extract is probably more valuable; it is given hypodermically. The dose varies with the preparation. Needless to say, the head should be kept low, so as to help by gravity the circulation through the brain. It is quite probable that small doses of strychnine spread over several days before the operation may be of use.

By the adoption of such means as the above it is possible to bring about the resurrection of dogs whose hearts have stopped beating for fifteen minutes. 


\section{THE INTRACRANIAL CIRCULATION.}

There are two important regions of the body in which the ordinary laws regulating the blood-supply do not hold good, and to the consideration of these we now turn. We will speak first of the intracranial circulation.

It is an obvious fact that one cannot put more than a pint into a pint pot, and since the brain is incompressible, the total volume of blood inside the bony cranial cavity cannot vary. It is true that the volume of the cerebrospinal fluid is not absolutely constant. A trifling ebb and flow is possible along the sheaths of the spinal nerves. The occipitoatlantal membrane pulsates a little, and so does the membranous fontanelle in an infant. Nevertheless, the total volume of this fluid is so small that to all intents and purposes it does not alter the truth of the fact propounded.

Yet every organ, and surely the brain amongst the rest, needs more blood during moments of activity or excitement, and less during rest or sleep. At least, the supply of oxygen and nutriment must roughly correspond to the demand. How may this be brought about?

Although the volume of blood in the cranial cavity at any given moment must be a constant, there are two ways in which more oxygen can be supplied. In the first place, the arteries might be dilated at the expense of the veins. In the second place, the rate of flow might be increased, so that in a given space of time a larger volume should have passed through the 
capillaries of the brain. Both of these actually occur.

When it is desired to warm or light one particular room in a house where the supply of gas is insufficient, all unnecessary lights elsewhere are turned down. It is not possible to dilate in this way the pipes passing to the room in question, but the rate of flow of gas is increased. Similarly, when more blood is required by the brain; the vasomotor centre issues a universal vasoconstrictor impulse. This is not able to constrict the arteries in the brain, because the nerve fibres which undoubtedly run with them appear to have little or no vasomotor control over them. Hence these arteries are distended by the pressure of blood, the cranial veins are expressed, and the rate of flow increases.

Mental activity, therefore, should be accompanied by a rise of blood-pressure, and sleep by a fall. Further, during sleep the volume of a limb, as measured by a plethysmograph, should increase. Both these statements are found to be true in fact. Indeed, if a man go to sleep accurately balanced on a delicate see-saw, during deep sleep the legs are lowered ; when he wakes, the equilibrium is regained.

When part of the available cranial space is occupied by blood-clot, depressed bone, or inflammatory products, it is at the expense of the volume of blood. An adequate circulation through the medulla can be maintained in that case only by an exaggeration of the process just described, and the bloodpressure will necessarily be high. Any attempt to bring it down by violent purgation, drugs, or, worse 
still, by bleeding, can only defeat Nature in her efforts to keep the patient from fatal syncope. Lumbar puncture would give relief, but unfortunately the pressure is usually above the tentorium, and in this region it is scarcely at all affected by lumbar puncture. Nevertheless, it is always worth a trial.

After less severe injuries to the head, such as concussion, the blood-pressure is usually subnormal. This is presumably due to the inability of the vasomotor centre, which shares in the injury, to recover its full control of the arteries in the systemic circulation. Regular observation of the blood-pressure in these cases is a valuable clinical guide to treatment. Absolute quiet in bed and a milk diet should be insisted on till the blood-pressure is restored to the patient's normal, and if any liberty granted is followed by a fall in the pressure, it will be necessary to proceed more slowly. By observations on these lines we may hope to avoid the headaches and nervous prostration which so often follow head injuries.

\section{THE PULMONARY CIRCULATION. HEMOSTATICS.}

The circulation through the lungs also calls for special treatment, because here again the vessels do not respond to the impulses which elsewhere cause vasoconstriction. It has been exhaustively argued whether the lungs have any vasomotor nerves, and the answer seems to be in the negative (though nerve fibres certainly run on the vessels). Adrenalin is powerless to constrict the arteries of the lung and 
brain in consequence of the absence of efficient vasoconstrictors. Therefore the amount of blood in the pulmonary area is bound to vary inversely with that in the systemic area. Any drug which causes vasoconstriction of the systemic blood-vessels will engorge those of the lungs." We may find here the explanation of the uselessness, nay, the positive mischief of ergot and adrenalin in hæmoptysis, whether from injury or tubercle. On the other hand, there is an important field of usefulness for such drugs as the nitrites, the value of which is becoming increasingly recognized.

Hæmorrhage in the abdominal area, on the other hand, is more likely to be checked by vasoconstrictors such as adrenalin and ergot, though there is always a danger that the raised blood-pressure induced by them may excite fresh bleeding.

\section{REFERENCES.}

L. Hill._- "Further Advances in Physiology," Arnold \& Co., I 909, pp. 72, II 2 .

CRILE.--" Surgical Shock," N.Y., I897; Annals of Surgery, vol. Xxxv., I902, p. 44I.

Mummery.-Lancet, I905, (i), pp. 696, 776, 846.

WALTON.-Ibid., I908 (ii), pp. I 7, 85 . 


\section{CHAPTER $V$. \\ THE HÆMORRHAGIC DIATHESIS.}

The physiology of the coagulation of the blood.-Hæmophilia. - Pathology of hæmophilia. - Treatment of hæmophilia. - The therapeutics of calcium salts.

W $J^{\mathrm{E}}$ are still far from a clear conception of the exact pathology of hæmophilia, purpura, and the hæmorrhagic tendency in jaundice, but it will be only by a sound understanding of the normal processes of coagulation of the blood that we shall be able to comprehend the abnormal.

The phenomena of blood-clotting are beautifully designed to avoid two opposing evils ; if no provision was made for fibrin formation every injury would be fatal; but on the other hand, if all the essentials for the process were already present in the plasma, the - circulation would immediately be brought to a standstill by intravascular thrombosis. Therefore coagulation is made to be dependent on contact with damaged cells, either tissue-cells or leucocytes, and in particular with the nucleoprotein constituting their nuclei, while the intact lining endothelium of the blood-vessels has the power of preventing clotting. We have all been told that a length of jugular vein containing blood may be tied at each end and hung up for a week, and no clotting occurs until damaged tissue-cells are added. Thus we find that the very 
incision or laceration which excites the hæmorrhage provides also the wherewithal to stop it. The nucleoprotein furnished in this way by the tissues is called thrombokinase.

Next, we know that calcium salts are needful for clotting, and if they are precipitated by oxalates or citrates, no fibrin will be formed. An excess of calcium salts, however, delays clotting.

Concerning thrombogen or prothrombin we cannot speak so confidently. It is intimately associated with, and hard to separate from, fibrinogen, but is probably derived eventually from the leucocytes and platelets. Hydrocele fluid, which does not contain any corpuscles, will not clot until blood or fibrin is added.

The actual mother substance of the fibrin is of course the fibrinogen, a protein in the plasma. There is really a double reaction, thus :-

(i) Prothrombin + Thrombokinase + Calcium salts (=thrombogen) (from damaged (in plasma)

(? from leucocytes) leucocytes or tissue-cells)

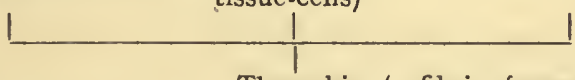

Thrombin (=fibrin ferment)

(ii) Thrombin + Fibrinogen (in plasma)

Fibrin

According to Mellanby, the name fibrin ferment is a misnomer, as a particular weight of thrombin will liberate only a certain definite quantity of fibrin from fibrinogen, whereas a ferment knows no limits to its activities. 
We have yet one more provision to refer to. The cells lining, the blood-vessels, and the leucocytes themselves, are not immortal. When they die, thrombokinase is shed out, and so thrombin would be formed and induce local clotting. This does actually occur in phlebitis and other forms of venous or arterial thrombosis. In the physiological state, however, the liver secretes in the blood an antithrombin sufficient in amount to deal with small formations of thrombin, but not sufficient to interfere with the natural process of arrest of hæmorrhage.

Considerable variations take place in the readiness with which the blood coagulates, and it is often easier to understand why than how this is brought about. For instance, at the end of pregnancy clotting is rapid ; in the diseases mentioned above it is deficient or slow. After a hæmorrhage, the fibrinoplastic (clot-forming) power rises quickly. Information may be obtained by means of the coagulimeter, a standard capillary tube into which the blood is sucked up so that the time which it takes solidifying may be measured. It requires some care in practice to avoid variations in the calibre, variations in temperature, the inclusion of lymph or clots, etc.

Associated with deficient coagulability there is often a tendency to effusions of plasma through the capillary walls on account of the low viscosity of the blood. The symptoms of such a tendency to effusion are liability to chilblains, headaches, nettlerash or patchy œdema, and transient or functional albuminaria. 


\section{HEEMOPHILIA.}

Of all the many conditions in which the hæmorrhagic diathesis is present, hæmophilia is at once the most interesting, the best understood, and the most tragically dangerous. We will not stay to speak of the curious problems of its inheritance, nor of the well-known tendency to bruising, joint effusions, and bleeding after the most trivial injuries. One or two of its peculiarities, however, deserve a word of mention, as they may throw a light on the production of the hæmorrhagic tendency. For instance, the locality and the nature of the injury have some significance. In a few cases, wounds below the neck may not bleed to excess, whereas abrasions of the most trifling description affecting the lips, cheeks, or gums may baffle all attempts to stanch the flow. Again, needle pricks, if small, do not bleed, probably because the elastic skin seals over the opening; it is even safe to withdraw blood from a vein. Further, it is not true that the hæmorrhage never stops. It may cease with or without treatment, sometimes permanently, sometimes only to come on again later. If a subcutaneous hæmatoma develops, the wall is lined by well-formed clot, but the central portion contains blood which shows no tendency to coagulation in spite of the contact with clot. It is the capillaries, rather than the arteries, which continue to ooze.

It will be a matter of opinion whether under the generic name of hæmophilia we should include cases that arise every now and then, in either sex, of a congenital and persistent tendency to bruise and 
bleed from every slight abrasion, apart from any family history of a similar kind. There is no doubt that the symptoms and course of some of these cases are identical with ordinary hæmophilia, ${ }^{*}$ and they are nearly as common. Bulloch states that the characteristic joint affections never occur except in the hereditary class.

\section{PATHOLOGY OF HÆMOPHILIA.}

Up to a certain point modern observers are agreed as to the cause of hæmophilia. Ever since Sir Almroth Wright, nearly twenty years ago, showed that the coagulation time in these patients is very greatly delayed, all students of the disease who have carefully fulfilled the proper conditions have been able to establish his discovery. Normal blood in a Wright's coagulimeter tube clots in five to ten minutes; hæmophiliac blood may take anything from fifteen to ninety minutes to solidify, although the eventual yield of fibrin is copious and firm. Addis has shown that the coagulation time is exactly related to the severity of the tendency to bleed, the mildest cases yielding the shortest times, and the severe cases the longest. It is true that a few who have used the blood shed out during an actual hæmorrhage have found no delay in the coagulation time, but apart from other fallacies, such as the danger of including fibrin ferment, the mere fact of the continued bleeding makes the blood clot more rapidly both in bleeders and in ordinary people, as Wright and Addis have shown.

* See instances given by Squire, Brit. Med. Jour., rgro, i., p. II68; and Osler, Lancet, rgro, i., p. 1226. 


\section{THE HAMORRHAGIC DIATHESIS}

Another abnormality in the blood is a frequent deficiency in polymorphonuclear leucocytes.

We may take it that the rival theory, that of the undue fragility of the vessel walls, is now definitely abandoned. Morawitz and Lossen have both shown that the œdema obtained by dry-cupping is no greater in hæmophiliacs than it is in normal individuals.

So far, then, there is substantial agreement. When we seek to go further, and to inquire just which we are to blame of the various elements that take part in regulating the coagulation of the blood, the problem becomes complicated.

Theoretically, the delay might be due to:(I) Deficient quantity or quality of the fibrinogen ; (2) Deficiency or excess of calcium salts ; (3) Deficient quantity or quality of the thrombokinase; (4) Deficient quantity or quality of the prothrombin ; (5) Excess of antithrombin.

In the examination of these factors we follow the researches of Addis. The main point to determine is whether the delay is in the first or the second of the two reactions involved,- that is, in the conversion of prothrombin into thrombin, or in the conversion . of fibrinogen into fibrin. It proves that the former is at fault ; the latter is quite normal. Hæmophiliac fibrinogen is as readily clotted by normal or by hæmophiliac thrombin as is normal fibrinogen, and normal fibrinogen is easily clotted by thrombin from a bleeder. But the hæmophiliac blood must stand a long time before any prothrombin is converted into thrombin. 


\section{THE HAEMORRHAGIC DLATHESIS}

Taking up the points, then, in order:-

I. The defect is not in the fibrinogen, because it is readily clotted if isolated and treated with thrombin. Moreover, when clot does at last form during a hæmorrhage, it is as firm and abundant as in ordinary blood.

2. The defect is not in the calcium salts, because analysis shows no abnormality in quantity, and the addition of these salts to drawn hæmophiliac blood, though it may hasten the time of clotting, does not bring it to normal.

3. The defect is not in the thrombokinase. Here Sahli joins issue with Addis, because the addition of washed leucocytes to hæmophiliac blood rapidly causes it to clot. These may, however, bring in prothrombin as well as thrombokinase, and Addis shows that solutions of thrombokinase, derived by crushing up testis in saline, have far less effect on hæmophiliac than on normal blood unless very concentrated extracts are used. Again, there is just as much thrombokinase in the serum of a bleeder, squeezed out after coagulation, as in that of a normal person.

4. It is in the prothrombin that the defect lies. A very little normal plasma, or a few washed corpuscles from a normal person, restore the coagulation power forthwith.

Addis believes that he has directly proved the point by the adoption of the following method for isolating the prothrombin, and at the same time he has established that in the hæmorrhagic diathesis it is deficient not in quantity but only in character. $\mathrm{He}$ 
prepared a solution of fibrinogen from normal or hæmophiliac plasma in the ordinary way by precipitating it by passing a stream of carbon dioxide through plasma kept from clotting by citrate or oxalate. Fibrinogen so obtained, as Mellanby shows, always carries with it prothrombin, and in the presence of calcium salts and thrombokinase would liberate thrombin. Addis, however, added instead a trace of thrombin, which clotted the fibrinogen and left its prothrombin in solution. When a trace of prothrombin so obtained from a normal blood was added to hæmophiliac blood, this promptly coagulated. The criticism would of course be that there was some unused thrombin present as well, too much having been added to the fibrinogen.

Thus, the exact pathology of hæmophilia would be, in Addis's opinion, a congenital defect in the constitution of the prothrombin, whereby it yields thrombin much too slowly. Possibly the leucocytes are ultimately at fault.

The practical deduction we shall see later.

5. There is no excess of antithrombin in the plasma of the bleeder. If there were, the addition of a trace of normal blood would not cause hæmophiliac blood to clot as it does, because any thrombin in the former would be overpowered and destroyed by the antithrombin in the latter.

To sum up, the secret of hæmophilia lies in a defective quality of the prothrombin, such that it takes much longer than usual to develop into thrombin. No evidence is yet to hand to show whether the hæmorrhagic tendencies in scurvy, 
purpura, pernicious anæmia, and occasionally in jaundice have the same explanation.

It is important to bear in mind the fact that certain cases of jaundice may ooze to death by capillary hæmorrhage after operation; most of us can recollect instances of this calamity. It has been recommended to give drachm doses of calcium chloride for three days before the operation, but probably a more useful proceeding would be to take the coagulation time by means of a Wright's tube, and to refuse to operate on any cases showing serious delay.

\section{TREATMENT OF}

THE HÆMORRHAGIC DIATHESIS.

It will be gathered that unfortunately the underlying causes of hæmophilia do not lend themselves to direct remedy. We cannot, except by one drastic proceeding, influence the quality or quantity of the more complicated and specialized fibrinoplastic elements in the blood, and we can use only those means which in a general way are understood to increase the coagulability.

Sometimes the ordinary surgical means such as rest, pressure, plugging, or adrenalin may be successful. It is usually advised not to stitch wounds, for fear of bleeding from the punctures, but if these are made with a small, perhaps a round-bodied needle, the elasticity of the skin will prevent oozing. Therefore if tight stitching would obviously bring useful pressure to bear, it should be resorted to, but only in the skin, not in mucous membranes. 
It has been advised, and the advice is physiologically sound, to apply normal human blood to the oozing point. Unhappily, even if a mass of clot is formed over the wound, it soon gets pushed away by the collection of unclotted blood beneath it. For the normal arrest of hæmorrhage it is necessary either that clotting should take place inside the bleeding vessel or that it should fill the wound so tightly about this vessel as to present a complete block to the flow. It is often impossible to get the remedy near enough to the actual rent in the artery or capillary to bring this about, and the shape of the wound may not lend itself to filling up tightly with firm clot. Nevertheless, the method is simple and painless, and has sometimes succeeded.

Styptics such as ferric chloride, tannin, or alum may be applied to the wound, but they are painful and lead to much sloughing, so it is well first to give a brief trial to fresh normal blood applied by wool pledgets, and to Wright's physiological styptic (thrombokinase), composed of one part of minced thymus in ten parts of normal saline. This produces a firm clot, but does not act as quickly as the escharotic styptics.

Internally, Wright gives calcium salts, preferably the lactate, but admittedly this is a bow drawn at a venture, because the calcium is often absorbed very badly, and may already be at the optimum in the blood. The first difficulty may be obviated in some patients by using magnesium lactate or carbonate. The doses of any of these drugs should be 60 grains for adults, and 15 grains for children, at once, followed 
by ro-grain doses three times a day for three days for adults, with a corresponding reduction for children. Calcium salts reverse their effect after three days.

To the same authority we are indebted for the suggestion that we should administer carbon dioxide gas, either from a Kipp's apparatus containing marble and hydrochloric acid, or from a cylinder of the gas. Venous blood is much more coagulable than arterial. Dyspnœa should be avoided.

Weil recommends the injection of horse-serum, conveniently obtained as diphtheria antitoxin. It probably increases the rate of blood-clotting, but apparently not until many hours have passed, and consequently it often fails in practice.

There remains one last resort in the most desperate cases, and no patient should be allowed to die of hæmophilia without its being attempted. We have seen that there is only one way to restore prompt coagulability to hæmophiliac blood, and that is to supply normal blood.

Goodman has published a well-written, almost dramatic description of his treatment of a Jewish boy, aged two and a half, a well-known bleeder and member of a bleeder family, who was moribund from hæmorrhage from a cut inside the cheek, which had oozed incessantly for two days. Pressure, adrenalin, styptics, calcium salts, and horse-serum (antitoxin) had all been tried in vain, and finally the child lay motionless and pallid, scarcely breathing, with hæmoglobin down to I2 per cent, and hæmorrhage continuing.

Goodman decided to inject normal human blood. 
A donor, not a relative, was tested by Wassermann's test for syphilis, and declared free. Under novocain anæsthesia his radial artery was connected by an Elsberg cannula with the child's femoral vein. There were some initial difficulties in getting a good flow, and hot cloths had to be applied; finally the basilic vein was substituted for the femoral, on account of differences in the level of these patients. Transfusion was continued for twenty-eight minutes. During this time colour gradually mounted up in the cheeks of the little sufferer, the breathing became audible once more, the almost watery blood acquired its normal hue, and the hæmoglobin rose to 70 per cent. Most significant of all, the bleeding was completely and permanently arrested, and there was no hæmorrhage from the incisions. Both made an excellent recovery. The donor required to rest in bed for a few days.

The above-described case by no means stands alone; excellent results have been obtained in septicæmia and in coal-gas poisoning as well as in hæmophilia. It will not do to use animal's blood, because bloods of different species are mutually destructive.

The connection between the two patients may be made by dissecting out a short length of artery and vein respectively under local anæsthesia, and uniting them either by a short oiled glass tube or by Carrel's immediate suture. Of course great care must be taken not to inject clots or air, and the technical difficulties may be considerable.

When a healthy adult supplies blood to an infant, 
the donor suffers no ill-effects, except that rest for a few days is desirable. In many cases, however, especially if older children or adults are to be transfused, it would be well to provide two donors, either simultaneously or successively. But probably it is not necessary to transfuse large quantities. We have seen that quite a trifling addition of normal blood will make it possible for hæmophiliac blood to clot promptly, and there is no need in most cases to do more than stanch the bleeding. Rest, fresh air, plenty of fluids, and iron, will speed the convalescence.

\section{THE THERAPEUTICS OF CALCIUM SALTS.}

So much interest has lately attached to this subject that brief mention only will be called for of the uses to which calcium salts have been put. It has long been recognized by physiologists that they are essential to the continued success of perfusion fluids, and now we know that they control the coagulation and viscosity of the blood, and probably the functions of the ovary and parathyroid glands also.

Remarkable results have been obtained in many cases by giving calcium lactate in I5-grain doses three times a day, for three days only, in the following conditions.

Transient or functional albuminuria.

"Lymphatic" headache frequently recurring in anæmic young women.

Some urticarial eruptions.

Chilblains. In this common complaint it may work like a charm.

All varieties of tetany. 


\section{THE HAMORRHAGIC DIATHESIS}

The symptoms of the menopause are sometimes greatly relieved by calcium lactate.

In all the above, however, there is one constantly recurring source of fallacy. The power to absorb calcium from the bowel varies much in different people, and some observers record negative results after giving the drug. Magnesium salts will sometimes be more effectual if calcium fails to get into the blood.

\section{REFERENCES.}

Mellanby.-Jour. of Physiology, 1909, p. 28.

Sir ALMroth Wright.-Allbutt's System of Medicine, Igog, vol. v., p. 918.

ADDIS.-Quart. Jour. of Medicine, Oct., 1910, p. I4; British Medical Jour., 1910 (ii.), p. 1422.

Goodman.-Annals of Surg., Oct., I910, p. 457. 


\section{THE PHYSIOLOGY OF URIC ACID AND OTHER URINARY DEPOSITS.}

Uric Acid: Derivation from food-stuffs; Derivation from the tissues; The purin bodies; Gout-Calcium oxalate-Cystin -General laws of calculus formation.

THE substances which may form a crystalline

1 deposit in the urine are many, but we shall here refer only to three, namely, uric acid and the urates, oxalate of calcium, and cystin. We shall first consider what light has been thrown upon the origin of these substances in the animal body, and then inquire what are the factors that lead to their precipitation and aggregation in the form of calculi.

\section{URIC ACID AND THE URATES.}

For many years totally erroneous views were held by physiologists with regard to the origin of these substances. It has been customary to argue the physiology of the mammal from that of the bird, with disastrous results. Removal, or rather isolation, of the liver in geese was shown by Minkowski to diminish the output of uric acid, whilst ammonium salts and lactic acid were increased in the urine. Hence it was concluded that uric acid was formed in the liver from ammonium salts and lactic acid; and for birds and reptiles this is true. In mammals, the metabolism is totally different. The end product 


\section{THE PHYSIOLOGY OF URIC ACID 83}

of protein metabolism in birds and snakes is uric acid; in mammals it is urea. It by no means follows, therefore, that uric acid is formed in the mammalian liver. We may say at once that urea is formed in the mammalian liver.

We now believe that uric acid in mammals is derived partly from certain substances in the food, and partly from the breaking down of cell nuclei, which takes place in most organs in the body, notably in the spleen. From these organs it is carried to the kidney, and excreted thereby. As we shall see, however, there is a curious complicating factor, in that any uric acid which chances to reach the liver instead of the kidney is changed into urea. The liver, like all other glands, furnishes a little uric acid to the blood, but it probably destroys more than it supplies.

The researches of Fischer and his pupils have demonstrated that uric acid belongs to a group of bodies containing a hypothetical nucleus, the purin ring. Other members of the group are xanthin and hypoxanthin, which occur in muscle and meat extracts; caffeine, which occurs in coffee; and theobromine, in cocoa. Many food-stuffs contain small quantities of these bodies ; amongst vegetables, peas, beans, lentils, and asparagus may be mentioned as yielding them; there is also a small quantity in beer. Milk, eggs, and most vegetables contain practically no purin bodies.

The nuclei of all cells in the animal body contain a special form of protein called nucleoprotein, in which the protein is combined with nucleic acid. On ultimate analysis this substance yields, amongst 


\section{THE PHYSIOLOGY OF URIC ACID}

other products, certain purin bodies, called guanin and adenin.

The uric acid and other purin bodies in the urine (xanthin, etc.) are derived from two sources, referred to as exogenous and endogenous. By exogenous origin we mean that substances capable of yielding purin bodies taken as food are broken down by the digestive juices, the purin bodies are then liberated and absorbed by the blood, carried, with or without alteration, to the kidneys, and by them excreted in the urine. These have never been built up into the protoplasm of the living cells of the body. By endogenous origin we mean that purin bodies are end products of the breaking down of certain of the constituents of the living protoplasm of the individual. In other words, the purin bodies of the urine may be derived from the food, or from the living tissues of the body. The normal man on an ordinary diet excretes exogenous and endogenous purin in about equal quantities.

Variations in the amount of uric acid excreted may be affected, then, by variations in the food, or by variations in the breaking down of the tissues.

Considering first the effect of diet, it is found that on a purin-free diet the uric acid and the purin bodies in the urine drop to about half the ordinary amount. Feeding on meat, broths, coffee, etc., increases the excretion of the uric acid and other purin bodies, and the same effect may be obtained by feeding with hypoxanthin itself. Again, any tissue rich in nucleoprotein, that is to say rich in cell-nuclei, will, if given by the mouth, increase the output of uric acid and 


\section{AND OTHER URINARY DEPOSITS}

purin bodies. Calf's thymus, the roe of fishes, liver, and pancreas (sweetbread), all have this effect. To sum up, uric acid and other purin bodies are derived from feeding on :-

I. Purin bodies in meat, broths, coffee, etc.

2. Nucleoproteins.

Strange to say, feeding on uric acid itself causes no increased output in the urine; instead, there is a greater excretion of urea. If urates are injected into the blood-stream, uric acid and urea are both increased in the urine, only part of the uric acid injected being recovered as such. Evidently then some organ is capable of converting uric acid into urea. This organ is the liver, and a uricolytic ferment, destroying uric acid, may be obtained from it.

The whole of the purin body given by the mouth does not appear as purin body in the urine. A good deal appears as urea. There is a fraction, constant for the species, representing to what extent this takes place. In man, half the purin body absorbed is destroyed by the liver. In the dog, nineteentwentieths are destroyed. The difference appears to depend on the differences in relative size of the blood-vessels of the liver and kidney in the various species, those of the dog's liver being very large.

It has yet to be explained how it is that adenin and guanin-derived from nucleoprotein-and xanthin and hypoxanthin-derived from muscle-come to be excreted partly as urea, partly as uric acid, and partly as less oxidized purin bodies.

It is now known that many organs of the body, notably the spleen, contain a remarkable series of 


\section{THE PHYSIOLOGY OF URIC ACID}

ferments acting upon these substances. Thus there have been obtained :-

Nuclease, splitting nucleoprotein, and liberating guanin and adenin.

Guanase, converting guanin $\left(\mathrm{C}_{5} \mathrm{H}_{3} \mathrm{~N}_{4} \mathrm{O} \cdot \mathrm{NH}_{2}\right)$ into xanthin $\left(\mathrm{C}_{5} \mathrm{H}_{4} \mathrm{~N}_{4} \mathrm{O}_{2}\right)$.

Adenase, converting adenin $\left(\mathrm{C}_{5} \mathrm{H}_{3} \mathrm{~N}_{4} \cdot \mathrm{NH}_{2}\right)$ into hypoxanthin $\left(\mathrm{C}_{5} \mathrm{H}_{4} \mathrm{~N}_{4} \mathrm{O}\right)$.

Oxidase, converting xanthin $\left(\mathrm{C}_{5} \mathrm{H}_{4} \mathrm{~N}_{4} \mathrm{O}_{2}\right)$ and hypoxanthin $\left(\mathrm{C}_{5} \mathrm{H}_{4} \mathrm{~N}_{4} \mathrm{O}\right)$ into uric acid $\left(\mathrm{C}_{5} \mathrm{H}_{4} \mathrm{~N}_{4} \mathrm{O}_{3}\right)$.

If spleen pulp, which is rich in nuclei, is left to digest itself at a suitable temperature, xanthin and uric acid are formed in situ.

The purin bodies, then, split off from protoplasm in the body or derived from food containing purin bodies or nucleoprotein, are acted on in the spleen and in all other organs by these ferments, and eventually uric acid would be produced. This is excreted by the kidney as rapidly as it is formed, so that it is not possible to isolate it from normal blood.

Side by side with this, the liver is exercising its destructive function on so much of the uric acid as may be brought to it. The products of its action are urea, and probably glycin (amino-acetic acid). If the liver is largely shut out of the circulation by means of Eck's fistula (putting the portal vein into the inferior vena cava), uric acid appears in the blood even on a purin-free diet, because now so much of it escapes the activity of the liver cells. The same effect is observed if the aorta is tied above the cœliac axis, both the liver and the kidney being shut off by this operation. 


\section{AND OTHER URINARY DEPOSITS}

A little remains to be said with regard to the endogenous origin of purin bodies. They are derived from two main sources, the xanthin of the muscles and the nucleoprotein of all cell nuclei. Much of the purin bodies split off from these is oxidised into uric acid by the above-mentioned ferments, but only that which chances to be carried to the kidney before it reaches the liver appears in the urine as uric acid or urates. That which finds its way to the liver appears in the urine principally as urea.

The excretion of purin bodies on a purin-free diet is of course entirely endogenous, and the daily output is a constant for the individual, depending roughly on the weight of his muscles. It is, however, increased greatly by muscular exercise. Whilst the hard work is proceeding the uric acid output falls a little, while the xanthin output rises correspondingly; the muscles take up so much oxygen that there is none to spare to oxidize xanthin. After the work is over, the uric acid rises. Unaccustomed work is much more effectual than routine work. There is also a considerable rise in any conditions where cell nuclei are rapidly broken down. As is well known, there is an increase of both uric acid and purin bodies in the urine in fever, and especially in leukæmia. In gout, less uric acid than usual is passed.

It appears that purin bodies are not utilized by the body in the synthesis of nucleoprotein in the protoplasm. It seems to be formed from proteins.

Indeed, it is very doubtful if purin bodies serve any useful purpose. It is certain that they are powerful stimulants in some cases; caffeine is of course 


\section{THE PHYSIOLOGY OF URIC ACID}

one of the most powerful and satisfactory stimulants known, producing a really increased capacity for mental and physical work. Every one knows how a cup of strong tea, coffee, or beef-tea will refresh the weary and give new energy to the student. We know that squads of soldiers doing forced marches are greatly helped by caffeine. It has been repeatedly proved in every army that the cold-tea brigade comes in first, the water men second, and the alcohol squad a bad third. But we must set against this the certainty that purin bodies produce earlier degeneration of the arteries, and occasionally they are responsible for very severe types of migraine.

A few words should be said here on the subject of gout. The immense controversies which have raged about this interesting disease are gradually giving place to some settled conclusions. The essential point is that the kidneys are not sufficiently permeable to uric acid, or rather, to the urates. In many cases, but not all, they are obviously diseased, some form of chronic interstitial nephritis being the commonest abnormality. The daily, output of uric acid is therefore found to be subnormal, whereas the blood contains too much. Whenever any unusual amount of purin bodies has to be disposed of, whether after a meal too rich in meat, broths, or the vegetables previously named, after some unusual exercise, or an attack of fever, or when katabolic changes in the body have been stimulated by alcohol, an acute attack of gout results. The output of uric acid in the urine rises, the high blood content forcing its way as it were through the resistance of the 


\section{AND OTHER URINARY DEPOSITS}

kidneys. Even so, the percentage in the blood remains too high, and crystals of sodium biurate are deposited in the cartilages. In joints, this is usually a painful process.

There is evidence, however, that the impermeable kidneys are not the whole secret of gout. Apparently the tissues, and particularly the joints, are more vulnerable to uric acid in this disease than they should be. In leukæmia, in consequence of the formation and death of the many leucocytes, there is probably more uric acid in the blood than ever exists in gout, yet no joint symptoms are produced. As Walker Hall has stated, "Few will doubt that gouty individuals possess some inborn defect or alteration of nuclein metabolism which lowers the resistance of the tissues in certain directions, and so permits a response to irritants which is scarcely appreciated by those whose metabolism does not exhibit this peculiarity."

We are now in a position to draw some practical and clinical deductions from the work of the physiologists. An explanation is furnished of the appearance of the uric acid or urates deposit in the urine so common in functional or organic affections of the liver; this organ is evidently less active than usual in destroying uric acid. We may draw the following conclusions with regard to the prevention of calculus or gravel in those threatened with these complaints. Meat and broths should be restricted, also tea, coffee, and cocoa; muscular exercise must be mild, and warning given that fever is dangerous. Of course if uric acid crystals tend to form, plenty of fluid must be taken, and alkaline citrates, acetates, or tartrates 


\section{THE PHYSIOLOGY OF URIC ACID}

given. Salts of lithium used to be preferred, since lithium urate is the most soluble of the urates, but potassium is cheaper and better. The uric acid shower of crystals may often be prevented by Gee's treatment, consisting of a large cupful of whey three times a day.

A simple apparatus for determining the amount of total purin in the urine has been invented by Walker Hall. It is readily used for clinical work. The principle adopted is to precipitate the phosphates with magnesia mixture, then add ammoniacal silver nitrate, leave standing for twenty-four hours, and read the amount of the silver purin precipitate. With regard to the treatment of gout, it becomes evident at once that as it is impossible to repair the damaged kidneys, all that can be done is to keep the purins as low as possible by dieting, and by avoiding the various causes of increase of those purin bodies which are formed in the body. We continue to give colchicum, but without any adequate physiological explanation of its undoubted powers over the disease. Abundance of fluid will help to carry the urates through the kidneys, and potassium salts will furnish the most soluble base with which to combine them.

\section{Calcium oxalate.}

It has been found very difficult to obtain reliable estimates of oxalates in the urine. The method commonly employed, introduced by Dunlop, is open to serious objections from the chemical standpoint. Working with O. C. M. Davis, the writer has used a 


\section{AND OTHER URINARY DEPOSITS 91}

new and, theoretically, more reliable method, but it is not claimed that the results are more than approximate. There is still, therefore, some difference of opinion as to the metabolism of the oxalates, but the following conclusions are becoming generally accepted.

In ordinary circumstances, the whole of the oxalate in the urine is derived from articles of food. Milk, meat, and bread contain scarcely any oxalate; most vegetables contain it, and rhubarb, strawberries, and sorrel contain a relatively large quantity. I have by taking much rhubarb induced an attack of oxaluria sufficiently marked to cause a good deal of smarting pain in the urethra from the sharpness of the oxalate crystals. On a milk diet, oxalates disappear from the urine. This may be demonstrated by adding methylated spirit and allowing to stand, when any oxalate present in solution is precipitated in characteristic octahedra. On a milk diet, no such crystals will be obtained.

None of the ordinary derangements of metabolism cause the appearance of oxalates in the urine if they are withheld from the food. Thus there is no oxaluria in fever, in leukæmia (illustrating the katabolism of nucleoproteins), or in diabetes. In a case of oxalic acid poisoning under my care, the excretion was enormous, and there was a heavy deposit of calcium oxalate crystals.

It is not, however, correct to say that oxaluria never occurs on an oxalate-free diet, though such a condition is rare. As is well known, the usual products of bacterial fermentation of carbohydrates 


\section{THE PHYSIOLOGY OF URIC ACID}

in the bowel are various gases $\left(\mathrm{CH}_{4}, \mathrm{CO}_{2}\right)$, lactic, acetic, and butyric acids, and alcohol. Miss Helen Baldwin has pointed out that in certain abnormal circumstances oxalic acid also may be formed in this way. Copious feeding on sugar will ruin a dog's digestion, and then oxalates may appear in the urine even on an oxalate-free diet. Occasionally she has met with such cases in man. I have not chanced to observe such a case personally, and believe that they are not common.

Fermentation of carbohydrates in the stomach and intestines to an excessive degree is common enough, but it is only rarely that there is any formation of oxalates. I have never been able to obtain the crystals, either from the gastric contents or from the urine, of patients with obstruction of the pylorus and gastric dilatation, on an oxalate-free diet.

When ammoniacal fermentation of urine takes place, as on standing, any oxalate crystals present are rapidly dissolved and disappear.

The oxalate calculus is by far the most important variety occurring in the kidney. B. Moore has shown that a pure uric acid stone is found only in the bladder, and that all renal calculi are composed for the most part of calcium oxalate. This is fortunate for the $x$-ray diagnosis of the condition, and as it is comparatively easy to control the oxalate excretion, it makes it possible for us to advise the patient how to avoid a relapse after operation. To draw the practical lessons from our study, it is evident that any patient suffering from oxaluria should abjure the use of green vegetables, and fruits should be 


\section{AND OTHER URINARY DEPOSITS 93}

taken sparingly. If he is obeying directions, a fresh specimen of his urine, mixed with an equal amount of spirit and allowed to stand, will deposit only a few small crystals of oxalate, and a specimen without the addition of spirit will show no crystals even on centrifugalizing. Occasionally, however, one may find a case in which oxaluria persists even on a milk diet. We must then restrict the sugars and starches of the diet, and give remedies calculated to diminish fermentation in the stomach and intestines.

If patients object to dietetic restrictions, potassium citrate will often relieve, both by acting as a diuretic, and by making the urine alkaline, thus dissolving the crystals.

\section{CYSTIN.}

Cases of cystinuria are not common. Sometimes the deposit forms a yellowish-green waxy calculus ; more often, flat hexagonal crystals are passed.

In the chapter on the digestion and absorption of proteins, it was explained that our modern conception of the molecule is that of a long-linked chain of aminoacids, grouped as monoamines, diamines, and aromatic amines. The diamines ordinarily met with in a protein digest are called arginin, lysin, histidin, and ornithin. Of this group, cystin is a member, though it is not ordinarily present amongst the products of protein dissolution. Its formula is diamino- $\beta$-thiopropionic acid; it therefore contains the sulphur of the protein molecule. It has been obtained from hair by chemical disintegration.

It is suggested that in cases of cystinuria a physiological ferment is lacking which should convert the 


\section{THE PHYSIOLOGY OF URIC ACID}

cystin into some simpler product. In a few of the patients, other abnormal diamines, such as cadaverin, have also been found in the urine; in some cases no abnormal amines except the cystin have been detected. In a number of cases leucin and tyrosin were being excreted as well.

Variations in the diet influence but little the output of cystin in a cystinuric. Feeding on arginin (a diamine) or tyrosin (an aromatic amine) makes no difference. Feeding on cystin itself merely increases the output of sulphates.

Cystin is soluble in ammonia.

It will be observed that we cannot exercise any useful control over the output of this deposit.

GENERAL LAWS OF CALCULUS FORMATION.

When the chemist sets aside a fluid to crystallize out, he does not obtain a single rounded mass of concentric layers, but many hundreds of separate crystals, some large, some small, each with its characteristic symmetry. The same is generally true in the bladder, and separate crystals, of oxalate, phosphate, or uric acid, are commonly passed. Yet in certain circumstances a totally different picture is obtained, and a calculus forms, with its microcrystalline structure, its concentric layers, and its nucleus. What determines the difference?

The geologist is confronted with the same problem. Spherical concretions, whose structure is essentially similar to that of urinary calculi, are repeatedly met with in Nature. They may be composed of carbonate of lime, of silica, or of any of a score of other chemical 


\section{AND OTHER URINARY DEPOSITS}

bodies. The stalactites which depend from the roofs of our limestone caverns show an analogous structure.

The most marvellous natural illustration of concretionary action is the so-called Cotham or landscape marble, which occupies only a single geological horizon, but is widely distributed throughout the south-west of England. All the foliated layering of an oxalate calculus is reproduced in the marble, but with the addition of tall " trees " with " branches" rising to a "sky" composed of thickly stratified microcrystalline layers.

It was shown long ago by Rainey that the desideratum for calculus formation is the presence of some glutinous matter in the solvent. $\mathrm{He}$ was able to manufacture small concretions of calcium carbonate by allowing an alkali and a lime salt very gradually to interdiffuse in the presence of gum. A nucleus also is very desirable.

If the simple experiment be made of allowing urine to undergo ammoniacal fermentation in a closed flask over a layer of gelatin, the raison d'être of this is clearly seen. The urine should be replaced every other day by fresh, leaving the deposit of triple phosphates undisturbed. When the experiment is carried out without a gelatin layer, the crystals deposited are all separate. When, however, there is a gelatin layer at the bottom of the flask, extensive films form on the surface and the sides, composed of hundreds of minute crystals stuck together. Evidently a succession of such films, deposited concentrically around a nucleus in the bladder, would make up a concretion or calculus. 


\section{THE PHYSIOLOGY OF URIC ACID}

The glutinous substance in the bladder or pelvis of the kidney is presumably albumin or mucus.

It is not easy to see, however, how this knowledge will help us to prevent the formation of calculi, and it must remain for the present a matter rather of theoretical interest than of practical importance.

\section{REFERENCES.}

\section{URIC ACID AND Gout.}

L. Hill.- " Recent Advances in Physiology and Biochemistry," Arnold \& Co., London, 1906, p. 387.

Von Noorden.- "Metabolism and Practical Medicine"; edited by I. Walker Hall, Heinemann, London, I907, vol. iii., p. 647 .

\section{Oxaluria.}

A. Rendle Short.-Von Noorden's "Metabolism and Practical Medicine," vol. i., p. I48.

\section{Cystinuria.}

GARROD.-Lancet, r9o8, vol. ii., p. 214.

T. S. Hele.-Jour. of Physiol., I909, vol. xxxix., p. 52. 
CHAPTER VII.

\section{ACIDOSIS, ACETONÆMIA, AND DIABETES.}

Conditions of occurrence of acetone, diacetic acid, and $\beta$-oxy butyric acid.-Origin from fats.- -Sugar starvation the cause of acidosis.-Acid poisoning. - The diagnosis of starvation. - The essential nature of diabetes. - The treatment of non-diabetic acidosis.-The prevention of post-operative coma in diabetics.

TEXTBOOKS of medicine published fifteen or 1 twenty years ago introduced us to the fact that in diabetic coma, that tragic termination to so many promising young lives, the urine is loaded with three substances whose relations were not well understood-namely, acetone, diacetic acid, and $\beta$-oxybutyric acid. A constant study of the behaviour of these bodies by many observers has led to some settled conclusions of considerable interest and value.

It has been shown that they are not peculiar to diabetic coma, although in no other disease are they excreted in such quantity. They appear in the urine in the following conditions also:-

(a). Starvation.

(b). Periodic (cyclical) vomiting of children.

(c). Delayed chloroform poisoning.

(d). Salicylate poisoning.

(e). Severe vomiting of pregnancy.

Starvation may be voluntary, or due to such affections as gastric ulcer, fevers, acute abdominal 
catastrophes, prolonged vomiting, or diarrhœa. The amount of acetone and other bodies is large only if the starvation is prolonged.

Cyclical vomiting is a curious and not uncommon condition, usually seen in young children, who for a few hours or days at intervals get bouts of vomiting, which are accompanied by the excretion of acetone and these acids. The attacks usually pass off harmlessly.

Delayed chloroform poisoning is considered at some length in Chapter VIII.

It is known that an unusual sequence of overdosing with salicylates is drowsiness with vomiting, some collapse, and particularly hissing dyspnœa or airhunger. Here again the above substances are excreted in the urine.

The presence of acetone, indeed, is perfectly physiological. On an ordinary diet we excrete about 0.01 to 0.03 grammes of acetone daily in the urine and rather more in the breath, but these amounts are too small to be recognized by clinical methods. During starvation the excretion by the seventh day may be forty times as much (F. Müller). Diacetic and oxybutyric acids are not normally present in the urine.

\section{ORIGIN OF ACETONE, DIACETIC ACID, AND $\beta$-OXYBUTYRIC ACID.}

It was at first supposed that these were all derived from glucose, because of their appearance in diabetes ; at a later time they were accredited to the proteins; but it is now definitely established that they are the 


\section{AND DIABETES}

result of a peculiar abnormal process of breaking down of the fats.

The physiological process of dealing with fat is to resolve it into carbon dioxide and water. If we make a pound of fat into tallow candles and burn it, we shall obtain carbon dioxide and water, and a certain amount of heat will be evolved. If the pound of fat is eaten and absorbed by a man or an animal, it will be burnt to the same end-products, and the same amount of heat will be given out. But in certain circumstances, an abnormal mode of breaking down is followed, and there are produced first $\beta$-oxybutyric acid, then diacetic acid, and finally acetone. If this takes place on a large scale, the conversion into acetone fails to keep pace with the production of the acids. Therefore first acetone appears in the urine, then diacetic acid, and finally $\beta$-oxybutyric acid; the last may rise rapidly to an enormous figure ; 30 , 50 , or even I8o grammes may be passed daily in diabetic coma (Magnus Levy).

Feeding on fats will always cause some rise in the output of acetone and of these acids if they are already present; in starvation it will cause a very marked increase. Butter, which contains lower fatty acids (butyric, etc.), as well as fats, is particularly active in this respect.

It is of no great importance to us to know where in the body this process of breaking down takes place; the liver is usually supposed to have the power to effect it.

-We next ask, What are the special circumstances in which the breaking down of fat deviates from 
its normal course, and follows this dangerous route? The answer is clear and decisive. When the tissues are unable to obtain sugar from the blood, fat is broken doren via these abnormal acids to acetone, instead of to carbon dioxide and water.

This remarkable proposition has been abundantly proved, and along several independent lines of research. Thus in one case, an experimenter (Satta) ate nothing for two days but milk sugar, and excreted the normal amount of 0.01 gramme of acetone daily. Then he took a diet of $300 \mathrm{grm}$. each of meat and fat, which is of course quite an adequate amount to sustain health, and the excretion rose to 0.8 gramme and I. I gramme on the two days of experiment. Thus :

Day 1. Diet only lactose. Excreted $0.01 \mathrm{grm}$. acetone.

Day 2. ". ." ." ". 0.01 . ."

Day 3. " meat and fat. " " 0.80 ". ",

Day 4. ." ." . $\quad$ " 110 ."

As we shall see, if the tissues can be supplied with glucose, pathological acetonæmia and acidosis are rapidly cured.

It now becomes evident why acetone and the acids are formed in the conditions above referred to. In starvation the tissues cannot obtain glucose because there is none in the blood. In cyclical vomiting of children, and in delayed chloroform poisoning, the conditions are a little more complex. Mild acetonæmia is set up in the first place either by abstinence from carbohydrate food for a longer time than usual or by some toxic agent preventing the tissues from obtaining the requisite sugar for the blood by paralysing in some way their activity; in many 
cases both these causes are combined, as when a patient with a perforated gastric ulcer, who has absorbed nothing for hours, is given chloroform. The vomiting induced by the acetonæmia of course prevents the retention of carbohydrate food, and so the bad becomes worse.

Salicylates presumably act by paralysing that function of the tissues which enables them to take up sugar from the blood. As we shall see, this is also the pathology of diabetes. The tissues, starved of sugar, break down the fat to acids and acetone instead of to carbon dioxide and water. In the vomiting of pregnancy it is very probable that the formation of acids and acetone is due merely to the prolonged and severe starvation necessitated by the vomiting, but as soon as they are produced in excess, they complete the mischief already wrought, and the patient, if unrelieved, may die in coma.

\section{THE MECHANISM OF POISONING IN ACIDOSIS AND ACETON ÆMIA.}

Neither acetone, diacetic acid, nor $\beta$-oxybutyric acid is poisonous, except in quite large doses. Why then do such marked and indeed fatal symptoms occur when they accumulate?

The blood is normally alkaline. All the functions of the tissues are attuned to a medium of a particular alkalinity. If this alkalinity is greatly reduced, almost to the point of neutralization, the symptoms produced experimentally are not dependent on the particular acid used. They include dyspnœa, collapse, and coma. In diabetic coma the alkalinity of the 
blood is much reduced by the increase of diacetic and especially of $\beta$-oxybutyric acids in the plasma. This condition is called " acidosis." It would perhaps be going too far to say that absolutely unlimited quantities of $\beta$-oxybutyric acid may be formed and tolerated if sufficient alkali is supplied to neutralize it ; there is a point beyond which even sodium $\beta$-oxybutyrate becomes toxic; and by keeping the urine alkaline, although we may greatly delay, we do not altogether prevent the onset of diabetic coma.

The body is able for a long time to defend itself against the increased production of diacetic and $\beta$-oxybutyric acids, by furnishing enough alkali to neutralize them more or less completely. First, the reserves of sodium and potassium are called upon, but the main defence is the production of large quantities of ammonia. In normal metabolism the proteins of the tissues split off their effete nitrogen in the form of ammonium salts (carbonate, carbamate, etc.), and these are converted into urea by the liver. When diacetic and $\beta$-oxybutyric acids are present, these unite with the ammonia, and it escapes conversion into urea; consequently there will be an increase of ammonia nitrogen in the urine (as ammonium diacetate and ammonium $\beta$-oxybutyrate). At length, however, the production of the acids becomes so excessive that the supply of ammonia from the tissues fails to keep up with them. Then the normal alkalinity of the blood falls, and dyspncea, collapse, and coma begin to appear. 


\section{AND DIABETES}

\section{DIAGNOSIS OF STARVATION.}

It may become very important to know if a patient is or is not obtaining adequate nourishment. This is particularly the case when on account of vomiting, hæmatemesis, or typhoid fever, mouth feeding has to be restricted or becomes altogether impossible. It is easy to find out. Daily estimates of the urea output will show if the protein absorbed is adequate, and tests for acetone, diacetic acid, and oxybutyric acid will show if the supply of carbohydrate has fallen too low. The normal ratio of ammonia nitrogen to urea nitrogen is about 5 per cent. If it rises to IO, I5, or 20 per cent, there is severe acidosis present due to starvation, but masked by the ammonia supplied to neutralize it. When the supply of ammonia fails, fatal coma will follow.

In the Appendix figures are given showing the application of these methods to the problem of nutrient enemata.

\section{THE ESSENTIAL NATURE OF DIABETES.}

Seeing that it is in diabetics that the most terrible consequences of acidosis are exhibited, it will be well very briefly to consider just in what way the metabolism has gone wrong in this disease.

Glycosuria may be experimentally induced in animals by the following means:-

(a). By puncture of the medulla.-This is perhaps a vasomotor effect, the increased blood-flow washing glycogen out of the liver. Or there may be some interference with secretory nerves to the liver. Stimulation of the vagus acts in the same way. 
To this class belong those clinical cases in which transient glycosuria follows head injury or cerebral compression.

(b). By very excessive feeding on sugars.-Doses of over I50 grammes of glucose or cane sugar will set up a sort of overflow glycosuria; smaller quantities of lactose or maltose (from beer) will do the same.

(c). By administration of phloridzin, which is a glucoside occurring in the bark of plum and cherry trees. This drug has the remarkable power of compelling the secretory epithelium of the kidney to break down serum-albumin so as to yield sugar; the glycosuria is not therefore associated with any increase of sugar in the blood.

It is of course conceivable that human diabetes, in some cases at least, might be of renal origin in a similar manner, and an attempt has actually been made in France to separate off a class of renal diabetics, but very few English, German, or American authorities allow the justifiability of this. Phloridzin glycosuria would be devoid of practical interest if it were not that it has recently been taken up by the surgeon for diagnostic purposes. When a patient has severe tuberculosis of, shall we say, the right kidney, but the condition of the left is doubtful, it would of course be a serious risk to remove the right kidney, and indeed a fatal result has several times been recorded. Of the methods of investigating the function of the left kidney, one of the best is to give phloridzin. If sugar fails to appear in the urine, both kidneys are seriously diseased; if it does appear, there is still an efficient amount of renal 
substance. To give precision to the test it is usually wise to catheterize both ureters, and to analyse the urines separately.

(d). Pancreatic diabetes.-Removal of the pancreas in dogs or other animals if complete induces fatal diabetes exactly corresponding to severe cases of the disease in man; a sub-total removal induces a milder type of the disease. The symptoms are improved by pancreatic grafting. If less than four-fifths of the pancreas is taken away, $n$ glycosuria follows. After complete removal, but not after removal of four-fifths, sugar will continue to appear in the urine even when all carbohydrates are excluded from the food, being derived in this case from the breaking down of food and body protein.

In ordinary human diabetics, the pancreas is found at autopsy to present some abnormality in such a large proportion of cases that the smaller group in which nothing is found amiss may safely be attributed to functional deficiency apart from organic disease. To quote an analogy, mental defect is so often associated with gross changes in the brain that we think we are justified in assuming that there must be some functional derangement of that organ, even when in cases of insanity it appears to be quite normal.

In what way may destruction of the pancreas conceivably produce diabetes?

The present-day teaching is that the pancreas supplies to the blood some internal secretion, some chemical substance, which is carried to the muscles and other tissues to enable them to make use of the sugar brought them by the blood. The tissues are 
positively in need of sugar. It is probably the main source of muscular energy. A beating mammalian heart, through which a solution of salines containing sugar is repeatedly passed, will use up that sugar. It is a principal source of heat. It is probably a necessity for nearly all the functions of the protoplasm of the tissues. The blood always contains sugar (about $0 . I$ per cent) to supply this need; the whole process of glycogen storing in the liver is designed to keep the percentage at a constant level in the blood. The internal secretion of the pancreas is the link whereby the tissues may take hold of and utilize this circulating sugar. In diabetes the internal secretion of the pancreas fails, and the link is missing. The tissues are in the position of the hungry boy outside the sweet-shop; he longs for the sweets and the supply is abundant, but he has not the means to purchase. So the sugar in the blood, lacking a market, goes on accumulating, till it reaches a figure of 0.2 or 0.3 per cent ; it runs to waste in the urine, but the tissues cannot touch it. Like a starving town through which rich convoys are passing, the plenty comes to their very doors, but cannot be utilized. Urgent messages for food are sent to the liver, to other organs, to the intestine; these are depleted of all their reserves of glycogen, and even the proteins themselves are broken down wastefully to obtain a sugar which, though obtained, can never be used. So we see the patient losing flesh, and not only sugar but also excess of urea appear in the urine, derived, of course, from the proteins.

Naturally, in most cases matters have not progressed 
quite so far; a little of the pancreatic secretion continues to be supplied, and if carefully husbanded, as by reducing the carbohydrate in the food, may suffice for the bare needs of the body. To return to the illustration, the hungry boy is not quite penniless, and if he spends his money wisely he may yet keep himself going by alternating periods of self-denial and mild indulgence.

Various authorities have tried to go further with the explanation of human diabetes, and have stated that the internal secretion is derived from the clusters of cells called islets of Langerhans, whereas the digestive juices are derived from the acini; it has further been stated that in diabetes sometimes the islets are destroyed whilst the rest of the pancreas is normal. It is very doubtful, however, whether the islets are more than gland acini exhausted by secretion (Dale).

Again, such wide currency has been given to an experiment of Cohnheim's, that it is necessary to state and refute it. He taught that muscle extract with pancreatic extract was able to break down sugar, but that neither was able to do so without the other. It has since been abundantly proved that muscle extract can break down sugar just as well by itself. Von Noorden considers that the pancreatic secretion is necessary to enable the tissues to build up sugar $\left(\mathrm{C}_{6} \mathrm{H}_{12} \mathrm{O}_{6}\right)$, into the more complex glycogen $\left(\mathrm{C}_{8} \mathrm{H}_{10} \mathrm{O}_{5}\right)_{n}$, where the $n$ may stand for a very high figure; glycogen he takes to be a necessary stage in the absorption of sugar into the molecule of protoplasm. Certain it is that both in experimental and 
human diabetes, glycogen is absent from the liver and muscles in all but mild cases.

Returning to the question of acidosis in diabetes, we are now able to understand why it is so marked and so fatal an occurrence. We saw that the cause of acidosis was the failure of the tissues to obtain sugar. Obviously severe diabetes will be a far more potent factor in leading up to this condition than even starvation. And indeed, of severe cases of diabetes, that is, cases in which complete deprivation of carbohydrate food will not abolish the glycosuria, about four-fifths die in coma. Most of us have known instances. It may have been a young man or woman, the victim of diabetes certainly, but otherwise apparently in good health, with only the fatal red fringe on touching the urine with ferric chloride to hold out any warning. There was a long walk, a feverish cold, an anæsthetic; or some physician too suddenly instituted a severe deprivation of carbohydrate food, and within a few hours coma had set in, and death was inevitable.

\section{THE TREATMENT OF NON-DIABETIC ACIDOSIS.}

It will probably be agreed that the time has now come when no examination of the urine in cases of diabetes, of abdominal catastrophes, of vomiting, or of starvation, will be complete unless we record the presence or absence of acetone and diacetic acid as well as of albumin and sugar. Unfortunately there is no simple clinical test for $\beta$-oxybutyric acid. It has been usual to estimate it by the amount of 
lævo-rotation of a ray of polarized light, from which of course must be deducted the dextro-rotation due to any glucose which may be present.

A fairly simple qualitative test is Stuart-Hart's : Take $20 \mathrm{cc}$. of urine, add $20 \mathrm{cc}$. of water and a few drops of acetic acid. Boil the mixture till the bulk is reduced to about Io cc. ; thus acetone and diacetic acid are driven off. Add water to restore the bulk to $20 \mathrm{cc}$. ; put Io cc. into each of two test-tubes $\mathrm{A}$ and B. To A add I cc. of hydrogen peroxide; just warm it, but do not boil, for one minute. Cool. Add to A and B $\frac{1}{2}$ cc. of glacial acetic acid, a few drops of fresh sodium nitroprusside, and overlay with 2 cc. of ammonium hydrate. Stand four hours. If $\beta$-oxybutyric acid was present it will have been oxidized to acetone, and a purple-red ring will form where the fluids meet in A, but not in B. The presence of sugar does not interfere with the reaction.

The presence of acetone cannot be definitely excluded without distilling the urine, but too delicate tests are usually less valuable than more approximate ones because, as in this instance, a trace may be found normally. The presence of diacetic acid is of more clinical importance.

Tests for acetone in the urine :-To $3 \mathrm{cc}$. of urine add a few drops of fresh sodium nitroprusside (a crystal in $5 \mathrm{cc}$. of water). Cover with strong ammonia. A magenta ring appears at the line of junction, and spreads upwards (Jackson-Taylor). Or, to $5 \mathrm{cc}$. of urine add $\frac{1}{2}$ cc. of 5 per cent sodium nitroprusside; make just alkaline with caustic soda, and acidify with acetic acid. A reddish-violet colour develops. 
Acetone is excreted in the breath as well as in the urine, and the sweet odour is perfectly apparent to many medical men, more so to some than others; some can smell a diabetic excreting acetone at a great distance.

Test for diacetic acid in the urine :-

To $3 \mathrm{cc}$. of urine add a few drops of liq. ferri perchlor. A deep red colour which disappears on heating is positive. The test is often performed on a white slab as a contact test. One must not be deceived by the frequent reddish precipitate of iron phosphate from a normal urine.

Turning now to the prevention and treatment of acidosis, we may clear the ground by reserving diabetic coma for a special word later on in the chapter, and delayed chloroform poisoning for consideration in Chapter VIII.

We saw that the cause of this peculiar perversion of metabolism is inability on the part of the tissues to obtain sugar, and that the fatal element in the poisoning is the swamping of the blood with acids. Therefore prevention lies in the supply of glucose, and treatment is to introduce alkalies. In practice, as might be expected, glucose alone is better than alkalies alone; probably both together would give the best results.

On account of vomiting it may not be possible to administer either by the mouth. They may be given by the rectum, or directly into a vein. If the case is urgent, the latter method would be adopted, if not, the former. Glucose should be given in either case in 6 per cent solution in warm distilled water, using 
two or three pints. Sodium carbonate may be given in doses of 4 drachms to the pint, again using two to three pints. It should be the object of the treatment to make the urine alkaline.

In milder cases, of course, it will be possible to. give remedies by the mouth. The addition of enough starch or sugar to bring the daily supply of carbohydrate up to 150 grammes ( 5 ounces) will effectually banish the pernicious acids from the urine. Alkalies are best given in the form of sodium citrate, 30 grains or more three times a day, until the urine is alkaline.

It is important to bear in mind the danger of this auto-intoxication, that is, poisoning by the products of the patient's own internal processes, in all the numerous conditions in which insufficient food may be absorbed, so that serious or fatal symptoms may be warded off. Diarrhœa, wasting, or vomiting, from whatever cause, should lead to an examination of the urine for diacetic acid, and the same is specially necessary when a patient is being fed only by the rectum.

The old-fashioned treatment of rheumatic fever, by combining alkalies with the salicylates, will prevent acidosis from the use of the latter.

The Prevention of Diabetic Coma.-In the treatment of a severe case of diabetes the physician is on the horns of a dilemma. To relieve the ordinary symptoms of diabetes, which are due to the excess of sugar, and to enable the patient to make the best possible use of what little internal secretion of the pancreas he has left, the indications are to reduce or exclude the carbohydrates from the food, replacing 
them by fats and proteins. To prevent the formation of the abnormal acids from fat in the absence of available sugar, the indications are to reduce the fats and to supply carbohydrates. The one has to be weighed against the other.

The general treatment of diabetes is not discussed here. The writer has neither the space nor the special experience which would be necessary. We shall confine ourselves to the physiological problem of averting diabetic coma.

Let it be an axiom that no case of diabetes is suddenly to be put on a carbohydrate-free diet on first acquaintance. Particularly would this be dangerous if he already had diacetic and $\beta$-oxybutyric acids in the urine. If they are absent, that is, if there is no red colour on bringing the urine into contact with ferric chloride, a strict diet will be safe and valuable.

It would be going too far to say that severe limitation of the carbohydrates is never indicated when diacetic acid is present. Von Noorden has a daily quantitative analysis made of the excretion of $\beta$-oxybutyric acid, and with this safeguard, which of course involves a complicated procedure, strict dieting is often safe. Patients with the acids in the urine may live for many years.

Apart from an analysis of the excretion of $\beta$-oxybutyric acid, it will usually be justifiable to limit the carbohydrates, provided that the patient is carefully watched for any slight drowsiness, vomiting, or airhunger, and, further, that the urine is kept alkaline with sodium citrate. Fortunately, feeding diabetics 
on fat does not greatly increase the excretion of acetone bodies, especially if the lower fatty acids in butter are washed out with cold water before it is taken.

When there is severe acidosis, as evidenced by the quantity of diaceticand $\beta$-oxybutyric acids in the urine, or when there are threatening symptoms such as a little tendency to drowsiness or vomiting, it is necessary at all costs to get in carbohydrate at once. The most effectual method of doing so, and one which only very slightly increases the glycosuria, is to adopt von Noorden's oatmeal treatment. He allows nothing for three or four days but seven or eight ounces of oatmeal, given as gruel every two hours, with butter, eggs, and vegetable protein, tea, coffee, wine, or whisky. Then for a day or two he gives nothing but vegetables.

The effect on the acidosis is usually very marked, the ferric chloride reaction disappearing in a few days. The glycosuria also may improve to a considerable extent. It is extraordinary that so much starch as the oatmeal contains should not make the glycosuria worse, but apparently it does not do so. A diet restricted to potatoes may have the same beneficial effect.

At the same time, of course, alkalies should be administered, either by mouth, rectum, or intravenously.

It is well known that diabetic coma may be precipitated by a surgical operation. In some cases matters are so urgent that there is no time for precautions to be taken to avoid this calamity, but 
if a day or two can be secured first, it should be possible with our present knowledge to banish this bugbear from surgery. It will be much safer to give ether than chloroform, on account of the danger of delayed chloroform poisoning. If the urine contains no diacetic acid this precaution will be sufficient. Should the red coloration with ferric chloride be present, however, the patient ought to be put on the oatmeal diet, and alkalies introduced by mouth, rectum, or intravenously, until the acid reaction of the urine disappears. These measures must be kept up for a day or two after the operation, until the danger has passed.

Perhaps we are scarcely yet entitled to speak of the treatment of diabetic coma. It is true that after intravenous injection of two or three pints of a solution of sodium carbonate ( $3 \mathrm{iv}$ to the pint), patients have made a marvellous rally, and, as in one case in the writer's experience, may be so far recovered as to sit up in bed, eat an orange (without leave), and talk to friends. But the symptoms soon recur, and proceed to a fatal termination. The alkaline injection must not be given subcutaneously, but intravenously; the former method will often cause gangrene.

\section{REFERENCES.}

L. Hill.- " Recent Advances in Physiology and Biochemistry," Arnold \& Co., London, 1906, p. 3I 2.

VoN Noorden. - "Metabolism and Practical Medicine," Heinemann \& Co., London, 1907. Edited by I. Walker Hall. Vol. i., p. I69 (Acetone Bodies); vol. iii., (Diabetes Mellitus).

Von Noorden.- - "Diabetes Mellitus," J. Wright \& Sons Ltd., Bristol, x906; "Acid Auto-intoxications," J. Wright \& Sons Ltd., Bristol, 1904. 
CHAPTER VIII.

\section{IMMEDIATE AND REMOTE POISONING BY CHLOROFORM.}

The mode of action of the organic hypnotics.-The immediate dangers of chloroform narcosis.-Vagus inhibition.-Lowering of the blood-pressure.-Delayed chloroform poisoning.

G NTHUSIASTIC advocates of chloroform as the L ideal anæsthetic (usually hailing from the north) used to say, "Chloroform kills your patient to-day, and ether kills him to-morrow." They referred of course to the pulmonary complications which may follow the use of the latter drug. We are now finding out that chloroform too may not claim its victims until to-morrow. Before proceeding to classify the counts in the indictment against chloroform, it may be of interest to relate a plausible theory of the mode of action of the anæsthetics and other organic hypnotics.

Hans Meyer reminds us that the nervous system is largely built up of fatty substances such as lecithin; that the organic hypnotics, including ether, chloroform, ethyl chloride, chloral hydrate, trional, and sulphonal have it in common that they are comparatively insoluble in water, but very miscible with fats and oils. It would be reasonable to suppose, therefore, that when these substances are circulating in dilute solution in the blood-stream after administration, fatty structures such as the nervous system 
would take up a far larger quantity of the drug than aqueous substances such as the protoplasm of the muscles, heart, and glands. Hence the principal action should be upon the nervous system. The rapidity and evanescence of that action depend on the volatility of the drug. Ethyl chloride, ether, and chloroform would act rapidly, the solid drugs more slowly. Meyer supports his hypothesis by arranging a series starting with trional, which is relatively least soluble in water but most soluble in fat, and passing through butyl chloral to sulphonal, next chloral, and finally to urethane, which of the five is most soluble in water, but least soluble, relatively, in fat. He finds that the narcotic power of these drugs for tadpoles is greatest with trional, and passes in the same order to the least toxic, urethane. The hypothesis has scarcely yet passed out of the realm of suggestion, and in any case would be of greater theoretical interest than practical importance.

Chloroform may cause a fatality in three distinct ways: first, by vagus inhibition; secondly, by poisoning the heart and vital centres in the medulla of the brain; and thirdly, by inducing acute fatty degeneration of the viscera, and acidosis.

\section{VAGUS INHIBITION.}

Some of the most tragic calamities of surgical practice are due to vagus inhibition by chloroform, and few and happy are the surgeons who have never seen it. Here we must place those cases where the patient is far from under, perhaps struggling and 
shouting, and then without warning draws a few deep breaths and dies. Here also, those who seem to be under, but whose heart and respiration cease on being lifted into position for the surgeon. Here, again, those who have been given a mere whiff of the anæsthetic for a trifling operation, and whose life ebbs away at the bare touch of the knife.

All of these may be reproduced in experimental animals, and we are exactly informed as to what takes place. Chloroform has the deadly power of causing an undue irritability of the vagus centre, especially in people of the "lymphatic" type, in whom the thymus is enlarged. Later in its action, if anæsthesia is gradually induced, this hyper-excitability gives place to depression. During the stage of excitability, a stimulus is likely to cause reflex stoppage of the heart, just as in the frog with spinal cord and vagus nucleus intact, tapping the intestines will reflexly stop the heart. During the induction of anæsthesia there are several possible stimuli which may be sources of danger. The most important is the sudden inhalation of a chloroform vapour stronger than 2 per cent, which is particularly liable to occur during struggling. Lifting, or commencement of the operation before the patient is under, may also furnish such a stimulus, either directly or by causing deep inspirations of concentrated vapour.

An apology must be made for saying again what we all know, yet never can know too well. It is courting disaster to hurry the patient under. We must feel the pulse all the time, as well as watch the pupil and the respirations. We must withdraw the mask 
during struggling. "Whiffs" are far more dangerous than proper anæsthesia. No lifting, or cutting, or painful pressure is permissible until the patient is properly under. There is no danger of an overdose during quiet breathing if the mask is kept half an inch away from the face.

What is to be done if the calamity is not successfully averted, and the heart and breathing cease? The books advise a dozen expedients. A moment's consideration of physiological principles will lead us to put most of them aside. How can amyl nitrite, which is simply a vasodilator, possibly help a heart stopped by the vagus? Strychnine and brandy are perfectly futile. It is no use giving oxygen to a patient who is not breathing. "Galvanization of the phrenics" is equally likely to galvanize the vagus.

There are just four measures which matter. The first is to have the head low, so as to keep the vital centres alive. The second is, of course, artificial respiration, which fills the auricles' with blood as well as the lungs with air, averts death from asphyxia, and so gives the heart a chance to recover if it can. The third is to stimulate the heart to contract again by manual compression, if possible through the diaphragm. The fourth is to administer as quickly as possible atropine, which must be injected right into the heart by a long hypodermic needle. Atropine is well known to paralyse the terminals of the vagus. Every medical student is taught to resuscitate by its means the frog's heart stopped by muscarin or pilocarpine (which stimulate vagus nerve-endings). 
Its value in overcoming chloroform inhibition has. been abundantly proved by Dixon and others in dogs, and though its use in such cases in man is but recent, successes are already recorded. That there have been failures is admitted, but there is good reason to hope for recovery with immediate injection into the heart itself. There is ground for hoping, also, that a preliminary injection of scopolamin, now becoming popular for employment before the administration of a general anæsthetic, may help to eliminate these terribly sad occurrences.

Several patients apparently passed beyond the shadowy Rubicon which separates the living from the dead have been brought back to life by rapidly opening the upper abdomen and rhythmically squeezing the heart against the chest wall through the diaphragm.

\section{POISONING OF THE VITAL CENTRES.}

Turning to the second danger, we must realize another outstanding difference between chloroform and ether. The latter stimulates the circulation, and death from an overdose of ether will be death from paralysis of respiration. During the prolonged administration of chloroform, on the other hand, the circulation is depressed, the heart dilates, and the blood-pressure, as measured by the Riva-Rocci instrument, falls steadily. It is well known that when the operator complains of hæmorrhage obscuring his view, the substitution of chloroform for ether will usually diminish the bleeding. In very prolonged operations, or in surgical procedures 
involving some degree of shock, the depression of the operation added to that of the chloroform may lead to a fatal result which would not have occurred with ether. This may to some extent be obviated if, on account of bronchial complications, it is necessary to trust mainly to chloroform, by giving an occasional mask-full of ether to stimulate the great vital centres in the medulla.

If the surgical operation does not involve much shock, but chloroform is carelessly pushed in spite of dilating pupils and disappearance of the light reflex, the breathing will fail, and in these circumstances the heart will be found still beating when respiration ceases.

\section{DELAYED CHLOROFORM POISONING.}

The third danger is subtle and unexpected; it has been recognized only recently, and we do not know how to treat its symptoms.

In Chapter VII. reference is made to the remarkable process of abnormal decomposition of fats which may take place when the amount of glucose supplied to the tissues by the blood is deficient. In these circumstances, $\beta$-oxybutyric acid, diacetic (or aceto-acetic) acid, and acetone are produced, and the patient is poisoned by the acids, while the acetone imparts a sweet odour to the breath and urine. We saw that starved patients and diabetics were particularly liable to this condition of "acidosis" or " acetonæmia," as it is variously called. Fat children and sufferers from peritonitis are frequently the subjects of acidosis after operations in which 
chloroform has been used, and there is greater danger if there has been a long interval between the last feed and the anæsthetic. A prolonged administration is more dangerous than a brief one. The train of symptoms is referred to as delayed chloroform poisoning. A hospital of 200 beds may perhaps furnish one or two such cases annually, if chloroform is used frequently as the anæsthetic of choice. The signs are incessant vomiting, drowsiness or unconsciousness, and a sweet acetone odour in the breath. Acetone and aceto-acetic acid are present in considerable amount in the urine. A trace may often be found after any anæsthetic. Death follows within a few days. At the post-mortem examination the liver, kidneys, and other organs show signs of acute fatty degeneration. Whether this is the cause or the consequence of the acidosis may be in doubt, but the vomiting and drowsiness are almost certainly due to the effect of the acid intoxication on the brain. Most surgeons who are aware of the condition can recall sad cases where an operation promised well, but this fatal complication stepped in and banished all hope of a favourable issue. Recently it has been found possible to imitate the condition in experimental animals. To draw the practical lesson, we can at present hope only to prevent, not to cure. Every patient to whom it may be necessary to administer chloroform should be guarded as far as possible against this complication. The urine should be tested with ferric chloride. A prolonged starvation should be avoided. Glucose and alkalies have been advocated as remedies 
likely to prevent trouble, and the former would appear to be the better. If possible, ether should be given to patients who have been starved, to fat children, and, especially, where the urine strikes a red colour with ferric chloride. Diabetics require sṕecial care. If prolonged vomiting follows recovery from the anæsthetic, the poison should be diluted by a large injection of saline into the rectum, which often works wonders. If acetone can be smelt in the breath, glucose or alkalies, or both, should be introduced into the blood by transfusion, but success is not very probable, as these remedies cannot restore the fatty liver and other viscera to normal.

Whether the acidosis is the cause of the vomiting, or whether the starvation consequent on the vomiting causes the acidosis, is not yet certain, but we may safely attribute the drowsiness to the acids in the blood, and they probably share in bringing about the fatal termination. 


\section{CHAPTER IX. \\ NERVE INJURIES.}

The effects of nerve section.-Epicritic, protopathic, and deep sensibility.-Causation of trophic lesions.-Diagnosis of partial nerve section.-How degenerated nerve is regenerated.-The results of primary and secondary nerve suture.-Methods of dealing with wide gaps.

$\mathrm{T}^{\mathrm{T}}$ will be necessary in compressing this immense 1 subject into the limits of a single chapter simply to mention the better-known phenomena, and refer to the original monographs those who wish to become more fully acquainted with the interesting results here alluded to.

THE EFFECTS OF DIVISION OF A NERVE.

The effects of division of a nerve are as follows :(a). Flaccid paralysis of the muscles supplied, with loss of reflexes.

(b). Loss of epicritic sense over the anatomical area supplied by the nerve. Loss of protopathic sense over an area, usually smaller and encircled by the former. Sometimes loss of deep sensibility over an area smaller still. (These terms are explained subsequently.)

(c). Reaction of degeneration.

(d). Wasting of muscles.

(e). Paralysis of the pilomotor nerves, so that the hairs lie irregularly, and "goose skin" does not so readily. occur. 
$(f)$. Paralysis of sweating in the area supplied.

(g). Vascular dilatation (transitory).

(h). Trophic changes, such as glossy skin, onychia, sensitiveness to injury, ulceration, and certain histological changes.

(i). Wallerian degeneration of the distal part of the nerve cut off from its nerve cell.

(j). Nissl's degeneration (chromatolysis) of the nerve cells from which the nerve fibres are derived.

Concerning two of these headings a few words of explanation may be useful.

The terms epicritic, protopathic, and deep sensibility were introduced by Head and Sherren to denote some very important distinctions, failure to observe which has led to endless mistakes and confusion in the past.

We may take as an illustration the consequences of section of the ulnar nerve at the elbow.

Epicritic Sense will be lost over the whole of the little finger, over the ulnar half of the ring finger, and over a corresponding area of the ulnar surfaces and border of the hand, both back and front; that is to say, over the region described in the anatomy books as supplied by this nerve. In this area the patient will be unable :

(i.) To detect a light touch ;

(ii.) To detect mild ranges of heat or cold;

(iii.) To distinguish two points of an opened compass as separate; and

(iv.) His localization will be imperfect.

In the glans penis epicritic sense is normally absent. Protopathic Sense will be lost over the whole of 
the little finger, and over a small area of the ulnar border of the hand. In this region the patient will be unable to detect :

(i.) A pin prick ;

(ii.) Extremes of heat and cold.

Deep Sensibility will be lost over a smaller area still, of variable dimensions. That is to say, deep pressure will no longer be appreciated by the nerve endings in the tendons, joints, and bones.

It is easy to deduce from the above that serious pitfalls await the unwary observer in testing such a case. He may make pressure on the little finger over the metacarpo-phalangeal joint, or over the ulnar border of the ring finger, and on being told by the patient that both are readily felt, may conclude quite incorrectly that the ulnar nerve is intact. Testing with a pin point will probably bring out an area of anæsthesia smaller than that currently supposed to be supplied by the ulnar nerve.

The only reliable method of testing for anasthesia in such cases is to make the patient close the eyes, and ask him to indicate with a finger of the opposite hand each point touched as lightly as possible by a pencil of wool. In testing hairy parts, the hairs should be shaved, or protopathic or deep sensibility may be excited. If these directions are followed an area of anæsthesia will be mapped out corresponding to the anatomical distribution of the nerve.

It is astonishing, at first sight, to find that a patient can feel a pin-prick or pressure in a region to which the anatomist can trace only one nerve, and that one known to be divided. By what path 
is he made aware of the stimulus? We must remember that tiny nerve twigs are to be found in unexpected places; in fasciæ, tendons, and bone, entering them far up the limb; in the walls of cutaneous vessels; also that there is always a considerable overlap of the distribution of neighbouring nerves, at any rate of their finest terminals, to be followed only by the microscope. The deep distribution both of the ulnar and radial nerves, in the instance given, is wider than their cutaneous distribution. It is probable, though not certain, that extremes of temperature and painful stimuli are effective because they penetrate to the subepithelial tissues.*

We do not now refer the so-called "trophic changes" to loss of innervation by special nerve fibres whose sole function is to maintain the nutrition of the part. The vulnerability of the parts to injury or invasion by bacteria can be explained without any such theory. To find the simpler explanation, we have to ask how a particular part of the body is able to obtain a better blood-supply at need. The answer is twofold. There is a local chemical action independent of nerves. A nerveless limb will show hyperæmia when a mustard plaster is applied. A

\footnotetext{
* Head denies this, believing that there is a different and more primitive sensory apparatus, the protopathic, detecting extremes of heat and cold, and a more recently acquired sensory apparatus, the epicritic, detecting the smaller ranges. He bases his opinion principally on the examination of a small area in his own arm after division of the radial nerve : in this area epicritic sense was intact, but protopathic sense was lost. He also states that the viscera possess only protopathic sense: it is, however, probable that the stomach and colon have no temperature sense at all.
} 
limb all but amputated - left connected with the body only by its main artery and vein-will show active hyperæmia if its blood-supply has been stopped for a minute, and then released. The chemical substances liberated in starved, fatigued, or damaged tissues exert a local action on the small arteries supplying them, causing them to dilate. But there is also a vasomotor reflex, whereby a message is sent to the spinal cord and vasomotor centre in the medulla asking for more blood, and in consequence vasodilator impulses are sent to that part, and vasoconstrictor impulses to the rest of the body. Normally, these occurrences are the inevitable result of every insult or injury, of every invasion by a few bacteria, and we know nothing of them in consciousness. But when the nerves of the part are cut, the vasomotor reflex fails, and the local hyperæmia takes place too late to check the mischief.

One may illustrate the circumstances by the analogy of a guarded frontier. An armed raid is made by an enemy; the nearest garrison is too weak to repel it, and telegraphs to the base to urge a hasty concentration of the troops. The message goes astray because the wire has been cut. The garrison must make what resistance they can with the aid of local volunteers and small levies summoned by runners. The analogy fails in this particular, that the bacterial invaders of the human frame will not remain constant in numbers till the belated defending forces are at last mustered against them, but will multiply a thousand-fold in the 
interval and do irreparable damage. This is the pathology of " trophic lesions."

We pass from the effects of total nerve section to those of an incomplete division. If less than onethird of the fibres are cut, there may be no symptoms at all except perhaps pain. In general the sensory disturbance is greater than the motor, except in such a nerve as the musculo-spiral, even complete section of which may cause no anæsthesia.* Epicritic sense is more affected than protopathic. If any muscular weakness is present, a very characteristic electrical reaction may be obtained, the faradic response being lost, but the galvanic response being brisk, not sluggish, and K.C.C. greater than A.C.C. It will be remembered that with complete division, the galvanic response is sluggish, and A.C.C. is greater than K.C.C. $t$ Pain and mottling of the skin are often more evident with partial than with complete divisions of the nerve.

\section{REGENERATION.}

Much discussion and research have been devoted in the past decade to clearing up the problem as to how the nerve fibre is reproduced when it has been cut off from its nerve cell and has degenerated in consequence. We know that the fibres peripheral to the section degenerate; we also know that if the cut ends are brought together, whether at once

* It is often forgotten that the radial nerve is joined in the forearm by branches of the musculo-cutaneous.

$+I$ do not explain these terms, because only an expert would undertake the investigation of the electrical reactions. 
(primary suture) or many months later (secondary suture), medullated nerve will in time be reproduced and the function restored. There are two schools of interpretation. The one holds that the central cut end buds out new fibres which find their way down the old track to their old destinations. This is the theory of central regeneration. The other school contends that the severed piece of nerve, after degenerating, eventually recovers itself, and the continuity of its fibres is restored, though admittedly very few of them, if any, acquire a medullary sheath. It only needs, according to this school, that the nerve thus regenerated should be put into continuity with its old stump for its function to be restored and the medullary sheath to develop. This is the theory of peripheral regeneration.

The arguments in favour of the latter theory are as follows :-

(a). A nerve is cut across, and the cut ends kept apart. After some months, it is said, long beaded fibres may be demonstrated by suitable staining methods, running continuously the whole length of the nerve. They are not, in ordinary, surrounded by a medullary sheath.

It is objected to this that more reliable staining methods show only the discontinuous fibres which make up ordinary white fibrous tissue ; and that no nerve elements are present at all in the degenerated piece of nerve thus cut off from its trophic centre.

(b). It has been claimed repeatedly that if in man a nerve is divided and not sutured for many 
months, the patient may have some degree of recovery of sensation in the anæsthetic area within a few days after the suturing. We know that if the nerve had been restored by primary suture, it would have been months before any recovery could have taken place. The deduction would be that the isolated segment of nerve had regenerated its continuity, and only needed to be put into communication with an efficient nerve to become efficient itself.

One might illustrate the two theories in this way. A telegraph wire near a town $\mathrm{A}$ has been cut, and the whole line from $\mathrm{A}$ to $\mathrm{Z}$ completely destroyed, leaving only the track of the broken poles. Villagers at B, C, D, etc., along the line effect a certain amount of rough repair, and finally restore a continuous wire from $B$ to $Z$. After some months, when this has been done, a telegraph operator reunites the wire near A. Communication with $Z$ is at once restored. This illustrates the theory of peripheral regeneration.

But let us vary the process, and suppose that the operator starts from $\mathrm{A}$ and unites a new wire to the cut end, and then works slowly through B, C, $D$, repairing as he goes, until finally he reaches $Z$. This would illustrate the theory of central regeneration. If it be true that communication can be restored within a few hours of the reunion of the wires, it is evident that peripheral regeneration must have taken place.

It is doubtful, however, whether the clinical observations of immediate return of sensation after 
secondary suture are trustworthy. As we have seen already, there are many fallacies in testing sensation, and since these have been recognized there is no evidence that such immediate return of sensation has been proved to occur in any well-authenticated case. Patients are often over-sanguine as to the benefit of operations, and may deceive themselves. The irritation of the stump by the stitches may induce sensations referred to the surface. It is certain that in most cases improvement after secondary suture is not more but less rapid than after primary suture.

(c). Bethe and others have found that if a nerve is divided and not sutured, but a gap is left which prevents union, after a year or two a few medullated fibres may be seen in the degenerated peripheral segment, and feeble muscular contractions of the paralysed muscles may follow stimulation. He took this to indicate that peripheral regeneration had occurred. Langley and Anderson have, however, proved that these few medullated fibres are derived from some other nerve in the limb, which has grown down the old path, in obedience to the mysterious chemical attraction which is presumably the cause of central regeneration. Thus if the sciatic nerve was divided and the upper part cut away, any medullated fibres found in the tibial nerves will degenerate after section of the anterior crural or obturator. The observation thus becomes strong evidence in favour of the theory of central regeneration.

There is indeed abundant proof in favour of the 
view that the new nerve fibres formed after suture are budded out from the cut central end. It will be found that new medullated fibres are present only in the proximal part of the regenerating nerve at first, whereas at a later date they reach the periphery. Only a few millimetres may have regenerated in a month. It has recently been shown, by Perroncito, that the fine fibrils which constitute the axis cylinders of the central end commence to grow, curl, bud, and branch within a few hours of the injury, apparently "feeling for" the old track.

Mott and Halliburton have shown that if a nerve is cut and sutured, and time allowed for regeneration, after a second section at the same place the new medullated fibres peripheral to the injury all degenerate. Had they been developed in situ by the activity of the sheath cells, one would not expect degeneration after the second section, because they would not in that case have been cut off from their centre of origin. The deduction is that the new fibres were derived from the central end.

Convincing proof has been advanced by embryologists that the nerves in the embryo are not formed in situ, but are budded out from the nervous elements of the brain and spinal cord. By removing. the medullary groove in frog embryos and planting it in lymph clot, Ross Harrison has actually observed the developing nerve cell grow out its axon at the rate of $20 \mu$ in twenty-five minutes. The outgrowing axon is actively amœboid. He was able also, by destroying the ventral part of the developing spinal cord, to obtain tadpoles in which the muscles had no motor 
nerves. If it is allowed that in the embryo the nerves grow out from the central nervous system, the theory of central regeneration is placed upon a strong basis, and indeed it is now almost universally accepted, whereas ten years ago it was losing favour.

Two questions of great interest have recently received answers. First, Why does the medullary sheath of a nerve fibre break up into fatty droplets when it is cut off from its trophic centre, that is, from its cell of origin in the central nervous system ? Second, How does the budding axis cylinder of the central end of a divided nerve manage to find its way so accurately along the old path ?

The questions are intimately related. Each furnishes the answer to the other. The medullary sheath breaks up that it may liberate the chemical substance which attracts the sprouting axis cylinder. The new fibre follows the old path, because of the chemical attraction along that path.

Nature is full of analogies to this process of chemical attraction. Chemical particles, though infinitely diluted with air or soil, attract the vulture to the corpse in the desert, or the bloodhound to the hunted criminal. Smell is only a chemical analysis. Similarly, the leucocytes crowd out of the vessels to an inflamed area, in obedience to a law of chemical attraction.

If two celloidin tubes are presented to the central end of a divided nerve, the one containing emulsion of liver, and the other emulsion of brain, all the sprouting fibres pass into the brain emulsion, none into the tube containing liver (Forssman). The 
disintegration of the nervous matter lays down a line of bait to entice the regenerating fibres along paths of usefulness.

The phenomena of repair after suture next call for remark. It may be said at once that the sooner the operation is performed the better will be the results. If the muscles have ceased to contract to any form of electrical stimulus, operation is useless. It is very seldom that benefit will be obtained if two years have elapsed since the injury. If asepsis is secured, accurate primary suture seldom if ever fails.

Sherren gives average time relations as follows:5-25 weeks: Commencing return of protopathic sense. 6-12 months: Complete return of protopathic sense. I2-I8 months: Return of epicritic sense.

I2-24 months: Motor recovery.

Taking the ulnar nerve as an example, recovery may be hoped for in twelve months when it has been divided at the wrist, or in twenty-four months when the injury was at the elbow.

During recovery, a remarkable phenomenon has been described by Trotter, who had nerve sections performed upon himself. Any stimulus over the cutaneous area affected gives rise to a decidedly painful sensation, referred usually to the most distant part of that area.

Recovery after incomplete division of a nerve is more rapid, usually taking less than six months for sensory restoration; it is perhaps a year before motor power is normal. Protopathic sense does not return before epicritic, as it does when the nerve is 
completely divided; they are restored side by side at an equal rate.

The last point we shall consider is how best to proceed when so much nerve has been lost that the ends cannot be got together. Many methods have been adopted, some of which are of little or no value and should be allowed to drop out of use. Amongst these may be mentioned the introduction of a bridge of nerve derived from a cat, dog, or rabbit (which will undergo dissolution), or of silk or catgut, and the device of splitting the nerve longitudinally and turning down one-half across the gap. It is quite evident why these fail. The silk, catgut, and probably the animal's nerve, cannot provide the necessary chemical attraction for the down-growing nerve fibres. The splitting "en-Y" does not lay down a continuous "scent" along the tract; it is broken at the stem of the $Y$. Infinitely better results may be obtained by suturing into the interval a length of human nerve. This may be obtained from an amputated limb, but it is always possible to excise several inches of some unimportant nerve such as the internal cutaneous of the arm, and if this is too slender two or more pieces may be used parallel to one another. It is an advantage to protect the nerve junctions from invasion by fibrous tissue; this may be done by enclosing them in a ring or tube of superficial vein, or in Cargile membrane.

There is yet another method, which is sometimes the only one available. Langley made some very interesting experiments on the effects of joining up the cut ends of different nerves, and found that their 
functions could be transposed. Thus he turned the cat's vagus into the cervical sympathetic, and allowed regeneration to take place. The vagus is of course the nerve of swallowing, and therefore, whenever the cat lapped milk, all the effects of stimulation of the cervical sympathetic were seen on the side operated on-dilatation of the pupil, sweating, retraction of the nictitating membrane, pallor of the ear, and bristling of the hair. When, however, the (purely sensory) lingual nerve and the (purely motor) hypoglossal were crossed in like manner there was no result.

The method of nerve anastomosis was introduced into practical surgery by Ballance, who put part of the spinal accessory nerve into the peripheral end of the degenerated facial nerve to relieve intractable facial palsy. The result was excellent, but there was a tendency, of course, for the face and the trapezius to contract together, and smiling was accompanied by jerking of the shoulder. To avoid this the hypoglossal is now utilized instead of the spinal accessory. It was hoped that there was a wide field of usefulness before this device of nerve anastomosis, especially in infantile palsy. For instance, if the anterior tibial muscles and peronei alone were affected, the external popliteal might be divided and the peripheral end put into a notch in the internal popliteal. Unhappily, published results are very disappointing, at. any rate in the case of infantile paralysis; probably even the anterior horn cells supplying useful muscles have been somewhat damaged, and cannot take on more than ordinary 
work.* The method remains hopeful, however, for paralysis following other forms of nerve disease or injury.

\section{REFERENCES.}

A few recent papers of importance are :-

Ballance and Stewart.- "The Healing of Nerves," London, rgor.

Head, Sherren, and Rivers.-“"Brain," 1905, pp. 99, ir6. HarRison, Ross.- "Embryonic Transplantation and Development of the Nervous System," Anatom. Record, Balt., 1908, ii., No. 9. "Observations on the Living Developing Nerve Fibre," Amer. Jour. of Anatomy, I907, vii.

KILVINGTON AND OsBORNE.-Jour. of Physiol., I909, vol. xxxviii., pp. 268, 276.

LANGLey and ANDERSon.-Jour. of Physiol., vol. xxxi., I904, pp. $365,418$.

Mott and Halliburton.-Proc. Roy. Soc. B., Ig06, lxxviii., p. 259.

Morr. - "Present Position of the Neurone Doctrine." Pres. Address, Pathological Section, Med. Chir. Soc., London, 1909.

SHERREN-- " Injuries of Nerves and their Treatment," London, 1908.

Bethe.-." Allgemeine Anatomie und Physiologie des Nervensystems," Leipsig, I903.

* See Murray and Warrington, Lancet, xg1o, i., p. 912. 


\section{THE SURGICAL PHYSIOLOGY OF THE SPINAL CORD.}

The effects of division of the posterior nerve roots. - The diagnosis and localization of tumours of the spinal cord.-The exact diagnosis of injuries of the spinal cord.

\section{THE EFFECTS OF DIVISION OF THE POSTERIOR NERVE ROOTS.}

$7 \mathrm{HE}$ effects may be classified as follows :-

1 I. Anæsthesia of the spinal area of skin supplied. The distribution of these in the human subject has been worked out thoroughly, and the charts of Head, Sherrington and others are well known. Section of a single nerve root scarcely ever causes any complete loss of sensation.

2. Ataxia of the corresponding limb, which may be severe.

3. Loss of tone, leading to marked flaccidity of the corresponding limb.

4. A variable degree of functional paralysis. Owing to the loss of sensory impulses, the ataxia, and lack of tone, the patient, man or animal, prefers not to use the limb, although there is not a genuine paralysis.

5. Loss of reflexes.

6. Trophic lesions, such as ulcers, whitlows, etc.

7. Usually not shock. This is rather surprising. 
I have taken the blood-pressure in two patients whilst four or five nerve-roots in the lumbar and sacral plexus were cut on each side, and there has been no sudden fall. There was a steady drop throughout the whole operation (under open ether anæsthesia) amounting to less than eight millimetres of mercury.

8. Certain degenerative changes. The posterior columns of the spinal cord show Wallerian degeneration running up to their termination in the gracile and cuneate nuclei of the medulla. As Warrington and others have shown, in animals the cells of the anterior horn on the same level as the severed roots show signs of chromatolysis, or dissipation of their Nissl granules. I have recently been able to demonstrate this in man. A patient who had been treated for gastric crises by resection of the posterior nerve roots from the seventh to the tenth dorsal, died about two months afterwards. In the cervical region all the nerve-cells were normal, but in the region of the divided roots more than half the anterior horn cells, and all the cells of Clarke's column, showed marked chromatolysis. This is interesting in the light of the various affections of the motor functions just mentioned.

The surgery of the posterior nerve roots is yet in its infancy, but it promises to have a future. When it is resorted to earlier, it will most probably have a greater value.

There are two main indications for dividing the posterior nerve roots. The one is pain, and the other extreme rigidity, in the course of spastic paraplegia 
or hemiplegia. The pain may be due to such a cause as the crises of locomotor ataxia, or the agonies of inoperable cancer.

When many roots are cut for spasticity, it is necessary to leave one or two intact, or a very decided amount of ataxy may be induced.

\section{THE DIAGNOSIS AND LOCALIZATION OF} TUMOURS OF THE SPINAL CORD.

Tumours of the spinal cord do not occur so commonly as tumours of the brain, but the results of surgical removal are a good deal better. It becomes important, therefore, to know how to make the diagnosis.

Before entering upon this subject, we must remind ourselves of the functions of the great paths or tracts running up or down the spinal cord.

DESCENDING TRACTS. - The pyramidal tracts convey motor impulses from the cortex, and particularly those acquired movements which call for skill and finesse. They also inhibit muscular tone. The rubrospinal tract (Monakow's bundle) controls stock movements such as standing, sitting, and walking. This tract starts in the red nucleus in the isthmus, and it is largely by its means that a man whose pyramidals have been destroyed in the brain may still be able to get about. It would appear, also, that this tract carries down impulses that inhibit any excess of muscular tone. The vestibulospinal and other tracts pass down in the antero-lateral columns, from the region of the pons and medulla. They_are important paths for motor impulses, at 
any rate in animals; in monkeys a section of these tracts produces more paralysis than one involving the crossed pyramidal. They appear to convey impulses increasing muscular tone, so that when the pyramidal fibres are damaged, as by a hæmorrhage in the internal capsule, muscular tone is increased and a spastic hemiplegia results. There are, however, other descending paths open to this class of impulses, some of them crossing in the cord.

AsCENDING TRACTS.- The dorsal and ventral cerebellar tracts pass to the cerebellum, and are practically uncrossed. They convey, amongst other things, the so-called kinæsthetic sense, composed of sensations derived from joints, muscles, and tendons, to the cerebellum, and so keep it informed of the position of every joint, and the state of contraction of every muscle.

The posterior columns (of Goll and Burdach) are also uncrossed in the spinal cord, and convey tactile sense, muscular sense, joint sense, and so-called "tactile discrimination," by which we determine whether two compass points are single or double; the sense (stereognosis) by which we recognize unseen objects by the feel-as on putting a hand into a pocket containing coins, keys, a penknife, paper, etc.-also travels by this route.

There is another sensory path composed of relays of nerve-cells in the grey matter, with short axons passing up to a slightly higher level either in or close to the grey matter. For the most part impulses travelling by this route cross the cord, usually about six segments after entering. Heat, cold, and pain 
sensations are conducted in this way and in this way only ; tactile sense can take either this path or the more direct route by the posterior columns.

A tumour of the spinal cord :-

I. May affect the nerve-roots, in which case the symptoms may be confined to those roots.

2. May press on one side of the spinal cord. In this case there is usually pain radiating along the nerve-roots involved at the same time, which is important in the diagnosis.

Let us take the case of a tumour in the left lower cervical area. This will involve :-

(i). The emerging roots of the lower cervical nerves on the left side, causing pain, dulling of sensation, and flaccid paralysis with loss of reflexes, wasting, and reaction of degeneration, in the left arm.

(ii). The pyramidal, rubrospinal and vestibulospinal tracts on the left side, causing paralysis of the left leg. Inasmuch as the pyramidal and rubrospinal tracts are involved, muscular tone will be greatly increased; the impulses leading to this increase perhaps descend on the other side of the cord. There will be, therefore, rigidity of the left leg and exaggerated reflexes.

(iii). The cerebellar tracts and posterior columns of the left side, causing loss of muscle and joint sense, and loss of tactile discrimination and recognition of objects on the left side.

(iv). The chain of nerve-cells and axons by which heat, cold, and pain travel up from the right leg, will also be pressed upon.

Tactile sense may or may not be lost in either 
leg, as a double path, the one crossed and the other uncrossed, is open to it.

Table to Illustrate the EFFects of a Tumour of the left lower Cervical Region.

\begin{tabular}{c|c}
\hline $\begin{array}{c}\text { Right Arm. } \\
\text { Normal. }\end{array}$ & $\begin{array}{c}\text { Left Arm. } \\
\text { Pain. Some anresthesia. } \\
\text { Flaccid paralysis, loss of } \\
\text { reflexes, wasting. }\end{array}$ \\
\hline $\begin{array}{c}\text { Right Leg. } \\
\text { Loss of sense of heat, }\end{array}$ & $\begin{array}{c}\text { Left Leg. } \\
\text { Loss of muscular sense, } \\
\text { joint sense, tactile discri- } \\
\text { minationandrecognition of } \\
\text { objects. Spastic paralysis ; } \\
\text { exaggerated reflexes. }\end{array}$ \\
\hline
\end{tabular}

3. It may arise in the central grey matter, when it becomes inoperable. In this case there will be loss of the heat, cold, and pain senses on both sides, but tactile and muscular sense will remain. There may be some spastic paralysis of both legs. In the early stages the diagnosis from syringomyelia may be only a matter of opinion.

4. In some cases it may produce bilateral spastic paralysis with involvement of the sphincter functions and with anæsthesia without any dissociation phenomena. The diagnosis is then very difficult.

Each of the thirty-one nerve-roots issuing from the spinal cord has a definite distribution, which may be motor, sensory, and visceral, and these have now been ascertained with some accuracy by a combination of anatomical, physiological, and clinical methods. As given in the various textbooks and monographs, the information is a good deal more 
144 THE SURGICAL PHYSIOLOGY

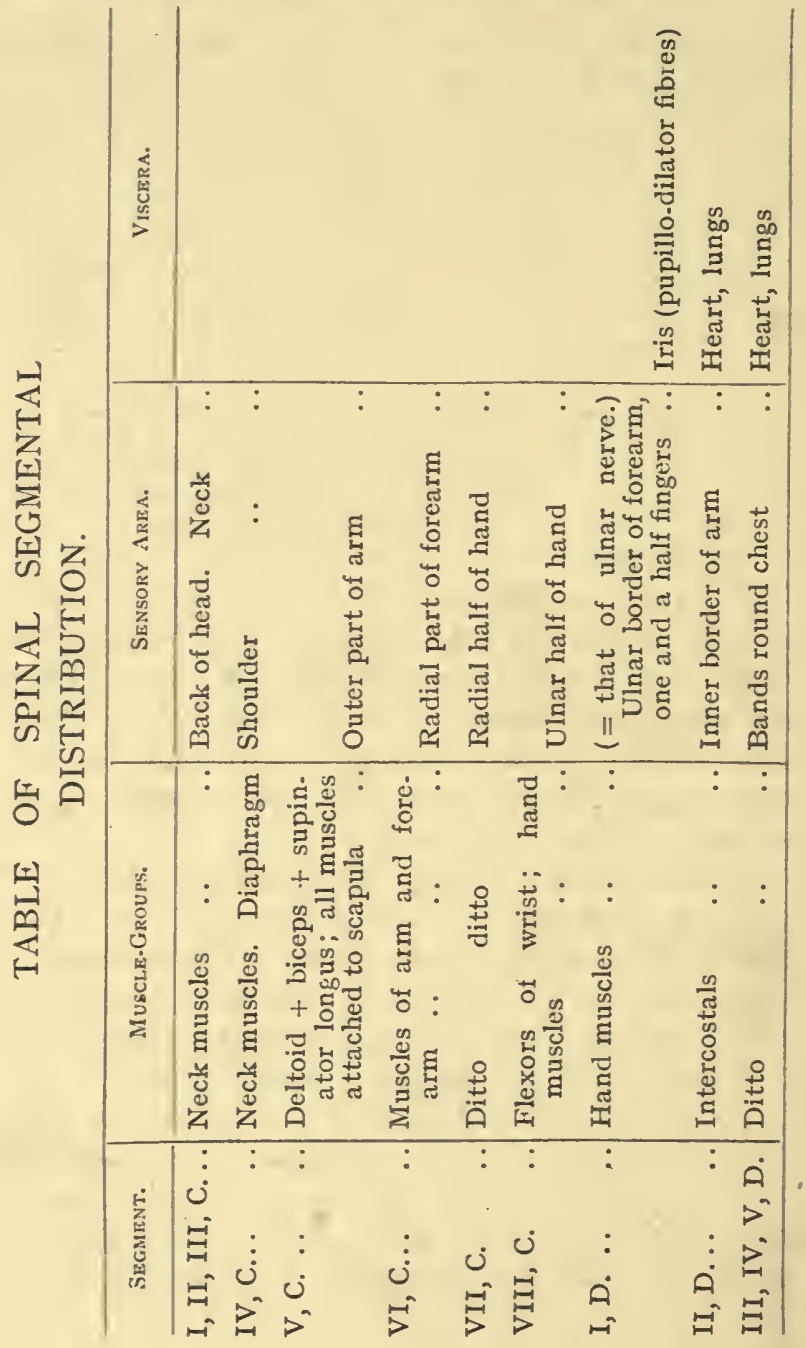




\section{OF THE SPINAL CORD}

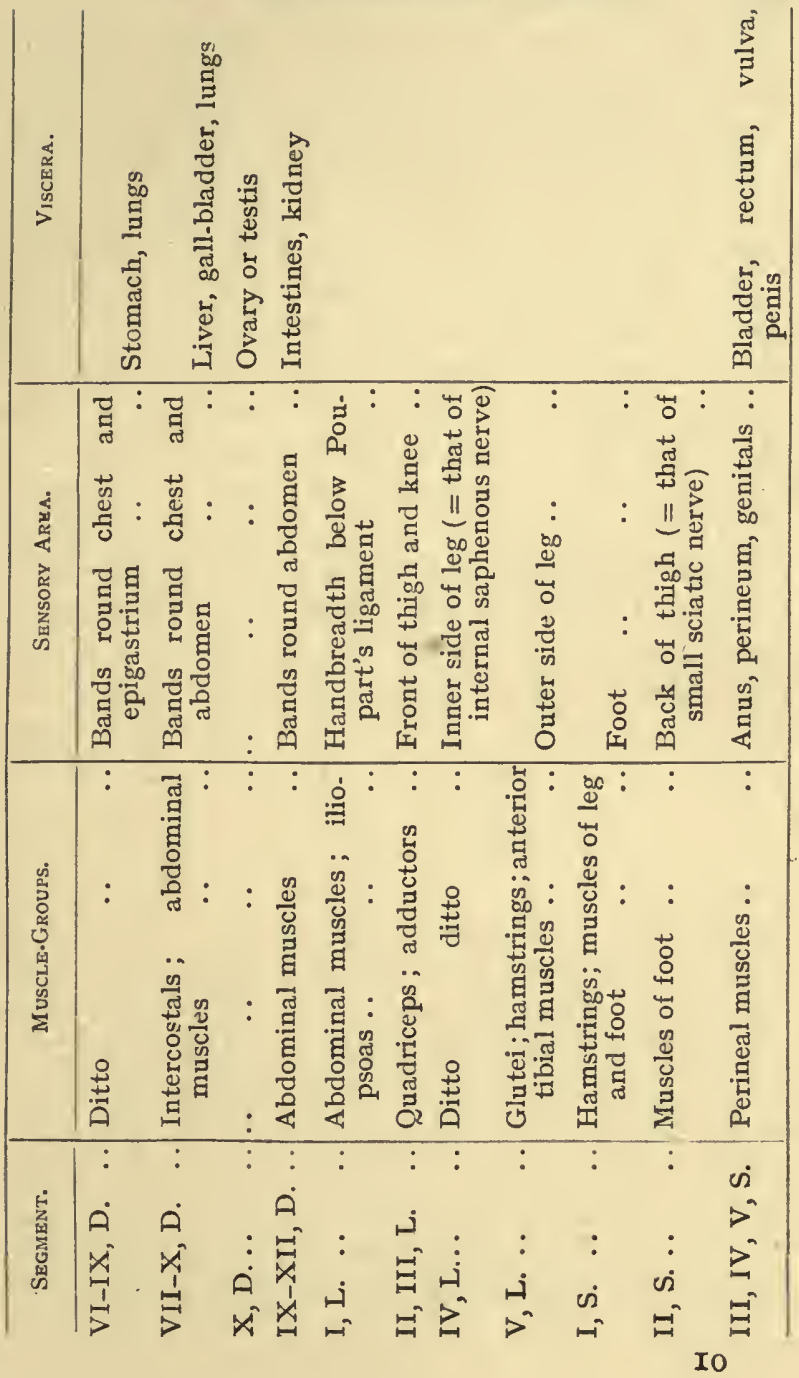


than most of us can carry conveniently in our memories. It is hoped that the bare elements set down below may be found easier to remember, and adequate for most purposes. No two accounts agree exactly.

The main points may be emphasized first. With regard to the sensory distribution, there is a good deal of overlap, especially in the hand, where the seventh cervical supplies the radial half, the eighth cervical the inner half, and the first dorsal the one and a half fingers to which the ulnar nerve may be traced. The twelve dorsal nerves supply the chest and abdomen in bands like successive strips of plaster stretched round the body; the nipple lies between the fourth and fifth dorsal, and the umbilicus between the ninth and tenth. If we place the open hand on the thigh just below and parallel to Poupart's ligament, we cover the first lumbar area ; the next handbreadth below is the second lumbar, and the next, including the region of the patella, is the third lumbar. The small sciatic nerve area corresponds to the second sacral.

With regard to motor distribution, the fifth cervical supplies the deltoid + biceps + supinator longus group, as well as the dorsal scapular muscles and rhomboids. In infantile palsy and other anterior horn or nerveroot affections, these muscles may be found paralysed and atrophied in company. On the other hand, a fracture of the spine irritating this area brings about a characteristic position of the arms $\Psi$. The first dorsal gives off sympathetic branches dilating the pupil. The hand and foot are each supplied by 
the two lowest nerves entering the brachial and sacral plexuses respectively.

The anatomy of the lumbo-sacral plexus makes it easy to remember that the quadriceps and adductors must be supplied from the lumbar nerves, whereas the hamstrings and crural muscles are innervated from the sciatic nerve. There is a general tendency for flexors to derive their nerve supply from a level slightly below that for the extensors. It is easy to see why this should be the case if we glance at a quadruped, where the flexors are posterior to the extensors.

\section{THE EXACT DIAGNOSIS OF INJURIES OF THE SPINAL CORD.}

The following lesions of the cord may be responsible for symptoms of paralysis or anæsthesia after an injury to the back.

I. Simple concussion, the injuries being microscopical or functional only, and the paralysis transient.

2. Complete division of all the nervous elements.

3. Pressure on the cord due to bone, callus, or a foreign body, not causing a total transection.

4. Hæmorrhage into the spinal membranes.

5. Hæmorrhage into the cord itself.

6. Later complications such as myelitis, traumatic neurasthenia, etc.

This is not the place to consider all these in their surgical bearing. We want to look at them in relation to the physiology of the spinal cord.

A total transection of the cord in man, not in animals, affects profoundly the functions of the 
segments below the injury, and either from the first or after the lapse of a little time they lose their reflex functions, the bladder and rectum and their sphincters become paralysed, and the effect is much the same as it would have been if the isolated portion of the cord had been removed in toto. In animals, the reflex functions persist.

Considerable difficulty may be experienced for a day or two in deciding whether a patient is suffering from a complete division of the cord due to the nip at the moment of fracturing the spine, or whether the symptoms are due merely to concussion. In the latter case a few days' rest will effect a cure. Sometimes one can get a hint earlier. If the distribution of the paralysis does not correspond with the distribution of the anæsthesia, and if the symptoms are asymmetrical, it is probable that they are due partly at least to concussion. In either case it is very seldom that any useful purpose will be served by operating, unless the injury involves the cervical region or the cauda equina.

When the cord is involved, but has not suffered a functional transection, the paralysis will probably be spastic in nature, and operation is more hopeful because there may be something exercising injurious pressure which can be removed.

Hæmorrhage into the spinal membranes produces pain and spasm by involving the issuing nerve roots. In addition, there will probably be some evidence of pressure on the cord, producing spastic paralysis and some anæsthesia below the lesion.

Hæmorrhage into the centre-of the cord sometimes 
abolishes the pain and temperature senses while tactile sense escapes. There will probably be spastic paraplegia as well.

It will not be necessary to refer here to the diagnosis of the later complications, such as myelitis and the various neuroses.

Unfortunately the central nervous system is so highly specialized that it has lost the power of regeneration after injury, not only in man (unless we accept the evidence of the famous Stewart-Harte case !) but also in nearly all animals. The newt, it is true, can form a new cord if its tail is lopped off, but the newt has marvellous powers of regeneration, and can even grow a new lens if the front of its eye is removed!

\section{REFERENCES.}

Förster.-Zeitschrift f. orthopäd Chirurgie, I908, Bd. xxii., p. 203.

HeAD AND Thompson.-_" The Grouping of Afferent Impulses in the Spinal Cord," Brain, r906, p. 537. 


\section{CHAPTER XI. \\ CEREBRAL LOCALIZATION.}

The causation and significance of optic neuritis.-Localization in the cerebellum.-Tumours in the cerebello-pontine angle. Localization of sensation in the cerebral cortex.-Functions of the frontal cortex.-Spasticity.-Apraxia.-Aphasia.-Misleading localizing signs of cerebral tumour.-The cerebrospinal fluid.

$T^{T}$ will be necessary here to assume that the reader 1 has an ordinary acquaintance with the structure and functions of the brain. We shall confine ourselves to a brief reference to the most important advances of the past decade in providing evidence for the localization of tumours, abscesses, and traumatic lesions, and therefore for their successful treatment by operation.

\section{OPTIC NEURITIS.}

It has long been in doubt why optic neuritis should develop in cases of cerebral tumour. It has been attributed to the effects of chronic meningitis, and to over-filling of the third ventricle, with consequent pressure on the underlying optic chiasma. It is now definitely established by the experiments of Cushing and Bordley, and confirmed by clinical experience, that it is a pressure effect. The growth of the neoplasm causes a great and continued rise of intracranial pressure; this tends to dam back the lymph flow returning in the sheath of the optic nerve. The usual consequence of lymphatic obstruc- 
tion is produced, namely, œdematous swelling of the area drained. So the optic cup fills up, the disc is obscured by transudate, and the vessels are buried from view in the œdema fluid. All this may be exactly reproduced by intracranial pressure in dogs, and when the pressure is removed, restitution to normal takes place.

Several methods of raising the intracranial pressure were employed, the best results being obtained by the insertion of sponge-tent material inside the skull. Swelling and œedema of the disc, tortuosity of the veins, and over-distention of the lymphsheath around the optic nerve, were all marked. Relief of the pressure rapidly cured them.

Although we use the conventional term " neuritis," the histological changes are not those of inflammation. For instance, there is no arterial hyperæmia, and the principal infiltration is with cells of connective tissue origin, not leucocytes.

Further, it has been stated by many observers, and recently defended, with all his great authority and experience, by Sir Victor Horsley, that the degree of the neuritis in the two eyes is a most reliable guide as to the side of the tumour. It is not so much the amount of swelling that is to be taken into account as the age and extent of the changes. These nearly always commence at the upper nasal quadrant of the disc. Thus, optic neuritis best marked in the right eye is of great value in pointing to a right-sided tumour. The further forwards the tumour, the more constant does this rule become.

It is well known that even if a cerebral tumour 
cannot be localized, palliative trephining should be performed to relieve headache and save the sight. If this is undertaken early, the optic neuritis passes off. As the tentorium transmits pressure badly, the trephining should be in the temporal region for supratentorial tumours, and in the occipital region for cerebellar tumours.

Another valuable observation which we owe to Cushing is that raised intracranial pressure, particularly by cerebral tumour, induces a considerable limitation of the field of vision for blue; indeed, there may be actual blue-blindness.

\section{THE CEREBELLUM.}

We have been in urgent need of some improvement in our means of localizing tumours and abscesses in the cerebellum. It remains to be seen how far the fresh light recently thrown on the subject and herein set forth will help us to obtain materially better results. During the past ten years, at the Bristol Royal Infirmary there have been eight cases of temporo-sphenoidal abscess, all of which have been successfully diagnosed, and ten cases of cerebellar abscess, of which only three were correctly located; in three of these ten cases the cerebrum was explored in vain, and in two the lateral sinus was thought to be the cause of the symptoms.

Sir Victor Horsley and R. H. Clarke have recently revised our knowledge of the functions and relationships of the cerebellum by an ingenious method. Reconstructions of a monkey's head have been made by cutting frozen sections and then piecing them 
together again; by this means it was possible to build a frame of metal to fit about the head of a living monkey, carrying an insulated needle which could be thrust, through a small trephine hole, into any desired portion of the cerebellum, its cortex, or its deep nuclei (roof nuclei), the exact position of the point of the needle having been determined by a study of the head reconstructed from the frozen sections. By this means various parts could be stimulated electrically without doing any but the slightest damage to the overlying structures ; moreover, by passing in a strong current and using a double needle shielded nearly to the points, small electrolytic lesions either of the cortex or of the roof nucleus could be made, and the resulting degenerations studied by suitable staining some weeks afterwards.

The general result was to prove that the cortex cerebelli is a receiving platform, and that its axons merely pass to the roof nuclei, from which the efferent tracts start. Stimulation of the cerebellar cortex by ordinary currents produces no obvious response; stimulation of the roof nuclei causes movements of the eyes and sometimes of the limbs. We see here the reason why laterally situated tumours or abscesses lie so quiet.

The classic signs of a lesion of the cerebellum, determined both by physiologists and by clinicians, are the following :-

(I) Ataxia ; (2) Atonia ; (3) Asthenia ; (4) Tremor; these all affect the same side as the lesion. (5) Nystagmus ; (6) Vertigo. 
I. Ataxia.-This, one of the most constant signs, is easily detected if the patient is able to walk. When he is in bed, it may be brought out by making him try to pronate and supinate rapidly for a minute or two ; or to make and unmake a fist quickly, over and over again. This sign is the more convincing if it is unilateral.

2. Atonia is very variable; the knee-jerks may be absent, normal, or excessive, and may change day by day.

Thiele and others have proved that the great increase of tone noticed in man or animals after lesions involving the pyramidal and other long descending tracts depends on the integrity of Deiter's nucleus. This lies just at the junction of the pons and medulla, beneath the outer part of the floor of the fourth ventricle, and therefore in close relation to the cerebellum. If it is destroyed, or if it is cut off from influencing the spinal cord by a complete transverse division below Deiter's nucleus, the spasticity and increased reflexes which ordinarily follow lesions of the motor paths will fail to develop.

Some cerebellar abscesses and tumours press on the pyramids (above their decussation) but not on Deiter's nucleus. These cause increase of tone on the opposite side. Others destroy Deiter's nucleus, and cause loss of tone on the same side. Others do not involve either, and tone may be normal, or a little increased on the same side as the lesion.

3. Asthenia may be evidenced by weakening of the grip, tendency to fall, or drooping of the head on the affected side. It is not very constant. 
4. Tremor is only occasionally in evidence.

5. Nystagmus. - These curious jerkings of the eyes are of considerable importance in the diagnosis of cerebellar affections, because, although seen in such conditions as disseminated sclerosis, they are very unusual with localized intracranial tumours. Unfortunately they are not constantly present even when the lesion is in the cerebellum, and, on the other hand, are usually to be observed in patients with disease of the labyrinth (vestibule and semicircular canals). Seeing that most cases of cerebellar abscess follow otitis media, it has been very difficult to be certain, in the past, whether any nystagmus in a patient with a suppurating ear was due to the labyrinth, or the cerebellum, or both.

Bárány, of Vienna, has shown that it is possible to induce nystagmus in a normal person by stimulating the labyrinth. This may be done either by rotating the patient, or by allowing hot or cold (not tepid) water to trickle in as far as the membrana tympani. Hot water in the right ear causes a nystagmus in which the eyes slowly turn to the left and are corrected by rapid jerkings to the right; with cold water the rapid jerkings would be to the left.

If a patient with a suppurating ear has nystagmus, and it is desired to know whether this is due to affection of the labyrinth or of the cerebellum, hot or cold water should be injected to see if the nystagmus can be reversed in direction. If it can, the labyrinth cannot be at fault; it must be the cerebellum.

Again, a patient with severe vertigo following on 
otitis media may be suffering from labyrinthitis or from cerebellar abscess. If injection causes no nystagmus, the labyrinth is destroyed.

\section{TUMOURS IN THE CEREBELLO-PONTINE} ANGLE.

This is a very common location for cerebellar tumours, and a comparatively favourable one for surgery, seeing that in many instances the growth is simple, and can be enucleated without recurrence. Allen Starr finds in the literature sixty-nine cases cured by removal. In many of these there was restoration to good, in some to perfect, health. Diagnosis, therefore, becomes peculiarly important.

In addition to the signs mentioned above, certain nerve-root symptoms may develop, and the pons may be pressed on. Mental trouble is quite unusual.

We may classify the evidence as follows :-

I. General : headache, vomiting, optic neuritis, slow pulse, blue-blindness, perhaps convulsions.

2. Cerebellar signs: staggering, vertigo, ataxia, weakness, tremor, and perhaps absent knee-jerk; these may be unilateral, on the same side as the growth. Nystagmus.

3. Nerve-root symptoms affecting the same side: pressure on the fifth, with corneal anæsthesia and loss of reflex, and weakness of jaw muscles; pressure on the sixth, with internal strabismus; pressure on the seventh, with facial weakness; pressure on the eighth, with tinnitus, loss of perception for upper notes (tested by Galton's whistle), or absolute deafness; pressure on the ninth, tenth, and eleventh, 
with dysphagia, laryngeal palsy, cardiac attacks, etc.; pressure on the twelfth, with deviation of the protruded tongue. Of these, the facial and auditory nerves are most often affected, there being complete unilateral deafness in most of the cases. In cerebellar tumours these two nerves may be interfered with, but not to any considerable degree.

4. Pressure on the pons, causing crossed hemiplegic weakness, with exaggerated reflexes and extensor response. The cases may live for years, but there is a liability to sudden death by crowding of the cerebellum down through the foramen magnum.

\section{LOCALIZATION OF SENSATION IN THE CEREBRAL CORTEX.}

HEARING.-Although it is certain that monkeys which have suffered bilateral removal of the temporal cortex give every evidence that they can hear, it is very difficult to be certain that sounds are still appreciated in consciousness by them, and recognized for what they signify. It is no more evidence of conscious hearing that a monkey looks round when a bell sounds, than it is of conscious pain that a man with a fractured spine withdraws a foot pricked by a pin.

At any rate, there is a fair amount of evidence, both anatomical and clinical, to locate this function in the temporal region, and none to locate it elsewhere. The most convincing observation on record was made by Cushing, who stimulated the exposed temporal cortex in a conscious man, and the patient said that he noticed a buzzing noise. 
Vision.-There is abundant evidence that visual sensations are received on the mesial surfaces of the occipital lobes, just above and just below the calcarine fissure. Histologically, the area is mapped out by the white line of Gennari ; it barely encroaches posteriorly on the convexity of the hemisphere.

The left half of each retina is represented in the left cerebral cortex, and the right half of each retina in the right cortex. The fovea centralis of each eye has a bilateral representation. The upper half of each retina is projected above the calcarine fissure; the lower half of each retina below the fissure. Therefore a tumour of the left cortex above the calcarine fissure would render the upper left quadrant of each eye psychically blind, and the patient would be unable to see objects downwards and to his right.

A smaller lesion, however, does not produce a smaller patch of blindness; it merely reduces the visual acuity over the whole of the corresponding quadrant.

Cutaneous Sensation.-There is some evidence that the cortical representation of heat, cold, pain, and tactile sense is identical. Possibly muscular sense has a somewhat different location.

It is universally agreed that the main receiving platform for cutaneous sensation is situated in the postcentral (ascending parietal) gyrus, just behind the fissure of Rolando, and that the general arrangement is the same as that of the motor centres; thus, the sensory centre for the leg is nearest the vertex, opposite the origin of the pyramidal fibres for the leg; next come the arm centres, and lowest of all those for the face and head. 
The localization in the limbic lobe once advocated by Schäfer and others following him, has now been given up, even by its author. Doubt still remains, however, whether the precentral or motor cortex takes any share in appreciating cutaneous sensation. If so, it is quite secondary to the part played by the postcentral convolution.

It is very difficult to be sure to what extent animals feel after the removal of small parts of either the postcentral or precentral convolutions, and very diverse views have been expressed; it is quite certain that a small lesion does not induce complete anæsthesia. It is probably wiser to put faith principally in the human evidence on such a subject. It is abundantly proved that lesions involving the ascending parietal convolution almost always cause a certain degree of interference with sensation, never amounting to a complete hemianæsthesia, which, indeed, occurs only in hysteria, or very transitorily after an apoplectic stroke. Bergmark quotes thirtythree cases of lesions of this gyrus with sensory symptoms but no paralysis.

Cushing excited the postcentral convolution in two conscious patients who had previously been trephined, by unipolar faradic stimulation. $\mathrm{He}$ found that the brain itself was devoid of any sort of feeling, but that sensations of stroking, tingling, or warmth were produced, referred to the hand of the opposite side. The sensation was quite well defined and localized; one area corresponded to the index finger, and another to the back of the hand. When the electrode was applied in front of the fissure 
of Rolando instead of behind, the fingers or hand moved, but there was no sensation. An incision in the postcentral convolution was quite painless, and caused some numbness of all forms of sensation in the hand.

It is more difficult to be certain whether the ascending frontal or motor convolution has also any sensory function; if so, it is less obvious than in the case of the postcentral convolution. Naturally occurring lesions limited to the front of the fissure of Rolando, and carefully studied before and after death, are rare, and the evidence is conflicting; some showed paralysis but no sensory loss, whereas others had both motor and sensory impairment. Many years ago, before it was realized that the convolutions in front of and behind the fissure of Rolando differed in function, Ransom and also Laycock observed that a tingling sensation was elicited when they stimulated the exposed cortex in a conscious man, and apparently they both applied the electrodes in front of the fissure; Cushing and others have failed to confirm this. Recently Sir Victor Horsley has published an account of the only case in which he has removed a cortical centre (part of the hand area) without encroaching upon the ascending parietal gyrus (for athetosis). Immediately after the operation there was complete flaccid paralysis of the arm, and some interference with sensation. The hand could detect cold, but not warmth, stroking with a wool pencil was not felt on the ungual phalanges, there were inaccuracy of location of pain and touch, loss of the sense of position, and objects placed in the hand were not 
recognized by touch (astereognosis). A year later, movement was recovered, except for some spastic paralysis in the two ulnar fingers; there were still astereognosis, inaccuracy of location, and slight dulling of sensation over the ulnar border of the hand. If the lesion had involved the postcentral convolution, the sensory symptoms, in his experience, would have been much more marked. The athetosis was cured.

Interference with sensation is of course no proof that a cerebral tumour is in the cortex; it may be found with a lesion of the optic thalamus, internal capsule, isthmus, pons, or medulla. In twenty-six cases of hemiplegia due to some trouble in the internal capsule, Bergmark found evidence of sensory, impairment in all who were intelligent enough to be tested with accuracy by modern methods, although there was never complete hemianæsthesia to all forms of stimuli.

\section{FUNCTIONS OF THE FRONTAL CORTEX:}

It is well known, of course, that the great motor centres are limited to the ascending frontal or precentral convolution. This has been abundantly proved by many methods : by the study of paralysis following localized lesions in man or removals in man or apes; by electrical stimulation in man and apes; and histologically, by the limitation to this region of the giant pyramidal or Betz cells, which are the only cells to undergo chromatolysis when the pyramidal tracts are destroyed in the spinal cord.

It often becomes of great importance to the surgeon 
to know whether a tumour causing hemiplegia is accessible, either in the cortex or close beneath it, or inaccessible, in the internal capsule or isthmus. The principal evidences of the former are the occurrence of monoplegias, the face, arm, or leg being affected alone without the others, whereas lesions of the internal capsule would paralyse all three ;* secondly, persistent aphasia may be present; and thirdly, there may be recurring convulsions. The degree of sensory impairment is not of much assistance.

There is a good deal of evidence that if the paralysis is of a flaccid type, the lesion is most probably cortical, though the converse is not necessarily true. Thiele has demonstrated in animals that tone is increased by impulses from Deiter's nucleus in the medulla, and inhibited by impulses generated in the optic thalamus and conducted by the rubrospinal tract (Monakow's bundle). It is this tract which subserves the stock movements such as standing and walking, which can often be carried out after complete destruction of the pyramidal tract. In man, a cortical lesion is often (not always) accompanied by a flaccid paralysis with no Babinski sign and with normal or diminished reflexes (see cases quoted by Bergmark), but when the optic thalamus and internal capsule are involved, there is always marked rigidity. Pressure on the isthmus, pons, medulla, or spinal cord will probably damage the rubrospinal tract as

* In monkeys the fibres to the head, arm, and leg are grouped in bundles in the internal capsule, but apparently this is not the case in man, and consequently small lesions cause mild hemiplegia, not monoplegia. 
well as the adjacent pyramidal tracts, and so set up spasticity, unless the whole cord is functionally divided, in which case impulses descending from Deiter's nucleus (possibly in the vestibulospinal tract), are also cut off, and a flaccid paralysis results.

It is, however, true that irritation of the cortex, such as may be present just after a traumatic lesion, or during the growth of a tumour, may cause early contracture, so we should regard the presence of rigidity as an equivocal sign, but absence of rigidity as evidence of a cortical lesion.

The frontal cortex lying in front of the motor region is described as a "silent area," and extensive tumours, degenerations, or injury may produce few or no symptoms. In a case under the writer's care a wound one inch deep into the brain caused by a chopper, from the vertex to the nose, made absolutely no difference to the woman's character, capacity, or intelligence, and indeed produced no symptoms at all beyond concussion, although she was under observation for many months. In the famous American crowbar case, where a large part of the frontal cortex on both sides was destroyed, there was no paralysis, but on returning to work the man, previously a capable foreman, had become weak, vacillating, inattentive, and profane. There are quite commonly signs of mental dullness in patients with frontal lesions. In cats there are, after excisions of the frontal cortex, changes in the disposition, and recently acquired tricks may be lost. 


\section{APRAXIA.}

More definite evidence, however, is now available. There are a number of carefully studied cases on record in which, with no actual paralysis, there has been a remarkable clumsiness in the performance of movements requiring any skill, and in which the patient has been quite unable to make some movement voluntarily or in response to command, although he may unconsciously do that very thing under the influence of emotion or by accident. This condition is called apraxia. It is most convincing when it is unilateral. Thus, a musician may lose the power of playing his instrument, or the clerk his power of writing. In Liepmann's classic case, one of the first to be described, there was apraxia of the right arm and leg. "Asked to put his right forefinger on his nose, he said, 'Yes,' and with his stretched forefinger executed wide circling movements in the air. He made the correct movement at once with his left hand. Asked to close his right hand into a fist, he performed various absurd movements of his arm and body, but attained the required goal at once with his left hand. When asked to give the examiner a certain object with his right hand, he frequently picked up the wrong thing, and still holding it in his hand, used the left to take up the required object and present it to the physician." A patient of de Buck's, asked to lift her right arm, crossed it over her body, put it in her left axilla, and after making various other vigorous but futile efforts, said plaintively, "Je comprends bien ce que vous voulez, 
mais je ne parviens pas à le faire " : this just expresses the condition.

In some of the cases, there is imperfect recognition of objects or of their uses (agnosia), but these are complicated and cannot be described here.

It is an important fact that apraxia of the left arm is common in right hemiplegics, whereas apraxia of the right arm rarely occurs in left hemiplegics; moreover, in the cases where there are apraxia of the left side and hemiplegia of the right, there is evidence that the lesion is cortical, not in the internal capsule. Thus Liepmann examined eighty-three hemiplegic patients, with these results :-

Forty-two had left hemiplegia ; they could nearly all obey directions with the right arm.

Forty-one had right hemiplegia ; of these 20 had apraxia of the left arm, and I4 in this group also had aphasia ; 2 I had no apraxia, and of these only 4 had aphasia (in most of the other I7 cases, the lesion was probably in the internal capsule).

Of course, as left-handed persons form one-twentieth of the community, it is possible to find a few cases of left hemiplegia with right apraxia.

There is good ground, then, for believing that the centres which consciously initiate voluntary movements for both sides of the body are limited to the left cortex in right-handed people, and that the precentral convolutions are merely the departure platforms for messages from the brain to the cord. Instructions are sent to the right precentral convolution by way of the corpus callosum. It is still in doubt whether the above-mentioned initiating centre 
is in the left precentral gyrus, or whether it lies in front of this, in the first and second frontal convolutions, as most neurologists maintain. It is quite certain that a lesion of the front part of the corpus callosum is characterized by apraxia of the left arm ; this important discovery may well lead to successful surgical removal of tumours there situated. A lesion in the left frontal cortex may cause apraxia of both arms; there will probably be right hemiplegia as well, which would mask the condition in the right arm.

To sum up, a lesion is cortical if there are present :-

I. A monoplegia.

2. Hemiplegia with either (i) Aphasia which persists ; (ii) Recurring convulsions ; (iii) Flaccidity; (iv) Apraxia of the opposite side.

Left-sided apraxia without hemiplegia indicates a lesion of the corpus callosum.

\section{APHASIA.}

The various types of aphasia have always presented problems of great complexity but of great interest. Recent studies of the subject have been very revolutionary in their tendency. We used to learn that there were three great centres for the appreciation and utterance of language, namely :-

I. The motor centre, controlling utterance, in Broca's convolution (the third left frontal).

2. The auditory word centre, appreciating spoken language, in the posterior part of the second left temporal convolution. This was also regarded as dominating and being necessary for the activity of the other two centres. 
3. The visual word centre, appreciating written language, in the left angular gyrus, behind and above the auditory word centre.

Now, however, the searching analyses of Marie and his pupils have raised very grave doubts about the first and third of the above, and many neurologists have agreed that Broca's convolution has no speech function at all ; very few now defend the existence of a separate visual word centre.

Briefly, the contention of Marie and Moutier may be put thus. Between I86r and I906, there have been published 304 cases of aphasia with autopsy. Of these 201 were useless and 103 were relevant.

\begin{tabular}{|c|c|c|c|c|}
\hline Useless & $\begin{array}{l}\text { Lesion too } \\
\text { Badly descr }\end{array}$ & $\begin{array}{lll}\text { xtensive } & - \\
\text { ibed } & - & -\end{array}$ & $\begin{array}{r}\mathbf{I} 75 \\
26\end{array}$ & 201 \\
\hline Relevant & $\begin{array}{l}\text { Favourable to } \\
\text { Broca's local- } \\
\text { ization } \\
\text { Unfavourable } \\
\text { to Broca's } \\
\text { localization }\end{array}$ & $\begin{array}{l}\text { Cortical lesions with } \\
\text { aphasia - } \\
\text { Subcortical lesions } \\
\text { with aphasia - } \\
\text { Aphasia, but Broca's } \\
\text { convolution normal } \\
\text { No aphasia, but } \\
\text { Broca's convolu- } \\
\text { tion destroyed (in } \\
\text { two cases, bilateral } \\
\text { destruction) - }\end{array}$ & $\begin{array}{l}8 \\
\text { I I } \\
57 \\
15\end{array}$ & I9 \\
\hline
\end{tabular}

The majority even of the nineteen cases allowed by these writers they consider to be inconclusive for various reasons.

Two cases of Burckhart's are of sufficient surgical interest to be worth quoting. In the first, he removed 5 grams of grey matter from the foot of the first and 
second left temporal gyri, but no word-deafness resulted. Eight months later he resected the cap and foot of the left third frontal gyrus (Broca's convolution), but no aphasia followed. In the second case he resected, in several operations, the left supramarginal, temporal, and third frontal gyri, but he failed to induce any speech defect. The patients were demented, with verbal delusions and logorrhœa.

Marie maintains further that all patients with aphasia are mentally deficient; thus, the cook can no longer compound an omelette, and the pianist can no longer play the piano. He locates all the speech functions diffusely in the left temporoparietal region, maintaining that this is merely a region of intelligence specialized for language, and not a storehouse of sensory images; a mild lesion destroys the function last acquired, viz., reading, and 1 a severer lesion produces loss of voluntary speech and of recognition of spoken language as well. What Marie calls " anarthria"-a word previously used in another sense-meaning loss of the power to utter speech, although the individual can say the words over to himself, is due to a lesion in "the quadrilateral," bounded in front and behind by the anterior and posterior limiting sulci of the island of Reil, internally by the wall of the lateral ventricle, and externally by the surface of the island of Reil. In most cases of so-called Broca's aphasia, both the temporal cortex and the "quadrilateral" are injured.

Defenders of the classical view, Dejerine in particular, have replied by advancing fresh cases with 
a lesion in Broca's gyrus with aphasia resulting; they contend that Marie's "quadrilateral " contains the projection fibres of the third frontal convolution, which in their view explains the anarthria ; and they maintain that most of the fifty-seven cases of aphasia in which Broca's convolution was intact were associated with much defect in understanding language spoken or written, and that the lesion was one of the dominant auditory word centre in the temporal lobe, without which Broca's convolution cannot work.

If it were proved that in cases of apraxia, previously referred to, the lesion was in the first frontal convolution for the legs, and in the second frontal for the arms, the location of speech just in front of the motor centres for the face and mouth would receive strong support by analogy, but all this is still very uncertain.

To sum up, we may express current opinion by accepting the existence of a large diffuse centre in the left temporo-parietal region in which recognition of spoken and written language and " internal speech " take place; when it is seriously damaged these are all lost and the intelligence is impaired. Whether there is a special departure platform in Broca's convolution for uttering speech is uncertain, but probably there is. Lesions of the projection fibres from the cortex ( (?) of Broca's convolution) will cause " anarthria," that is, loss of external but not of internal speech.

Practical deductions are not to trust aphasia as conclusive localizing evidence of a lesion in the left 
third frontal gyrus, but rather to look to the temporal region, especially if there is any defective appreciation of what is said or written. Moreover, we receive encouragement that there is no need to fear that small cortical injuries inflicted by the surgeon will cause aphasia; subcortical injuries are much more likely to do so, by cutting off projection fibres.

\section{MISLEADING LOCALIZING SIGNS OF INTRA- CRANIAL TUMOUR.}

It is very disappointing when definite signs usually regarded as of importance in localization give colour to a diagnosis as to the position of a cerebral tumour, but on the operation table nothing is found in that region. It is more than disappointing, because unsuccessful attempts to find the tumour are more fatal than actual removals. Some study therefore of the physiology of the production of misleading signs may be useful.

The principal traps are furnished by the following :

I. Cranial Nerve Palsies.-Paralysis of one or both sixth cranial nerves is quite common, and by no means proves that the nerve itself or its nucleus is involved in the lesion. It has been accounted for by stretching, due to a supposed backward displacement of the whole brain late in the development of a growth; the abducent nerves run straight forwards and are slender, so the first sign of the displacement is a convergent squint.

Other cranial nerves, including the third, fifth, seventh, and eighth, are occasionally affected by displacements of the brain or by pressure. 
2. Localized or General Convulsions.-Mistakes are particularly apt to arise if the fit starts in some definite area, follows a slow and orderly march to other areas, and perhaps affects only one side, consciousness being lost late if at all (Jacksonian epilepsy). It must, however, be remembered that all this may occur without any obvious cortical lesion; indeed, the commonest cause of a localized convulsion is ordinary idiopathic epilepsy.

Again, localized or general convulsions may give a wrong impression when arising late in the course of an intracranial tumour or abscess, especially if it presses on the ventricular system of the brain and dams back the cerebrospinal fluid, causing hydrocephalus. The accumulation of fluid in one or both lateral ventricles stretches the overlying cortex, and may give rise to fits, sometimes of a Jacksonian type.

3. Bilateral Spastic Paresis. - In many cases a hint is given of the true nature of these seizures, by the presence of a slight degree of bilateral spastic paresis, with clumsiness of movement, exaggerated reflexes, extensor plantar response, and a little rigidity.

Of course, if this should chance to be associated with paralysis of a cranial nerve, such as the sixth, the temptation to diagnose a lesion of the pons would be very great. Fortunately, this would not be of much surgical importance, as the pons is not an accessible structure. Pontine tumours are often unilateral, and optic neuritis is usually absent; whereas in the class of cases we are now considering, optic neuritis is marked and old-standing, and there 
is a long history of headache, vomiting, or other signs, previous to the development of spasticity or cranial nerve palsy.

In other cases, misleading localizing signs may arise from patches of secondary thrombosis, spreading œdema, or meningitis; but none of these are common.

The suspicious feature about all the signs here mentioned is their late development. Localizing symptoms appearing when headache, vomiting, optic neuritis or other evidences have been present for months or years are little to be trusted. Early localizing signs, on the other hand, are trustworthy in the main.

A few words may be said about the significance of ataxia. This is of course evidence of a lesion of the cerebellum, but it may be seen in other conditions also. Putting aside ataxia due to affections of the labyrinth, Friedreich's ataxia, and other general nervous diseases, it may also be caused by a tumour in the neighbourhood of the red nucleus in the isthmus, or in the pons.

\section{THE CEREBROSPINAL FLUID.}

This fluid is clear, watery, and of low specific gravity; it contains almost no albumin, but some sugar. Until recently this reducing substance was thought to be a pyrocatechin body. It contains no cells in health, nor does it contain the antitoxins, opsonins, or alexins which are present in plasma, lymph, and most serous fluids. This explains the great liability to septic meningitis after injuries to or operations on the central nervous system. As 
urotropin is excreted into the cerebrospinal fluid when given by mouth, it may usefully be administered to prevent septic complications such as the above, or following on suppurative otitis media. Some success is already claimed for this procedure.

The fluid is secreted by the choroid plexus into the lateral and third ventricles; it passes by the Sylvian aqueduct into the fourth ventricle, escapes by the foramina in the roof into the subarachnoid space, and is absorbed, partly by the aid of the Pacchionian bodies, into the superior longitudinal sinus and other veins. Hydrocephalus is produced by blocking of the foramina in the roof of the fourth ventricle. If an exit is provided, large quantities of cerebrospinal fluid may be lost daily.

Lumbar puncture is a very valuable aid to diagnosis in various forms of meningitis, parasyphilitic affections etc., and the fluid may be blood-stained after cerebral hæmorrhage or injury. It is also valuable in treatment as a means of reducing intraspinal and intracranial pressure, particularly if the trouble lies below the tentorium.

\section{REFERENCES.}

CUSHING AND BORDLEY.- " Observations on experimentally induced choked disc." Bulletin Johns Hopkins Hospital, r909, Xx., p. 95 .

Horsley.- "Optic Neuritis." British Medical Journal, I9ro, i., p. 553.

HORSLEY AND CLARKE.- " The structure and functions of the cerebellum." Brain, r9o8, xxxi., p. 45.

Thiele.- " The optic thalamus and Deiter's nucleus." Journ. of Physiology, r905, xxxii., p. 358.

Allen Starr.- "Tumours of the acoustic nerve." Amer. Journ. of Medical Sciences, Igro, cxxxix., p. $55 \mathrm{r}$. 
Bergmark. - "Cerebral monoplegia." Brain, 1909, xxxii., P. 342 .

Cushrng. " A note on faradic stimulation of the postcentral gyrus in conscious patients." Brain, 1909, xxxii., p. 44 .

Wilson.- "A contribution to the study of apraxia." Brain, 1908, xxxi., p. 164.

Collrer.- "Recent work on aphasia." Brain, 1908, xxxi., P. 523 .

Collier. " The false localizing signs of intracranial tumour." Brain, 1904, xxvii., p. 490. 


\section{CHAPTER XII. \\ THE ACTION OF CUTANEOUS ANÆSTHE'TICS.}

Local anæsthetics given hypodermically; cocaine, novocain, eucain, stovain.-Drugs applied to the unbroken skin; opium, belladonna.-Counter-irritants; the theory of their action.

7 HE drugs which may be used as local anæsthetics 1 and analgesics fall into three groups. Some of them are commonly given by hypodermic injection beneath the skin, although they may be painted or sprayed on mucous membranes with satisfactory results. Here we put cocaine and its derivatives, eucain (more precisely, $\beta$-eucain lactate), novocain, stovain, and tropocaine.

In another group we place the drugs which are applied to the unbroken skin in the form of ointments, liniments, and plasters, including preparations of belladonna, opium, aconite, cocaine, and menthol.

In the third group we place the drugs which are not credited with any local anæsthetic action, but which are classed as counter-irritants. This is an immense collection; it comprises all the volatile oils, especially mustard, camphor, and turpentine, also such substances as alcohol, iodine, cantharides, and ammonia. The thermo-cautery is not a drug, but its action calls for similar interpretation. 


\section{LOCAL AN ESTHETICS GIVEN HYPODERMICALLY.}

We have to compare in this group the value of cocaine, novocain, eucain, and stovain. A luminous report was published on these by a Committee of the British Medical Association in Igog. The ideal local anæsthetic should have the maximum power to relieve pain, it should not be toxic, it should not irritate the tissues, and it should be capable of sterilization by boiling.

The table below gives the comparison of these four drugs at a glance.

\begin{tabular}{|c|c|c|c|c|}
\hline Drug & $\begin{array}{l}\text { AN.fSTHETIC } \\
\text { POWER }\end{array}$ & Toxicitr & $\mid \begin{array}{c}\text { EPFECT ON } \\
\text { TISSUES }\end{array}$ & $\underset{\text { BoILING }}{\text { EFFect of }}$ \\
\hline Cocaine & Powerful & Most toxic & Rather & Spoiled \\
\hline Eucain & Powerful & & $\begin{array}{l}\text { Very } \\
\text { irritant }\end{array}$ & No effect \\
\hline Stovain & $\begin{array}{l}\text { Most power- } \\
\text { ful }\end{array}$ & & $\begin{array}{l}\text { Very } \\
\text { irritant }\end{array}$ & No effect \\
\hline Novocain & Powerful & Least toxic & $\begin{array}{l}\text { Not } \\
\text { irritant }\end{array}$ & No effect \\
\hline
\end{tabular}

It will be seen that novocain is the most satisfactory, and cocaine the least so. It is common knowledge that cocaine, like chloral, is very variable in its effects on different people, and a safe dose for one is fatal for another. With some patients the margin of safety between a dose that produces no effect at all and a dose that causes alarming symptoms is exceedingly narrow. The symptoms, again, vary widely.: Some get headache, others 
vomiting, and yet others fainting and collapse. Fatal cases have often occurred even after moderate doses, and it is never safe to give more than a quarter of a grain of cocaine unless the patient has had it before.

Most surgeons will doubt if eucain is really as powerful an anæsthetic as cocaine, but in its main details the correctness of the above table has been abundantly demonstrated by many independent observers.

Mr. Barker, and others following his example, have claimed great advantage from combining adrenalin with the cocaine or its derivative. The suggestion is that the vasoconstriction induced keeps the cocaine from being carried rapidly away by the circulation. Thus we increase the local effect, which is desired, and diminish the general or systemic effect, which is not desired. There is no doubt that the method is often most efficacious, but adrenalin is a powerful agent, and occasionally it seems to be responsible for alarming collapse.

Whatever drug or combination of drugs is used for hypodermic injection as an anæsthetic for operative purposes, it is of cardinal importance that it should be correctly given, and an extraordinary number of surgeons do not appear to know how to secure a good result. Again and again one sees cocaine injected, and one can foretell with certainty that the patient will scream with pain when the incision is made. In another case half the dose gives a perfect anæsthesia. The whole point is that the sensitive nerve-endings are not in the subcutaneous 
fat, but in the cells of the Malpighian layer of the skin, and the injection must be made into the skin, not into the fat. When the anæsthetic has been properly given, the skin will be white, and will present a flat-topped infiltration with a sharp edge, like that which is so characteristic of erysipelas. To make a satisfactory intradermic injection a small hypodermic syringe is seldom good enough. One needs a powerful syringe with a fine needle. An antitoxin syringe does excellently.

\section{DRUGS APPLIED TO THE UNBROKEN SKIN.}

It has been customary to relieve abdominal pain by the application of hot fomentations containing opium, to treat sprains and bruises with lead and opium, and to smear on glycerin of belladonna for the discomfort of white leg. What dyspeptic old lady has not worn a belladonna plaster over her heart, and what practitioner has not prescribed a belladonna liniment for vague aches and pains? The rationale of the treatment has been that belladonna, opium, and menthol are alleged local anæsthetics, and it is further supposed that they are absorbed by the unbroken skin. The truth is that they are not local anæsthetics, and that they are scarcely if at all absorbed through the unbroken skin. Neither aconite, cocaine, carbolic acid, belladonna, nor opium has any power to relieve pain when applied to the unbroken skin.

It has been well said that "You have not proved a lie to be a lie, until you have shown how it came to be believed." This is very true in science, and 
especially in medical science. The use of belladonna and opium to relieve local pain was an obvious deduction from their great power, when given by the mouth, to relieve general pain by inducing sleep or allaying colicky contractions. In the case of belladonna and its alkaloid atropine, the fallacy was the more natural in that they have a very genuine effect in paralysing nerve-endings, but, unfortunately, it is only the nerve-endings in glands and unstriped muscle that are paralysed, not the sensory twigs in the skin.

The fallacy has been maintained by the practice of combining these drugs with other and more potent treatment; thus, belladonna is given with counterirritants such as camphor or alcohol; warmth may be applied with the opium; friction helps the belladonna liniment to make a reputation, and even the support of the strapping, with counter-irritants in it, assists the patient to believe in the value of a belladonna plaster.

We may go one step further, and say that the application of opium and belladonna to mucous membranes is equally futile. There is no evidence that opium suppositories after the operation for piles, or laudanum dropped into aching ears, have any direct local effect. Of course, morphia may be absorbed from the suppository, but in that case it presents no advantage over a dose given by mouth or hypodermically, and is less certain in its action.

To sum up, there is no drug in common use capable of acting as an anæsthetic on the unbroken skin, except ether and ethyl chloride, which freeze it, and 
the only drugs which relieve deep-seated pain when painted on or rubbed into the skin are the counterirritants.

Full details of the experimental data for these conclusions, which are accepted by the leading pharmacologists, will be found elsewhere. Briefly, the methods adopted were as follows.

Strong, even dangerously strong solutions and ointments containing opium, atropine or belladonna, aconite, cocaine, carbolic acid, and menthol were tested on the skin of the finger, and on the tongue, and these were then examined to see if their sensibility was in any way altered. The methods of examining the skin of the finger were as follows. Each test was applied on more than one observer and after varying intervals of time.

I. The Intolerable Temperature Test.-For each observer there was a certain constant temperature which was just not intolerably hot, when the finger was dipped into warm water for half a minute. This was determined before and after applying the drug under consideration.

2. The Faradic Pain Test.-The strength of current was determined, before and after the application of each drug, at which the damp finger first found electrical stimulation by means of electrodes led off from a faradic coil actually painful, the current used being small at first and gradually augmented.

3. Thermal Discrimination Test.-We found that we were able, by immersing the finger first in one beaker of warm water and then in another, to detect a difference in temperature of not less than one degree. 
This was tested before and after the application of each drug.

4. General Testing by means of a pin point, the æsthesiometer, a wool pencil, etc., was also used. In testing the sensibility of the tongue, we used the faradic pain test as described above; we examined thermal discrimination by applying warm metal points at various temperatures ; we used the æsthesiometer, and studied the effect of the drugs on taste.

Judged by these standards, the various drugs fared as follows:-

Opium.-A 5 per cent solution of morphine tartrate in water had no effect on skin or tongue.

Belladonna.-Very strong liniments had no anæsthetic effect. Indeed, if they had, the drug could be used instead of cocaine for eye surgery. The only sign we could obtain was diminution of sweating over the skin area treated. There was no flushing or blanching of the skin or mucous membrane.

Aconite.-Neither the B.P. liniment nor ointment had any effect on the skin. Solutions produced tingling of the tongue, but we were not quite confident whether there was or was not a little reduction in sensibility.

Cocaine.-Strong ointments and alcoholic solutions had no effect on the unbroken skin. Of course, if the skin is broken, the effect is marked. A ro per cent solution applied to the tongue produced considerable reduction of sensibility, by all our tests.

Menthol produces a curious stimulation of the nerve-endings which detect cold, as is well known. A discussion of its other actions would lead us too 
far, but any anæsthetic effect is purely that of a counter-irritant.

Carbolic Acid rather increases the sensitiveness of the finger to painful stimuli. Its undoubted value in relieving toothache is due to its caustic action in destroying irritated nerve-endings. The numb feeling we get after prolonged soaking in I in 20 carbolic is due to the formation of a thin coating of killed epidermis over the hands.

The fact that even cocaine, which is thoroughly proved to paralyse sensory nerves, fails to produce the slightest effect when a ro per cent solution in alcohol, or a ro per cent ointment made with lanolin is rubbed into the skin, is strong evidence that little if any of these alkaloids reaches the nerve-endings at all. Atropine finds its way into the sweat ducts sufficiently to reduce but not to abolish sweating by its action on the sweat glands.

It may be objected that there is sufficient clinical evidence of benefit from these drugs to defy negative results by experimental methods, but any who claim this must not confuse the issue by combining the belladonna or opium with camphor, heat, rest, or strapping. Again, it may be suggested that atropine, at least, has some vasomotor effect, but we failed to observe any, and indeed we doubt if it ever reaches the blood-vessels when rubbed into the unbroken skin.

It is a thankless task to pull down strongholds of belief, but it is necessary if only to direct more attention to the true means of giving relief to pain, including general drug treatment, rest, massage, counter-irritation, heat, and passive hyperæmia. 
Moreover, a recognition of the failure of drugs saves useless expense, and may banish from patients' houses some of the commonest of powerful poisons. Belladonna liniment, for instance, has been responsible for an immense number of alarms, illnesses, and even fatalities.

\section{COUNTER-IRRITANTS.}

In order to have a clear conception of the subject before us, let us take three illustrations of the use of counter-irritants: (I) The application of diluted tincture of capsicum to the loin for lumbago; (2) Rubbing in soap liniment for a painful sprained ankle; and (3) Putting a blister behind the ear for earache.

These are old and tried remedies; have we any evidence of their value; and if so, how do they act? Why should an irritation of the cutaneous nerveendings make any difference to the sensations received from deep fasciæ, synovial membranes, or the middle ear?

No one can deny the great relief given by the above measures. The effect of the first is often marvellous, to which some of us can bear personal testimony. The liniments and other applications mentioned in the group we have just considered have traded for their reputation on the counter-irritation they produced. We have the analogous means of relieving pain, the use of hot fomentations and of the thermo-cautery, waiting for an explanation on similar lines.

Before considering why counter-irritants relieve 
pain, we should first inquire why inflammation is painful; in what way do the vascular and other changes that take place in inflamed areas irritate nerve-endings? It cannot be merely by the flushing with blood, because Bier's bandage greatly increases this, and yet relieves pain. It may be by the chemical irritation produced by the toxins, or more probably by stretching of nerve-endings owing to the swelling up of the tissues with inflammatory exudate. That stretching will cause acute pain is shown by its occurrence in colic. Dropsy is not painful, because in that condition the fluid passes out passively where the resistance is least, as in the subcutaneous tissues; whereas inflammatory exudation is an active process affecting all the tissues involved in the inflammation, even when they are tense and full of nerves.

It seems strange to claim that vascular dilatation should relieve such a condition. Would it not rather add to the painful tension? In unyielding structures this may be true; the general vasodilatation and falling blood-pressure just as we go to sleep will exaggerate the aching of chronic bone inflammation. But we must consider how the painful exudation of plasma into all the interstices of the tissues is to be removed; it can only be by increasing the lymph flow, by increasing the absorption of fluid by the venules, and by washing away the toxins which set up the exudation. To increase the lymph flow, the part must be elevated and a better " head" of water provided by vasodilatation. To increase absorption by the blood-stream, there must be vasodilatation. 
To carry off and dilute toxins, again, there must be vasodilatation. It is true that in the early stages, before any quantity of exudate has been poured out, and where the cause of the trouble is mechanical injury, not bacterial toxins, the vasoconstriction obtained by cold may prevent the increase of the fluid in the tissues. But when the outpouring has already taken place, we need some means of inducing vasodilatation.

We need not explain how heat and Bier's bandage will produce this effect, but at once turn to ask why putting irritants on the skin can cause vasodilatation in the deeper parts.

Each segment of the spinal cord, medulla, pons, and isthmus receives sensory impulses from the skin, and also from a viscus. Messages from the former we can localize accurately. Messages from the latter the segment cannot localize at all, but we know vaguely that the discomfort is in the visceral area which is innervated from that segment. Misinterpretations are common, and consequently there may be incorrect localizing of a pain, and tenderness of the corresponding skin area when really the viscus is at fault. To quote a few instances, earache without deafness is usually due to a carious lower back molar; skin tenderness of the right eleventh dorsal area is associated with commencing appendicitis; and painful affections of the ovary or testis may cause girdle pain in the tenth dorsal area. The liver, heart, and stomach all have their areas of referred pain. Dr. Head has published much research on these topics. 
Irritation of the cutaneous nerves by iodine, camphor, cantharides, menthol, or heat will be interpreted by the spinal segment as a call for local vasodilatation, and in responding to the appeal more blood is supplied not only to the skin area but also to the corresponding viscus. As we have seen, the better blood-supply will give some relief, if such relief is possible, to the pain. This is the theory of counter-irritation.

The practical corollary is that our counter-irritants should be those having a powerful and prolonged effect on the cutaneous nerves.

\section{REFERENCES.}

Report of B.M.A. Committee. British Medical Jowrnal, (i.), 1909, p. 783 .

A. Rende Short and Walter Salisbury, British Medical Journal, I9IO, (i.), p. 560. 


\section{APPENDIX. \\ URINE ANALYSIS IN CASES FED BY NUTRIENT ENEMATA.}

I AM given kind permission to set forth the following unpublished observations by $\mathrm{Dr}$. R. E. Thomas on patients under Dr. Nixon in the Bristol Royal Infirmary.

CASE I.-L. W., a girl aged 22, was admitted for hæmatemesis on Nov. 9, I909, and was treated with nutrient enemata consisting of $4 \mathrm{oz}$. of milk with one egg peptonized for twenty minutes, given every four hours. One to two pints of saline were also given daily by the rectum, and the bowel was washed out every morning. Nothing was given by mouth, except a little ice, until Nov. 22.

The urea was estimated by the hypobromite method, the ammonia nitrogen by the formalin method, and diacetic acid and acetone by the tests described in Chapter VII. (See Table, pp. I88, I89).

CASE II.-M. H., a girl aged 20, was admitted for hæmatemesis on June I, I909. The treatment was exactly as in Case I., but no analyses of the urine were made until June 19 , on which day mouth feeding began as well as the nutrients, which latter went on till July 7 . (See Table, p. r9o). 


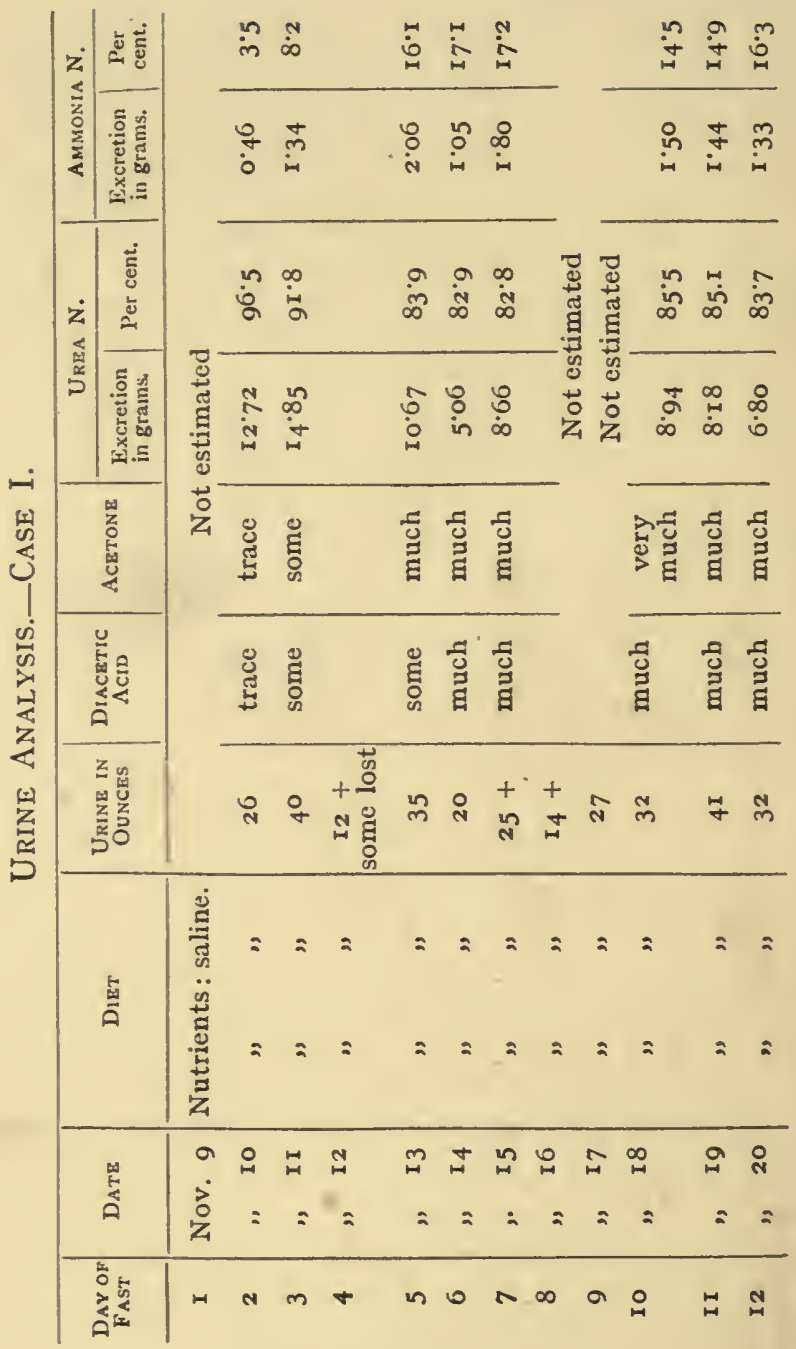




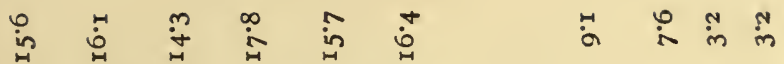

营

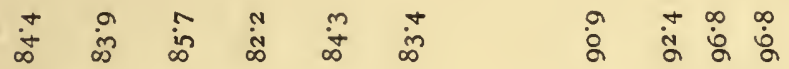

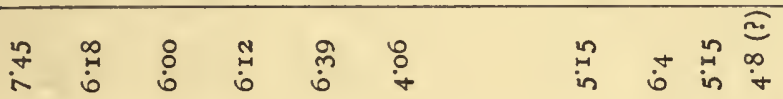

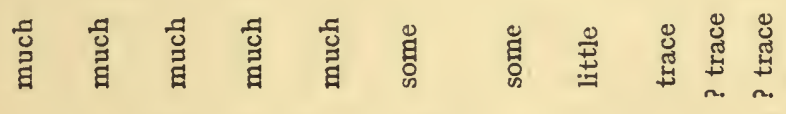

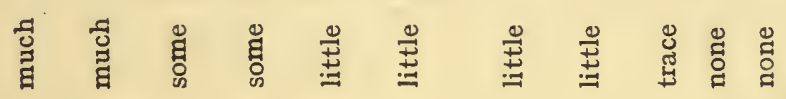

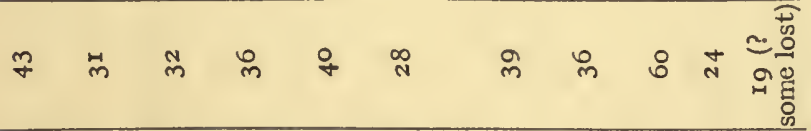

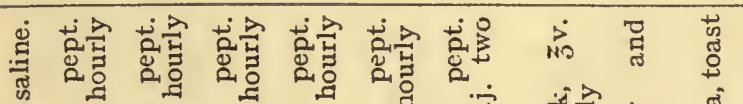

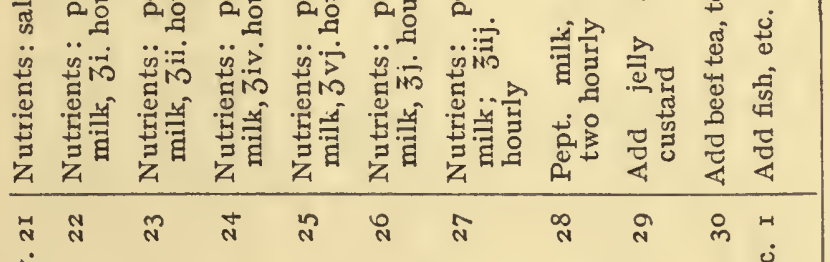

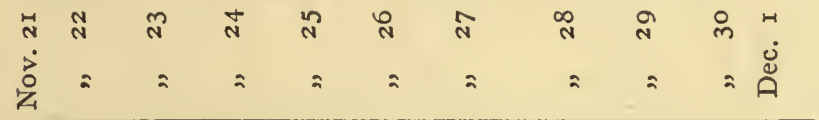

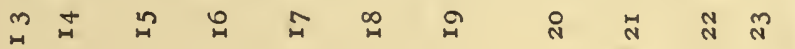




\begin{tabular}{|c|c|c|c|c|c|c|c|}
\hline$z$ & ڤ્ّ & $\stackrel{\sim}{\mathrm{\sigma}}$ 요 & $m_{i n}^{m}$ in & $\stackrel{N}{n=}$ & & $\infty$ & 0 \\
\hline z & 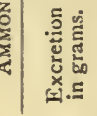 & 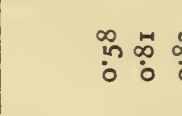 & $\begin{array}{l}\text { Nं } \\
\text { in } \\
0\end{array}$ & $\sim \alpha$ & & 8 & \\
\hline & 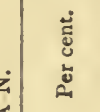 & $\dot{\infty} \infty$ & $\stackrel{\sim}{\dot{\sigma}} \stackrel{\sim}{\infty}^{n}$ & $\begin{array}{ll}\infty & 0 \\
\dot{N} & \vdots \\
\infty & 0\end{array}$ & & ชู & אै \\
\hline 2 & 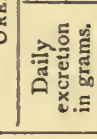 & 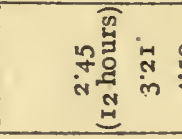 & $\begin{array}{ll}\text { n } & \text { mे } \\
0 & \text { in }\end{array}$ & $\sim$ & $\stackrel{m}{i}$ & $\begin{array}{l}\infty \\
\vdots\end{array}$ & \\
\hline & 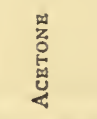 & 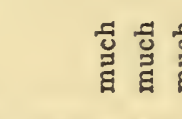 & 兘 : & 巳 & ๕્ & 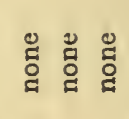 & 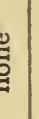 \\
\hline & 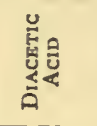 & 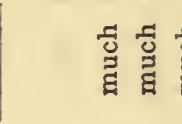 & 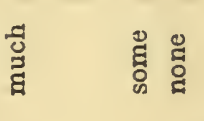 & : & ๕્ّ & $\begin{array}{l}\text { 巳 : } \\
\text { : } \\
\text { 임 }\end{array}$ & \\
\hline & 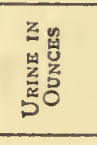 & 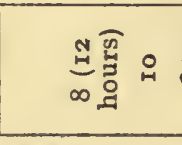 & สิ & 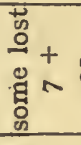 & 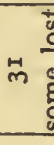 & $\begin{array}{l}0 \\
0 \\
0 \\
0 \\
0\end{array}$ & 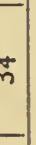 \\
\hline & 氙 & 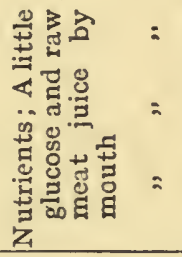 & 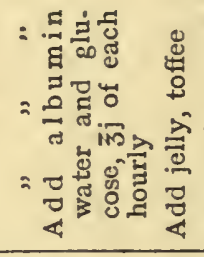 & 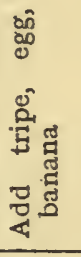 & $\begin{array}{l}= \\
= \\
=\end{array}$ & $\begin{array}{l}== \\
==2 \\
==2\end{array}$ & $\begin{array}{l}= \\
= \\
=\end{array}$ \\
\hline & $\stackrel{\text { 量 }}{\stackrel{4}{厶}}$ & 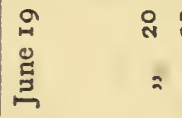 & $\begin{array}{l}\stackrel{M}{N} \\
=:\end{array}$ & $\begin{array}{l}+ \\
=\end{array}$ & $\begin{array}{l}\stackrel{\text { ก }}{2} \\
=\end{array}$ & $\begin{array}{l}\text { กิ } \\
=\alpha=\end{array}$ & \\
\hline & 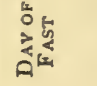 & 우: & M & ते & $\tilde{n}$ & ำ ล & \\
\hline
\end{tabular}


COMPARISON WITH CASES OF STARVATION.

(a). The Nitrogenous Output.-We may institute comparisons either with analyses of the urine of professional fasting men, or of patients suffering from hæmatemesis treated by saline or saline with glucose.

(The following figures are taken from von Noorden's "Metabolism," vol. ii., pp. 7, 33.)

Total Output of Nitrogen, in Grams.

\begin{tabular}{|c|c|c|c|c|c|}
\hline \multirow{2}{*}{$\begin{array}{l}\text { DAY OF } \\
\text { FAST }\end{array}$} & \multicolumn{2}{|c|}{ Fasting Men } & \multicolumn{2}{|c|}{$\begin{array}{l}\text { GirLs with Gastric } \\
\text { ULCERS }\end{array}$} & \multirow{2}{*}{$\begin{array}{l}\text { Aprroximate } \\
\text { AVERAGE }\end{array}$} \\
\hline & Succi & Cetti & Case I & Case II & \\
\hline I & I $3 \cdot 8$ & $13: 5$ & $9 \cdot 2$ & Io:36 & $\operatorname{II} 7(\quad)$ \\
\hline 2 & II'O & $12 \cdot 6$ & I I'5 & $9^{\circ} 53$ & II.I $\left(13^{\prime} 2\right)$ \\
\hline 3 & 13.9 & I $3 \cdot 1$ & $8 \cdot 0$ & $9 \cdot 38$ & $I I \cdot I(I 6 \cdot 2)$ \\
\hline 4 & $12 \cdot 8$ & $12 \cdot 4$ & & $9 \cdot 82$ & II.6 ( ) \\
\hline 5 & I $2 \cdot 8$ & 10.7 & $5^{\circ} 4$ & $7 \cdot 4^{8}$ & $9^{\circ} \mathrm{I}(12 \cdot 7)$ \\
\hline 6 & IO'I & IO'I & $3 \cdot 16$ & & $7 \cdot 8(6 \cdot I)$ \\
\hline 7 & 94 & I0.9 & $2 \cdot 69$ & & $7^{\circ} 7\left(\mathrm{IO}_{4} 4\right)$ \\
\hline 8 & $8 \cdot 4$ & $8 \cdot 9$ & & & $8 \cdot 6(\quad)$ \\
\hline 9 & $7 \cdot 8$ & 10.8 & & & $9.3(\quad)$ \\
\hline Io & $6 \cdot 8$ & $9 \cdot 5$ & & & $8 \cdot \mathrm{I}\left(\mathrm{IO}^{\circ} 4\right)$ \\
\hline I I & $7^{\circ} 9$ & & & & $7^{\circ} 9\left(9^{\circ} 6\right)$ \\
\hline I 2 & $7^{\circ} 2$ & & & & $7^{\circ} 2(8 \cdot 1)$ \\
\hline I3 & 3.5 & & & & $3.5(8.8)$ \\
\hline I 4 & $5 * 3$ & & & & $5 \cdot 3\left(7^{\circ} 2\right)$ \\
\hline I5 & $5^{\circ} \mathrm{I}$ & & & & $5^{\circ} \mathrm{I}\left(7^{\circ} \mathrm{O}\right)$ \\
\hline I6 & $5^{\circ} 5$ & & & & $5^{\circ} 5\left(7^{\circ} 4\right)$ \\
\hline 17 & $6 \cdot 2$ & & & & $6 \cdot 2(\quad)$ \\
\hline I 8 & $5^{\circ} 5$ & & & & $5 \cdot 51$ \\
\hline I9 & $5 \cdot 5$ & 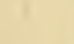 & 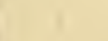 & & 5.51 \\
\hline 20 & 44 & & & & $4^{\circ} 41$ \\
\hline $2 \mathrm{I}$ & $3 \cdot 9$ & & & & 3.91 \\
\hline
\end{tabular}

The figures in brackets are the Urea $\mathrm{N}+$ Ammonia $\mathrm{N}$ of Case I, at the Bristol Royal Infirmary. 
It will be seen that there is a slight but constant improvement on the average when nutrients were given, which would be still more evident if the total nitrogen had been estimated in the Bristol cases instead of the urea and ammonia, though of course these together account for about 96 per cent of the total nitrogen.

In the second Bristol case, the figures are a trifle better than Succi's, but she was taking a little meat juice by mouth. It is very noteworthy that the urea output does not increase for several days after mouth feeding is started again.

(b). Carbohydrate Absorption.-This may be estimated by the relation of ammonia nitrogen to urea nitrogen, and also by the output of diacetic acid and acetone. It will be seen in the Bristol cases that acetone and diacetic acid rapidly increased in quantity until feeding by the mouth was commenced, when they passed away. The normal 5 per cent of ammonia nitrogen also rose to a high figure during rectal feeding, but soon became normal when food was given by mouth. Two comparisons may be instituted. The first compares Succi with Case I.

\section{AMmonia Nitrogen.}

$\begin{array}{ccccc}\text { Period of Fast } & & \text { Succi } & & \text { Bristol Case I } \\ \text { I-5 days } & - & 12 \% & - & 9 \% 3 \% \\ 6-10, & - & 12 \% & - & 16.3 \% \\ \text { II-15 }, & - & 17 \% & - & 15.4 \% \\ \text { I6-20", } & - & 31 \% & \text { (feeding commenced) }\end{array}$

The second compares the average of nine girls treated for gastric ulcer by simple starvation with the Bristol Case I. 


\section{APPENDIX}

Ammonia Nitrogen.

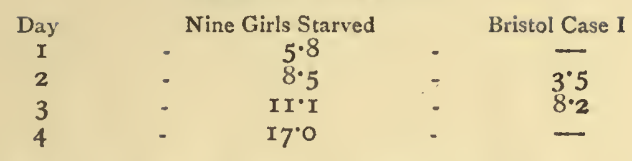

To sum up, it may be contended that nutrient enemata in both cases seemed to yield the body a small but very inadequate quantity both of protein and carbohydrate, but much more extensive observations are called for. It would be best to analyse the urinary nitrogen by Kjeldahl's method, which is of course a lengthy procedure.

NoTE.-Since the above was written, Langdon-Brown has contributed some important analyses showing how little nitrogen can be absorbed from nutrient enemata. (Proceedings Royal Society of Medicine, Pharmacological Section, I9I.) 
Chart comparing the OUtput of Nitrogen in Two Cases fed by Nutrient Enemata at the Bristol Royal Infirmary, and Average of Fasting Cases.

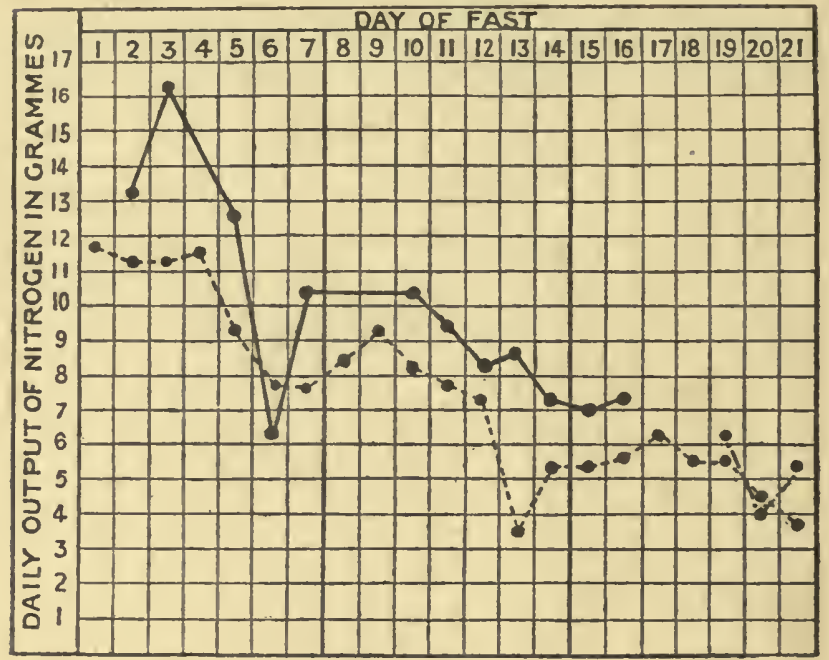

Case I. Case II.

..... Average of Fasting Cases. 


\section{N D E X}

PAGE

ASORPTION in the colon 52

A - of proteins .. .. 46

Acetonæmia after chloroform I20

- conditions in which seen .. 97

- treatment of .. ..

Acetone in urine normally .. $9^{8}$

- - test for .. .. . . Iog

- origin of, from fat $\quad \ldots \quad 98$

Acid dyspepsia of infants ... 38

Acids in dyspepsia .. . . 3 I

Acidosis after chloroform ... I20

- conditions in which seen ... 97

一 in diabetes .. .. .. I08

- pathology of $\quad$.. $\quad \ldots$ IOI

- treatment of ... .. 108

Aconite as local analgesic I78, I8I

Acromegaly .. .. .. 2 I

- treatment of $\quad$.. $\quad$.. 25

Addis on hremophilia ... .. 73

Addison's disease, blood-pressure in .. $\quad . . \quad \ldots 66$ I

Adenin ... $\quad \ldots . \quad \ldots . \quad \ldots .84$

Adiposity from removal of pituitary gland

20,22

Adrenalin, infiuence on blood. pressure

- toxic symptoms from

- transfusion for shock ..

- useless in hæmoptysis ..

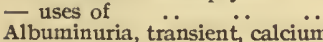
salts for

Alcohol, effect on digestion ${ }^{-30,32}$

- in shock .. .. .. 63

Alkalies, effect on digestion ... 30

Amino-acids ... .. .. 47

Ammonia nitrogen, variations

in $\quad \ldots \quad \ldots \quad 103,187$

Amputations, injecting nerves with cocaine before.

Amyl nitrite for hæmoptysis

Anasthesia, testing for .

Anæsthetics, local, how to use

Anderson and Langley on regeneration of nerve ..

Anterior horn cell changes after division of posterior

nerve-roots $\quad . \quad$.. I39

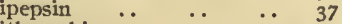

Antithrombin ... $\quad \ldots \quad \ldots 70$

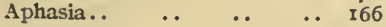

Appendicitis, hyperchlorhydria with $\ldots$... ..

Appendicostomy ... ... 36

Appetite juice $\quad$.. $\quad \ldots .28$

Apraxia.. $\quad \ldots \quad \ldots \quad \ldots \quad$ I64

A taxia, cerebellar .. ... I54

- not always cerebellar ... I72

- from division of posterior nerve-roots .. .. 138

Atheroma in cretin animals .. 5

- and myxœdema .. ... I3

Atropine for chloroform poisoning ... .. .. II8

Auditory nerve, tumours of ... I56

- word centre .. .. I66

Baldwin, Helen, on oxaluria ..

Ballance and Stewart on regeneration of nerve $\quad \ldots \quad 120$

Ballance on ncrve anastomosis 136

Barany on nystagmus .. I 55

Barker on local anresthesia .. I77

Barnard and Hill's sphyginometer ... .. .. 57

Baumann on thyroid $\ldots \quad$... $\quad 56$

Bayliss and Starling on secretin 42

Belladonna as local analgesic

I78, I8I

Bergmark on cerebral cortex

I59, I6I

Bethe on regeneration of nerve ${ }_{3} \mathbf{I}$

Bile .. .. .. .. 45

Billroth on tetany from thyroidectomy $\quad$.. $\quad$.. 3

Bismuth feeding to map out stomach $\quad \ldots \quad \ldots \quad 32$

Bitemporal hremianopsia $\quad$.. 22

Bitters, effect on digestion ... 30

Blood-clotting .. . . . . 69

Blood-pressure, arterial .. 57

- capillary, how measured .. 58

- normal .. $\quad$.. .. 58

- venous, how measured ... 58

- instruments for measuring 57

— falls during sleep .. .. 65

- in surgical shock .. . . 62

- influence of respiratory movements on.. $\quad$.. 59

- lowered by chloroform ... II9

- raised by intracranial pressure .. .. . 
Blue blindness in cerebral PAGE tumour .. $\quad . . \quad \ldots \quad I 52$

Bode on operations on the pituitaty gland ..

Bordley and Cushing on choked disc ... .. ..

$\beta$-oxybutyric acid, origin of from fat $\quad \ldots \quad \ldots 98$

- - in urine, test for $\quad .$. rog

Brain, circulation in ... $\quad . .64$

- localization of sensation in 157

Broca's convolution ... $\quad . . \quad$ I 66

Broths and gastric juice .. 29

Brown, Langdon, on nutrient enemata

Brown on parathyroid grafting I6

Brown-Séquard phenomenon I 43

Bulloch on hæn ophilia .. 72

Burckhardt on removal of speech centres $\quad . . \quad$ I67

Burdach's tract $\quad . . \quad \ldots$ I $_{4}$ I

Cafferve, effects of $\quad . . \quad \ldots \quad 87$

Calctum oxalate in urine. .990

- salts for hæmophilia .. 77

- - in tetany .. $\quad 15,80$

- - treatment by .. .. 80

Calculi, laws governing formation of .. $\quad$.. $\quad$. 994

Calculus, prevention of $\quad$\begin{tabular}{l}
39,92 \\
\hline
\end{tabular}

Cameron on gastrojejuno-

Cancer, gastric, $\ddot{\mathrm{HCl}}$ deficient in $\quad 4 \mathrm{I}$

Cannon on skiagraphy of

Cannon and Murphy on peri-

capillary blood-pressure, how

32,40 measured ... $\because$

Carbolic acid as local anæsthetic

Cerebellar tracts

Cerebello-pontine angle, tümours of $\quad . \quad$.. 156

Cerebellum, lesions of $\quad \ldots \quad$ I52

Cerebral localization ... I50 et seq. _ tumour, blue blindness in 152

- - late signs misleading ... $\quad$ r72

- - misleading localizing signs of $\quad . . \quad$.. 170

- - optic neuritis in $\quad .$. I5I

Cerebrospinal fluid .. $\quad$.. $\quad$ I72

Chilblains, treatment of ... 80

Chloroform causing sudden death .. $\quad . . \quad \ldots$ II 6

- effects of overdose of .. II9

- poisoning, delayed $\quad \ldots 120$

- - treatment of .. $\quad . . \quad$ II8

- possible dangers of $\quad \ldots$ II 6
Choked disc, cause of ... PAGE

Chromatolysis of anterior horn cells .. $\quad$.. $\quad$.. 139

Clarke and Horsley on functions of cerebellum .. 152

Coagulation of blood, physiology of $\quad \ldots .$.

Coagulimeter $\ldots \quad \ldots \quad \ldots \quad$ 7o

Cocaine as local anresthetic

$$
\text { I75, 176, I8 } 1
$$

- injected into nerves to prevent shock

Cohnheim on pancreatic diabetes ... .. $\ldots \mathrm{I07}$

Collier on misleading signs of cerebral tumour .. I70

Colon, functions of $\ldots \quad \ldots \quad 49$

Coma, prolonged after chloroform $\quad . \quad$.. $\quad$. 120

Concretionary action..$\quad \quad \ldots \quad 94$

Concussion, blood-pressure after 66

- of the spinal cord .. $\quad$.. 147

- treatment of $\quad$.. $\quad$.. 66

Congenital goitre $\because 3,9$, ro

Convulsions in cerebral tumour I70

- localized $\quad . . \quad \ldots \quad$.. 171

Corpus callosum, tumours of.. I65

- Iuteum, secretion of $\because 43 \mathrm{n}$.

Cortex, localization of sensation in $\quad . . \quad \ldots . \quad \ldots \quad 157$

Cortical tumours, localization of $\quad . . \quad$ I6I, I 66

Cotter, Patrick, the giant ... 2 I

Counter-irritants, mode of action of $\quad \ldots \quad \ldots \mathrm{I}_{3}$

Cretin lambs $\quad . . \quad \ldots . \quad \ldots \quad 8$

Cretinism, experimental, in $\begin{array}{llll}\text { animals } & \text {.. } & \text {.. } & 5\end{array}$

- treatment of $\quad \ldots \quad$.

Crile on surgical shock $\quad \ldots \quad 6$ I

Cushing and Bordley on choked disc $\ldots . . . \quad 150$

Cushing on blue blindness .. 152

- on localization of sensation in cortex $\ldots \quad x_{57}, x_{59}$

- on removal of pituitary

Cyclical vomiting I8, 19, 20

Cystin origin of $\quad . \quad 98, x 00$

.. $\quad$. 93

Davis, O.C. M., on oxaluria .. 90

Deiter's nucleus, influence on tone $\quad . . \quad \ldots . \quad \ldots \quad$ I54

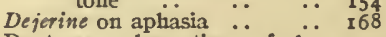

Dextrose, absorption of by

colon $\quad \begin{array}{llll} & \ldots & \ldots & 55\end{array}$

Diabetes, causation of $\quad \ldots \quad$ ro3

Diabetic coma, prevention of III

- - treatment of .. $\quad$.. 
PAGE

Diabetics, operations on ... III Diacetic acid, origin of, from fat 98 — - in urine, test for ... I Io Diagnosis of starvation $\quad . \quad \mathrm{IO}_{3}$ Diphtheria antitoxin for hæmophilia .. .. ..

Diuretic, pituitary extract as a Dixon on chloroform poisoning Dunlop on estimation of oxalates in urine ... ..

Dyspepsia, treatment by drugs 30

Edkins on gastric secretion ..

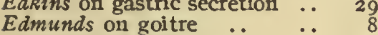

- - myxoedema $\ldots \quad \ldots 3,4$

- parathyroids .. $\quad . .4 \%$

- - tetany ... .. ..

Eiselsberg on experimental cretinism $\quad \ldots \quad \ldots 5, \mathrm{I}_{3}$

Enemata, nutrient $49,53,187,193$

Enophthalmos from thyroidectomy .. $\quad$. $\quad$.. 3

Epicritic sense.. $\quad$.. I23, I24

Erepsin $\quad \ldots \quad \ldots . \quad \ldots \quad 47$

Ergot useless in hæmoptysis.. 67

Eucain as local anresthetic $175, \mathbf{r} 6$

Exophthalmos from thyroid feeding ...

Exophthalmic goitre .. $\quad \ldots \quad$ r4

- - due to iodoform $\quad . . \quad 12$

Extractives and gastric juice 29

Fabre and Thevenot on congenital goitre .. .. ro

Facial palsy, treatment of $\quad$. $~ I 36$

- Fats cause pancreatic secretion

- inhibit gastric juice

Farecett on skeleton of a giant

Fenwick, Soliau, on hyperchlorhydria .. ..

Fibrinogen
Fischer on the protein molecule

- uric acid.

Forssman on regeneration of nerve $\ldots$.. $\ldots$

Forster on division of posterior nerve-roots .

Frohlich's symptom complex

Frontal cortex, functions of ..

Gastric juice, factors controlling flow of .. 28,29

- - inhibited by fat $\ddot{H}^{\circ} 32$

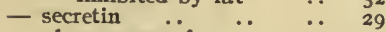

- vicer, cause of $\quad \ldots . \quad \ldots \quad 37$

- - hyperchlorhydria in .. 36

Gastrojejunostomy, course of food after

- for hyperchlorhydria or ulcer .. .. ..
Gastrojejunostomy, nutrition

PAGE

after .. .. .. 4I

Gastrostomy, feediug after .. 4I

Gee on uric acid shower .. 90

Generali on parathyroids .. 4

Gigantism $\quad \ldots \quad \ldots \quad \ldots 2$ I

Gley investigated parathyroids 4

Glucose, relation to acidosis .. I00

Glycosurla $\quad . . \quad \ldots \quad \ldots \quad \ldots 103$

Goitre, causation of .. $\quad$.. 99

- iodothyrin in $\quad . \quad \ldots \quad 7,9$

- relation to drinking water 7

- treatment of $\quad$.. $\quad$.. $\quad 15$

Goll's tract $\quad . . \quad \ldots . \quad \ldots$ I4I

Goodman on transfusion for hremophilia $\ldots \quad \ldots \quad 78$

Gout, pathology of $\ldots$.. 88

- treatment of $\quad . .9 \quad \ldots 90$

Grafting for myxodema, cretinism, or tetany .. I6

Graves' disease $\quad \ldots \quad \ldots$ I4 $_{4}$

- - caused by iodoform .. 12

- - treatment of .. $\ldots . \quad$ I6

Gravity, effect of on blood. pressure.. ... ..

Gray on skiagraphy of stomach

Groves, Hey, on the colon 32,40

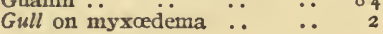

HAMATEMESIs, treatment by nutrient enemata .. I 87

Hæmophilia, pathology of ..7 I, 72

- treatment of $\ldots \quad \ldots 76$

Hæmoptysis, treatment of .. 67

Hrmorrhage into spinal cord ${ }_{4} 8$

- - - membranes.. .. 148

Hæmorrhages, profuse $\quad$.. 68

Hæmorrhagic diathesis, cause of 68

Hall, Walker, on the colon .. 53

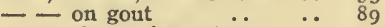

- - the purinometer .. 90

Halliburton and Mott on regeneration of nerve $\quad \ldots \quad$ I32

Halstead on partial thyroidectomy .. .. ..

Harrison, Ross, on developing nerve fibres ... $\quad . . \quad I_{32}$

Head on cutaneous sensation 124

- - referred pain ... .. 185

- - spinal segmental areas I3 $8^{8}$

Head and Thompson on spinal tracts .. I4I, I42, I43

Headache, lymphatic, calcium salts for .. .. 80

Hearing, cortical localization of 157

Heart, massage of for chloroform poisoning ... II8

Hele on cystinuria $\quad$. $\quad$.. 93 
PAGE

Herlz on gastric sensation 159

- - skiagraphy of stomach..

$H i l l, L$., on influence of gravity on blood-pressure

- on intracranial circulation

- - capillary pressure ..

Hill and Barnard's sphygmometer ..

Hormones "Clarke on func-

Horsley and Clarke on func-
tions of cerebellum

Horsley, Sir V., on cerebral cortex

- - on optic neuritis

$\overline{\text { Hour-glass stomach, diagnosis }}$ of

Hunger, explanation of $\because$.

Hunger-pain $\ddot{\text { Hund }}$ and on iodothyrin

Hydrocephalus, pathology of

Hydrochloric acid, deficient in gastric juice .. ..

Hydrochloric acid, variations in stomach .. ..

Hyperchlorhydria $\quad \ldots \quad$..

Hypoxanthin .. .. ..

Hypnotics, mode of action of

ILEOSIGMOLDOSTOMY, a draw. back of.. ... ..

Infantile palsy, nerve anastomosis for - .. ..

Infantilism from removal of pituitary gland

- treatment of

Intestinal paralysts, treatment of 52

- peristalsis, arrest of .. 52

Intestine, functions of large ..

Intracranial circulation pressure, effect on blood. pressure..

Iodides, action on gummata and atheroma ... ..

- for goitre .. .. ..

Iodine in foodstufis $\quad \ldots \quad$..

- thyroid $\quad . . \quad$.. ..

Iodoform poisoning ...

- and the thyroid $\ldots$..

$\begin{array}{llll}\text { Iodothyrin } & \ldots & \ldots & \ldots\end{array}$

Jacksonian epilepsy

Jackson-Taylor's test for acetone ... .. .

Jaundice, hæmorrhagic tendency in ... ..

Kilvington and Osborne on nerve anastomosis ..
Knee-jerk absent with posterior nerve-roots divided .. I $_{3} 8$

Kocher on tetany $\quad$.. $\quad \ldots$ is

Kohn the thyroid .. $\ldots$. r, 3

Kohn on parathyroids ... 4

Kossel on the protein molecule 47

Kropfbrunnen .. $\quad$. $\quad \ldots .7$

LABYRINTH and nystagmus .. I55

Iractation, cause of.. ․ $43 \mathrm{n}$.

Laidlaw and Ryffel on nutrient enemata $\quad . \quad \ldots . \quad 54$

Langley and Anderson on regeneration of nerve ... I I I

- - nerve anastomosis $\quad . \quad$ I35

Leukæmia, uric acid in $\quad . .87$

Liepmann on apraxia.. ... I64

Liver, action on uric acid $\quad . \quad 86$

Local anæsthetics, how to use 177

Localization, cerebral. . I 50 et seq.

Lossen and Morawitz on hæmophilia $\quad . . \quad \ldots \quad \ldots 73$

Lumbar puncture in diagnosis 173

- - for intracranial pressure 66

Lungs, circulation in .. .. 66

Macallum on tetany .. $\quad$.. $\quad$ I5

Magnesium salts, treatment by $8 \mathrm{I}$

Magnus-Lavy on acidosis _. 99

- thyroid feeding .. $\quad$.. 6

$\begin{array}{llll}\text { Marie on aphasia } \quad \ldots & \ldots & \text { I67 }\end{array}$

Marine on cretin lambs .. 8

Mayo on Graves' disease $\quad . .516$

- - hyperchlorhydria $\quad$.. 39

Mellanby on blood-clotting 69,75

Meningitis, prevention of .. I72

Menopause, treatment of $\quad .880$

Irenthol as local analgesic 178 , I 8 r

Meyer, Hans, on action of hypnotics ... .. II5

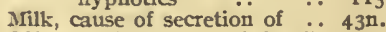

Miller, Reg., on infantile dyspepsia $\quad \ldots \quad \ldots . \quad 3^{8}$

Mfisleading localizing signs of cerebral tumour .. r ro

Monakow's bundle ... .. r ro

Monoplegia from cortical tumours

Moore, B., on calculi $\ldots \quad$.. 92

Morawits and Lossen on hæmophilia $\quad \ldots \quad$.. $\quad . .73$

Mott and Halliburton on regeneration of nerve .. I 32

Moussu on parathyroids $\quad \ldots \quad 4,5$

Morements of stomach $\quad . \quad 32$

Murray on myxcedema and cretinism

Murray and Warrington on nerve anastomosis for infantile palsy ....$\quad 137$

r36 Mummery on surgical shock.. 62 
Murphy on operations on PAGE jejunum $\quad \because \quad \because 33$

Murphy and Cannon on peristalsis $\ldots \quad$.. $\quad \ldots \quad$ sI

Myxœdema and atheroma .. I $_{3}$

- experimental $\quad . \quad \ldots \quad$ 2, 5

- treatment of $\quad \ldots \quad \ldots$ I5

Nerve Anastomosis $\ldots \quad \ldots \quad$ I 35

- grafting $\quad . . \quad \ldots \quad \ldots . \quad$ r 35

— injuries, effects of ${ }^{\cdots} \quad \ldots$ I23

- - regeneration .. $\quad \ldots .128$

- -roots, development of $\ldots \mathrm{I}_{32}$

- - distribution, table of $144, I_{45}$

- - effects of division of ... I ${ }_{38}^{8}$

- - surgical indications for dividing posterior ... 139

- scction, effects of incomplete 128

- suture, on bridging gaps .. $\quad$ I35

- - recovery after.. $\quad . . \quad$ I34

- transplantation $\quad . \quad$.. 135

Newt, regeneration in the $\ldots$ I 49

Nissl's degeneration in anterior horn cells after division of posterior nerve-roots 139

Nitrites for hæmoptysis

Nitrogen output on nutrient enemata .. I87, I94

Novocain injected into nerves to prevent shock $\ldots 62$

- as local anæsthetic.. I75, I76

Nucleoprotein and purin bodies $8_{3}$

Nutrient enemata $49,53,187,193$

Nystagmus, cerebellar .. I55

- labyrinthine $\quad . \quad$.. 155

O'B Yrive, Patrick, the giant.. 2 I

Occipital lobe, function of ... I58

Olive oil, action on bile flow .. 46

Operations on diabetics ... III

Opium as local analgesic 178,181

Optic neuritis, cause of $\quad . \quad 150$

Ord on myxoedema..$\quad \ldots 2_{2}$

Osborne and Kilvington on 136

Osler, cases of hæmophilia ${ }^{72} \mathrm{n}$.

$\begin{array}{lllll}\text { Oxaluria } & \ldots & \ldots & \ldots & 90\end{array}$

$\begin{array}{llll}- \text { prevention of } & \ldots & \ldots & 92\end{array}$

Pans sense, conduction in spinal cord $\quad . \quad$.. $\quad .$. I 4 I

Pancreatic diabetes $\ldots$.. 105

— fistulæ ... .. $\quad$.. 44

- juice, secretion of .. $\quad . .42$

Parathyroids, effects of removal of 5

Paterson on gastro-jejunostomy $4 \mathrm{I}$

- - hyperchlorhydria $\because 39$

Paulesco on removal of pituitary .. ... I8, I9

Pawlow on gastric juice $\ldots 27$

- pancreatic secretion $\quad . .43$

Pawlore on peristalsis PAGE

Peristalsis in colon

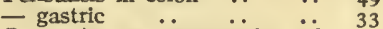

Perroncito on regeneration of nerve .. $\quad . . \quad \ldots \quad$ I32

Phloridzin and glycosuria $\ldots \mathrm{I}_{4}$

Pituitary extracts, feeding or injecting with .. 20

- - for shock .. .. 63

gland, effects of removal of I9

- - functions of $\ldots \quad$.. 23

- - structure of $\ldots$.. $\quad$ r 8

- - operations for removal of 22

Pons, tumours of $\ldots \quad \ldots$. I56

Post-central convolution, function of .. ... .

Posterior columins of Goll and

Burdach
Posterior nerve-roots, effects of

I59 division of $\ldots$.

Posterior nerve-roots, surgical indications for dividing

Precentral convolution, function of $\ldots$.. .. I 60

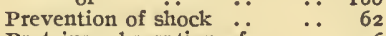

Proteins, absorption of $\quad$.. 46

$\begin{array}{llll}\text { Prothrombin } & \text {.. } & \text {. } & 6\end{array}$

- at fault in hæmophilia $\quad$.. 74

Protopathic sense ... I 23, I24

Pulmonary circulation $\quad \ldots, 66$

Parathyroids, anatomy of $\quad$. 4

Purin bodies, effects of ... 87

- - estimation of in urine ... 90

- - in food ..

Purinometer $\quad \ldots \quad$.. $\quad \ldots .99$

Pyloric spasm... $\quad . . \quad$.. 37

Pylorus, movements of $\quad \ldots \quad 33$

- stenosis of .. $\quad$.. $\quad$.. 38

Pyramidal tract $\quad \ldots . \quad \ldots \quad$ r 40

$\begin{array}{lllll}\text { Pyrosis } & \ldots & \ldots & \ldots & 37\end{array}$

Quadrilateral, Matie's .. I68

REACTION of degeneration after nerve section ... ...

- - - partial nerve section

Recurrent sensibility..
Reflexes lost from division of posterior nerve-roots .. I 38

Regeneration of nerve .. I28

Respiratory movements, in- I49 fluence on blood-pressure 59

Rhubarb, oxaluria from .. 9 I

Richardson on thyroid and parathyroid glands .. r

Riva-Rocci sphygmometer .. 57

\begin{tabular}{lll} 
Roos on iodothyrin $\ldots$ & $\ldots$ & 8 \\
\hline
\end{tabular}

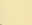




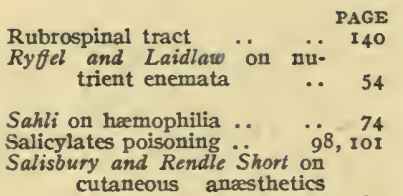
I 78,180

Saliva, factors controlling flow of 26 Sandstrom discovered parathyroids

Satta on acidosis $\quad \ldots \quad$.

Schafer on pituitary .. I I , 20

Schiff on removal of thyroid 1,2

Secretin.. $\quad . . \quad \ldots \quad 42,46$

Seidel and Hurit on iodothyrin ${ }^{42,4}$

Segmental areas, table of 144, 145

Semicircular canals and nystagmus $\quad \ldots \quad$.. 155

Sensation, conduction in spinal cord .. .. .. I4I

- localization of in cortex .. 157

— in stomach.. $\quad$.. $\quad$.. 34

Sensibility, recurrent .. $\quad . \quad 129$

Serum of horse, for hrmorrhagic tendency

Sharkey on nutrient enemata

Sherren on cutaneous sensation

Sherrington on concentration of blood in shock ..

- - spinal segmental areas. .

Shock absent when posterior nerve-roots are divided

- contributed to by chloroform ...

- imitated in animals ..

- pituitary extract in ..

- surgical, causes of .. ..

- - how to prevent ..

Shon, Rendle, on division of

_ - - iodoform and thy. roidism

Short, Rendle, and S̈alisbury on cutaneous anæsthetics $\quad \ldots \quad I 78, I 80$

Sight, cortical localization of.. I58

Soups and gastric juice .. 29

Spasticity, division of posterior nerve-roots for.. .. 139

Spastic paresis in cerebral tumour .. $\quad \ldots \quad \ldots$ I II

Speech centres.. $\quad$. $\quad \ldots \quad$ I66

Sphygmometers $\quad$. $\quad \ldots \quad 57$

Spinal cord, ascending tracts of I4I

- - descending tracts of .. I40

- - does not regenerate .. I 149
PAGE

Spinal cord, injuries of .. I I 47

140,142

- nerve-roots, effects of division of .. $\quad \ldots \quad \ldots \quad 13^{8}$

- segmental areas, table of

Spleen forming uric acid I44, 145

Squint, divergent, in cerebral tumour .. ... .. I 70

Squire, case of hamophilia ${ }^{72} \mathrm{n}$.

Standardization of thyroid extract ... .. .. I7

Starling and Bayliss on secretin ... .. .

Starr, Allen, on tumours of auditory nerve.. .. I56

Starvation, diagnosis of $\quad \ldots \quad \mathrm{IO}_{3}$

- survival in .. $\quad . . \quad \ldots .56$

Stereognosis $\quad . . \quad \ldots . \quad \ldots$ I 4 I

Stewart and Ballance on regeneration of nerve .. I 129

Stewart-Harte case .. .. I I 49

Stomach, movements of .. 32

Stovain as local ancesthetic I75, I76

Strychnine for shock .. .. 63

Stuart-Hart's test for $\beta$-oxybutyric acid .. .. IOg

Sudden death from chioroform I6

Suprarenal glands, influence in maintaining bloodpressure. . .. .. 60

TACTILE sense, conduction in spinal cord ... ..

Temperature sense, conduction in spinal cord ... .. I II

Temporal lobe, functions of ... I 57

Tetany, experimental.. $\quad \ldots \quad 2,4$

- treatment of ... 5, I5, 80

Theoenot and Fabre on congenital goitre .. .. IO

Thiele on muscular tone .. I 54

Thomas, $R$. E., on nutrient enemata $\ldots .54$, I 87

Thompson and Head on spinal tracts .. I I I, I 42, I43

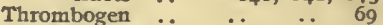

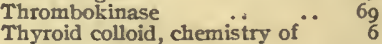

- effects of removal of .. 2, 5

- extract, standardization of 17

- feeding ..

- intoxication $\quad . . \quad \ldots .14$

- - from iodoform ... .. I I

Transfusion for hamophilia .. 78

Transplantation of nerve .. I35

Trephining, palliative, for tumour... ... ... IS I

Trophic changes from division of posterior nerve-roots $13^{8}$ 
Trophic lesions, cause of Trotter on nerve suture of 124, I 26 .. 134 Tone, Deiter's nucleus and ... 154 - in diagnosis of cortical tumours $\quad . . \quad \ldots \quad 162$

- influence of tracts on $140,1_{4} I$

- loss of from division of posterior nerve-roots .. $\quad 138$

- lost in cerebellar lesions I54 $_{54}$

Treatment of acetonæmia ... 108

$\begin{array}{lllll}\text { - acidosis } & \ldots & \ldots & \ldots & 108\end{array}$

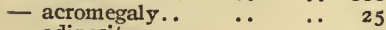

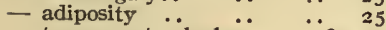

— to prevent calculus $\quad \ldots 89,92$

- of chilblains .. $\quad . .80$

- chloroform poisoning .. 1 I8

- late chloroform poisoning I2I

- - - to prevent .. .. III

- of coma from starvation.. I IO

- concussion .. $\quad . .6 \quad . .666$

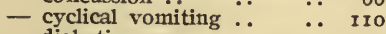

— diabetic coma $\quad . . \quad \ldots \quad$ II4

- to prevent diabetic coma.. III

- of dyspepsia by drugs .. 30

- epigastric pain $\quad . . \quad \ldots 39$

- facial palsy $\quad \ldots \quad \ldots$ I $_{36}$

- gastric carcinoma .. $\quad$.. 43

$\begin{array}{llll}\text { - gastric crises } & \ldots & \ldots & 430\end{array}$

$\begin{array}{lllr}\text { - gastric ulcer } & \ldots & \ldots & 39\end{array}$

- after gastrostomy $\ldots \quad \ldots \quad$ 4I

— of gigantism $\quad \ldots \quad \ldots \quad 25$

$\begin{array}{lllll}\text { - goitre } & \ldots & \ldots & \ldots & \text { I5 }\end{array}$

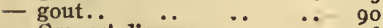

- Graves' disease $\quad \ldots \quad \ldots \quad \ldots \quad 16$

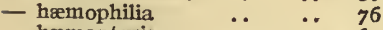

— hæmoptysis $\quad . . \quad \ldots 67$

- hæmorrhagic tendency in $\begin{array}{llll}\text { jaundice } & \ldots & . & 76\end{array}$

- hyperchlorhydria .. $\quad . .638$

- infantilism .. $\quad . . \quad \ldots \quad 25$

- infantile paisy by nerve anastomosis $\quad \ldots \quad \ldots \quad 136$

- injuries of spinal cord $\quad \ldots \quad 148$

- intestinal paralysis $\quad . .55$

- intracranial pressure $\quad . . \quad$ I73

- 1ymphatic headache .. 80

- to prevent meningitis $\quad . . \quad 172$

- of menopause .. $\quad . .880$

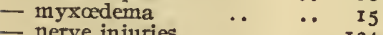

- nerve injuries $\quad \ldots \quad \ldots \quad$ r 34

- by nutrient enemata

- of oxaluria $49,53,187,193$

- painful inoperable cancer ${ }^{-} 92$

- pancreatic fistulæ .. .. 44

- post-anæsthetic vomiting ${ }^{-}$I2 I

- to prevent salicylate poison-

— of shock...$\quad \ldots$.. III

- spasticity $\ldots \quad \ldots \quad \ldots$ I $_{39}$
Treatment of transient albu- PAGE

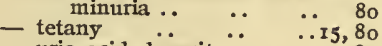

- uric acid deposit $\ldots \quad \ldots 15,80$

- urticaria $\quad . \quad \quad \ldots \quad \ldots 80$

Tumour of brain, misleading localizing signs of ... 170

Tumours in ccrebello-pontine angle $\quad . . \quad \ldots \quad \ldots$ I56

- of cortex, localization of .. I6I

- spinal cord.. .. I40, I42

UINAR palsy, symptoms of.. I24

Urates, origin of, in the body.. 82

Urea output on nutrient enemata .. .. I87, I94

Uric acid, origin of in body .. $88_{2}$

- - deposit, treatment of ... 89

Urticaria, treatment of $\quad . \quad 80$

VAGUS, action of chloroform on I I 6

- influence on gastric juice.. 28

Vasomotor reflexes $\quad \ldots \quad$ I27

Vassali on parathyroids $\quad \ldots .44$

Venous blood-pressure, how measured .. .. 58

Vestibulospinal tract ... $\quad \ldots \quad$ r 40

Vision, cortical localization of 158

$\begin{array}{llll}\text { Visual word centre } & . . & \ldots & \mathbf{1} 66\end{array}$

Vomiting, prolonged, after chloroform $\quad . . \quad \ldots \quad 120$

Von Noorden on diabetic coma 112

- - pancreatic diabetes 107

WALLERIAN degeneration in nerve fibres $\ldots \quad 124,133$

- - - spinal tracts $\quad . .139$

Walton on shock $\quad . \quad \ldots$ GI

Warrington on shock $\quad$ in 52

posterior nerve-roots .. I 39 nerve anastomosis for infantile palsy

$\begin{array}{llllll} & & & & \end{array}$

- supply and"goitre by bowel 53

Watson, Chalmers, on goitre .. 8

Weil on horse serum for hæmophilia $\quad \ldots \quad \ldots \quad 78$

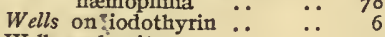

Wells and goitre $\quad . . \quad \ldots$ 7, I I

Wilms on goitre $\quad \therefore \quad \ldots$ II

Willcox on gastric $\mathrm{HCl} \quad \ldots \quad 35$

- - infantile dyspepsia $\quad \ldots \quad 3^{8}$

Wright, Sir Almroth, on hæmo-

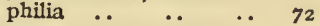

$\begin{array}{lllll}\mathrm{X}_{\text {ANTHIN }} & \ldots & \ldots & \ldots & 83\end{array}$

X-rays in mapping out stomach 32 



\section{MEDICAL WORKS}

John Wright \& Sons Ltd., Publishers, Bristol.

Ready Shortly. Demy 8vo. 6th Edition. Illustrated and fully revised. Net 21/-.

A $\mathrm{N}$ INDEX OF TREATMENT. By SeventyA eight Writers. Edited by Robert Hutchison, M.D., and H. Stansfield Collier, F.R.C.S.

Just Published. Demy 8vo. Fully Illustrated. 12/6 net.

THE MEDICAL DISEASES OF CHILDREN : 1 FOR GENERAL PRACTITIONERS AND SENIOR STUDENTS. By Reginald Miller, M.D. (Lond.), M.R.C.P., Phys. Out-Pat. Paddington Green Children's Hosp.; Asst. Phys. to OutPat. St. Mary's Hosp. ; Late Med. Regist. and Path. Hosp. for Sick Children, Great Ormond Street.

For practical utility this work is a complete text-book. The feeding of children is included. Illustrations have been freely employed where they have a teaching value, which is perhaps greater in pediatrics than in any other branch of medicine.

Super Royal 8vo. In 2 Vols. lavishly Illustrated, on fine paper, and with full page plates. Net $\mathbf{5 0 / -}$.

URGEnt SURGERY. By Felix Lejars, Prof. Agrégé a la Faculté de Médicine de Paris; Translation from the new and 6th French Edition. By W. S. DrCKIE, F.R.C.S. (Eng.), Surg. North Riding Infirmary.

Just Published. Third Edition. Illustrated. Revised and Enlarged. 9/6 net.

SYNOPSIS OF SURGERY: FOR STUDENTS AND $S$ Practitioners. By ERNEst W. Hey Groves, M.S., M.D., B.Sc. (Lond.), F.R.C.S. (Eng.), Assist. Surg. Bristol Gen. Hosp.; Senr. Demonst. Anat. Bristol University.

Illustrated with numerous Diagrams of Surface Markings.

"Gaining knowledge is one thing: retaining it for ready use is another, and equally important." This book is a wonderful help in both particulars.

London Showroom: 14, Paternoster Square. 


\section{MEDICAL WORKS}

John Wright \& Sons Ltd., PUblishers, Bristol.

Super Royal 8vo. With I46 Original Illustrations in the Text and 5 Coloured Plates. Net 8/6; Interleaved, net $\mathbf{9} / \mathbf{6}$.

$A \mathrm{~N}$ INTRODUCTION TO SURGERY. By A Prof. Rutherford Morison, M.A., M.B., F.R.C.S. (Edin. and Eng.).

Crown 8vo. Net 5/-.

A PRACTICAL GUIDE TO THE NEWER A REMEdiEs. By J. M. Fortescue-Brickdale, M.A., M.D. (Oxon.), Lect. on Pharmacol. to the Univ. of Oxford, Phys. to Clifton Coll., and Asst. Phys. to Bristol Roy. Infirm., etc., etc.

Sixth Edition. Thoroughly revised, with many new Illustrations, some of which are coloured. Limp leather, 2/6 net;

Paper, 1/- net

" GIRST-AID" TO THE INJURED AND SICK. I An Advanced Ambulance Handbook. By F. J. WARwick, B.A., M.B. (Cantab.), M.R.C.S., L.S.A., Assoc. King's Coll., London; Major R.A.M.C. (T.), 6th Battalion the Essex Regiment; and A. C. Tunstall, M.D., F.R.C.S. (Edin.), Major R.A.M.C. (T.), 7th Battalion the Essex Regiment.

Fifth Edition. On Sheets, 2ft. 2in. by 3ft. 4in. 2/-net each; 32/6 net the Set of 21 Sheets; or 52/6net if mounted on linen. With Nickel Head for Suspension.

Adopted by the WAR OFFICE and the ADMIRALTY.

T ARGE "FIRST-AID" WALL DIAGRAMS of L the Illustrations in Warwick \& Tunstall's ' 'First-Aid' to the Injured and Sick."

LANTERN SLIDES of most of the series can also be obtainedPrices: Plain $1 /-;$ Coloured $1 / 6$ each.

Price 6d. each net, or $1 / 6$ net the series of four.

Printed on Cardboards 18 inches by 19 inches.

FIRST-AID WALL CHARTS. By EDWARD C. Iborson, M.B., B.S. Lond. No. 1-Emergencies, Accidents, and Poisoning. No. 2-Fractures, Dislocations, and Sprains. No. 3Wounds and Hæmorrhage. No. 4-Insensibility or Unconsciousness.

For hanging in Factories, Mines, Schoolrooms, and all places where emergencies are likely to arise.

London Showroon: 14, Paternoster Squate. 



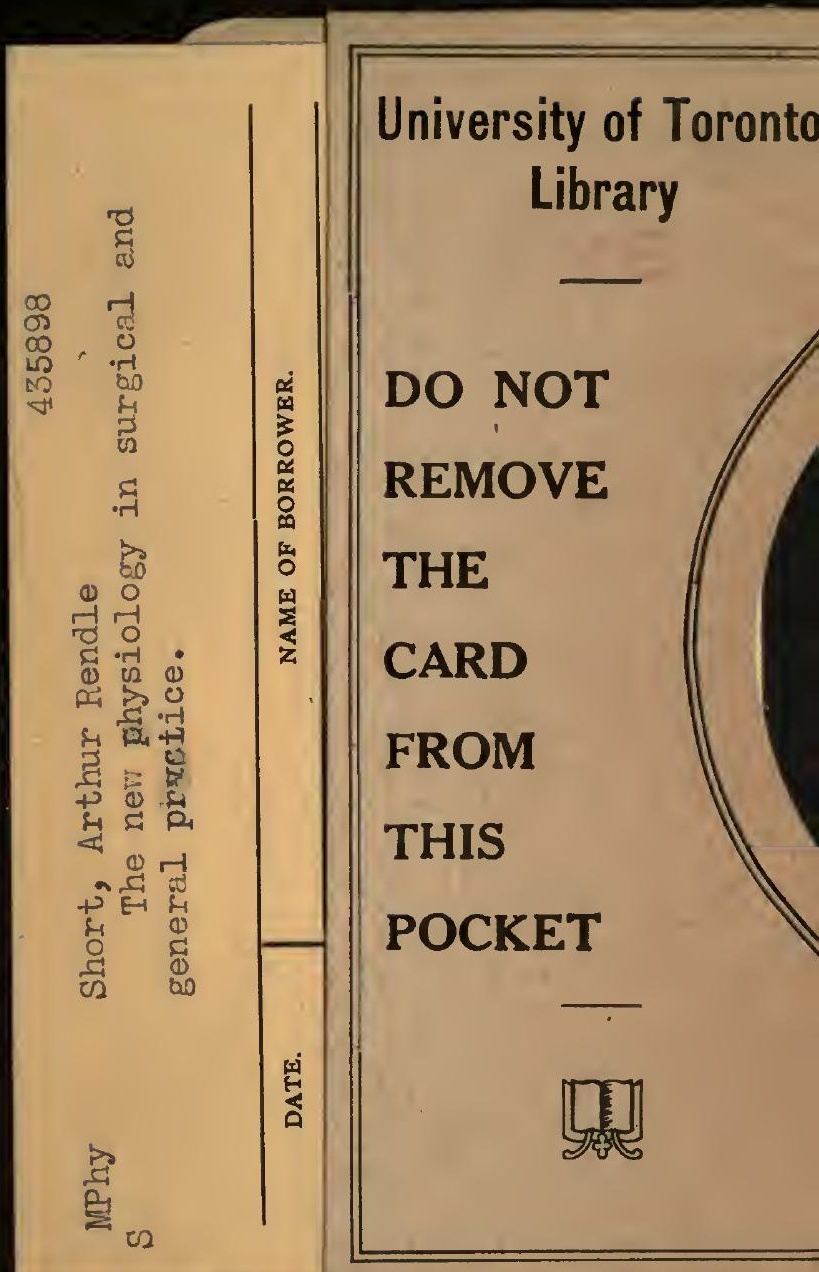


di.

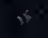

